UNIVERSIDADE DE SÃO PAULO

INSTITUTO DE FÍSICA E QUÍMICA DE SÃO CARLOS

\title{
A TOMOGRAFIA COMPUTADORIZADA COMO UM NOVO MÉTODO PARA ESTUDOS DA FISICA DA AGUA NO SOLO
}

\section{Silvio Crestono}
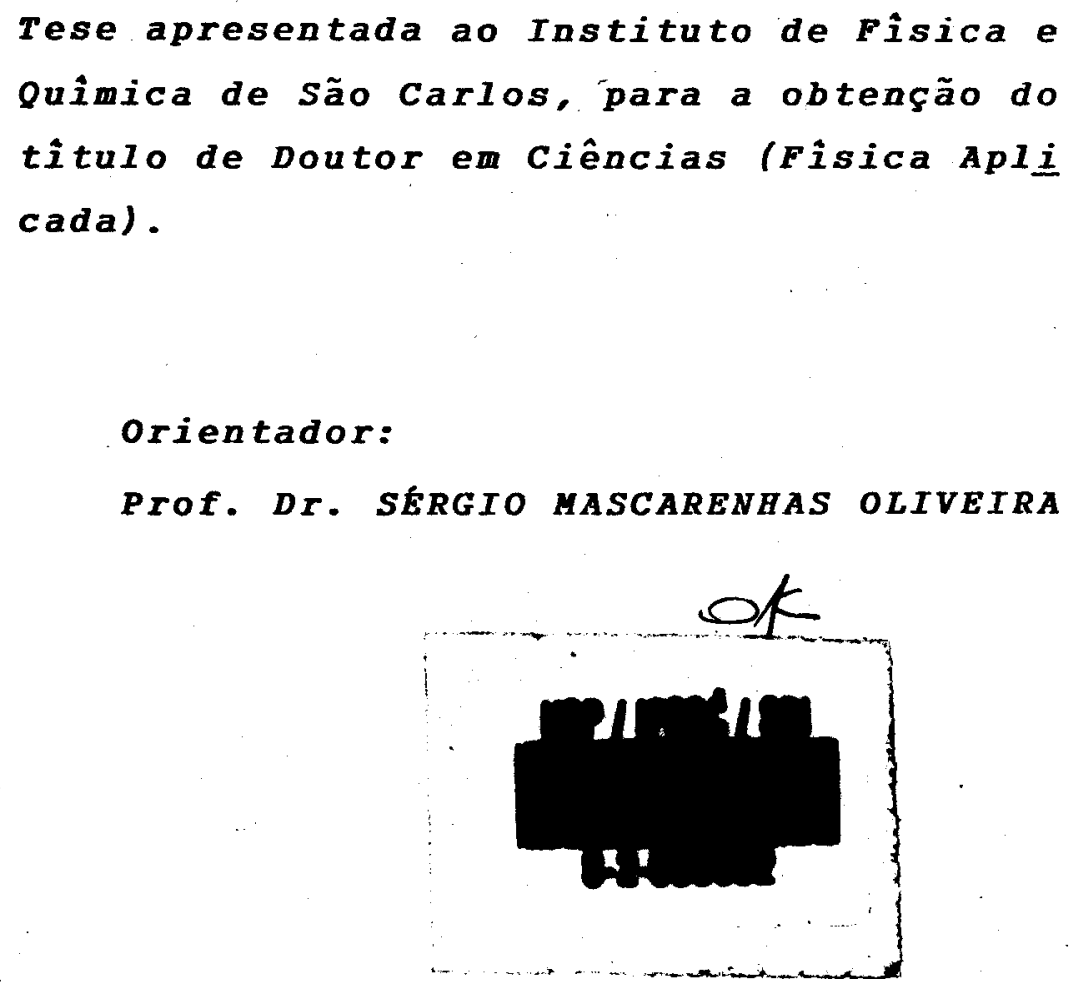

DEPARTAMENTO DE FÍSICA E CIÊNCIA DOS MATERIAIS SĂ0 CARLOS - 1985 
MEMBROS DA COMISSAO JULGADORA DA TESE DE DOUTORADO DE

Silvio Crestana

APRESENTADA AO INSTITUTO DE FISICA E QUIMICA DE SAO CARLOS, DA UNIVERSIDADE DE SAO PAULO, EM 13 DE agosto DE 1985.

COMISSAO JULGADORA:
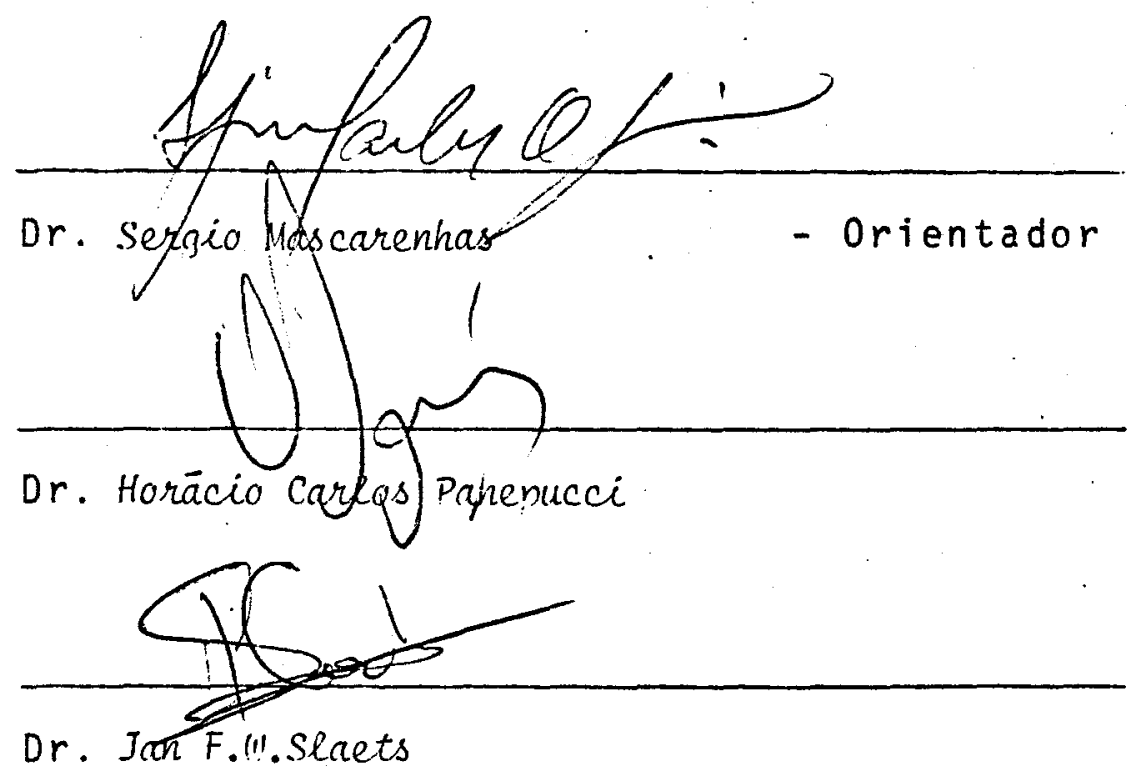

\section{nedesousasas}

Dr. Marce Souza Santos

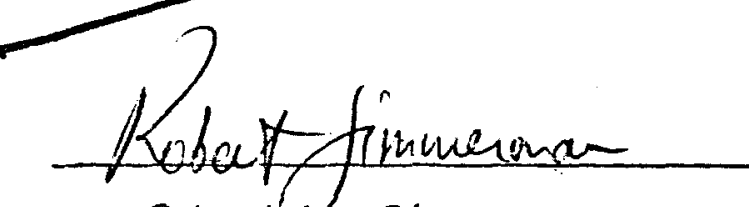

or. Robert kee Zimmerman 
Dedico

Aos.meus pais, à Rita Helena e a todos aqueles que acredi taram neste trabalho. 


\section{AGRADECIMENTOS}

Devo a minha gratidão a um grande número de pessoas $e$ instituições. Não é tarefa fácil expressar isto em palavras. Por mais que nos esforcemos, deixamos sempre algo a desejar. Mesmo as sim tentarei agradecer com algumas palavras.

Ao professor Dr. Sérgio Mascarenhas Oliveira, a quem muito devo não somente pela orientação deste trabalho, mas também pelo constante incentivo e entusiasmo dedicados. Tive o privilé gio do seu apoio e da sua amizade. Pude desfrutar intensamente do seu exemplo, da sua experiência e da sua competência. Testemunhei o seu amparo a novas idéias e em particular, aos jovens, mesmo que isto the custasse sacrifícios e incompreensões. Também fui testemu nho da sua angústia pelo nosso subdesenvolvimento. Pela sua cren ça de que a ciência e a tecnologia podem servir de instrumento de paz, de progresso e de libertação do Homem.

Espero poder continuar desfrutando deste privilégio e por ora registro o meu muito obrigado.

Agradeço também aos meus professores, colegas e funcio nários da Graduação e da Pós-Graduação do DFCM-USP, onde tenho a prendido muito através de belos exemplos de trabalho, de competên cia, de seriedade e de honestidade profissionais. Em particular a gradeço ao professor Rogério C.T. da Costa a quem muito devo pela sua valiosa orientação de Mestrado e também ao professor J.R. Drugowich de Felício, que tem acompanhado o meu trabalho, nestes últimos anos.

Aos professores, técnicos e colegas da Biofísica: Otaci ro, Sanches, Rosemary, Isabel, Sueli e Aparecido pela prestimosa colaboração, assim como à Wladeres, a Rosemari e a Loreni, da Sec ção de Pós-Graduação. 
Ao professor Edward E. Miller, pelo seu incentivo,

través do seu exemplo e de sua competência em Física de Solos.

Aos professores do CENA: Klaus Reichardt, Eneas Sala ti, Paulo Libardi, Sergio Moraes e também ao Antonio Saraiva, grandes colaboradores deste trabalho.

Aos professores Roberto Pozzi Mucceli do Hospital Cat tinara de Trieste e Roberto Cesareo da Universidade de Roma, pelo profícuo trabalho de colaboração que juntos desenvolvemos.

Aos professores Abdus Salam, Gabriels, Skidmore e Fur lan em nome do ICTP e do Programa Italiano, pelo apoio e pela ox ganização das facilidades que propiciaram realizar este trabalho.

Ao professor George Vachaud, que juntamente com o pro fessor Klaus Reichardt discutiram os nossos primeiros resultados. Ao Dr. Segundo Urquiaga pelas proveitosas sugestões, pela assessoria e pelas discussões dos aspectos agronômicos desta tese.

Ao Dr. Uebe Rezek por ter cedido o Hospital São Jorge para a realização dos primeiros experimentos.

Ao Paulo E. Cruvinel e Paulo H. Valim pelo constante a poio, entusiasmo e amizade que pude desfrutar.

Aos meus tios Armenio e Dina, meus incentivadores des de os primeiros tempos.

A todos os colegas e funcionários da EMBRAPA (UEPAE e UAPDIA) pelo excelente ambiente de trabalho.

A Socorro, à Ana, ao Valentim e à Vera, os meus agrade cimentos especiais pelos laboricsos serviços de datilografia; de desenho, de revisão e de montagem, onde demonstraram um alto ní vel de profissionalidade, de dedicação e de interesse.

Ao Programa de Centros Emergentes do CNPq e da FINEP, à EMBRAPA e ao ICTP pelo apoio financeiro e institucional.

Ao INTEC, à FEB, ao HCRP-USP, ao DFCM-USP e a to dos aqueles que contribuíram para a realização deste trabalho. 
AS PESQUISAS DESTA TESE FORAM PATROCINADAS POR:

PROGRAMA DE CENTROS EMERGENTES DO

CNRq - CONSELHO NACIONAL DE DESENVOLVIMENTO CIENTIFI CO E TECNOLÓGICO, e

FINEP - FINANCIADORA DE ESTUDOS E PROJETOS.

EMBRAPA - EMPRESA BRASILEIRA DE PESQUISA AGROPECUÁRIA UEPAE - Unidade de Execução de Pesquisa de Âmbito Estadual - são Carlos.

UAPDIA - Unidade de Apoio à Pesquisa e Desenvolvimento de Instrumentação Agropecuária.

ICTP - INTERNATIONAL CENTRE FOR THEORETICAL PHYSICS è PROGRAMA ITALIANO DE TREINAMENTO E PESQUISA -

Instituto de Radiologia da Universidade de Trieste.

Centro de Engenharia Biomédica da Universidade de Roma.

DFCM - DEPARTAMENTO DE FISICA E CIENCIAS DOS MATERIAIS - USP. 


\section{RESUMO}

Apresentaremos nesta tese, um novo método de investiga ção da Física da Água no Solo usando a Tomografia Computadorizada de Raio-X. Mostramos que o método está de acordo com as técnicas clássicas, tais como a da atenuação de raios $\gamma$ e a gravimétrica. Também demonstramos que o método permite novos enfoques e análi ses quantitativas dos problemas, tais como estudos dinâmicos bi e tridimensionais, deteç̧ão de heterogeneidades do solo e da distrị buição da água neste. Aplicamos o método para investigações da in filtração vertical da água em um solo úmido e compactado, para sị mulação da irrigação por gotejamento e para estudos preliminares de germinação de uma semente "in situ". Estas aplicações não tẹ riam sido possíveis sem os recursos e vantagens deste novo méto do.

Nossos resultados complementam aqueles encontrados por Petrovic et al e Hainsworth et al, onde investigamos experimental mente a dependência completa das U.H. (Unidades Hounsfield) com a densidade global, com o conteúdo da água no solo e com a energia.'

Finalmente, repetimos alguns de nossos resultados obti dos, utilizando um mini-tomógrafo de Raios $x$ e $\gamma$, não-médico, de considerável simplicidade que abrirá novas possibilidades de aplị cação do método proposto. 


\section{ABSTRACT}

In this thesis we present a new method for the investigation of water in Soil Physics using $\mathrm{X}$-ray Computed Tomographic scanning.

We show that the new method is in agreement with previous classical techniques such as $\gamma$-ray attenuation and gravimetric. We also demonstrate that the method allows new approaches and quantitative analysis of problems such as bi and tridimensional dynamical studies as well as of heterogeneity in soil and water distributions. We apply the method to investigations of vertical infiltration of water in wet and compacted soil, simulation of drop irrigation and for preliminary studies of seed germination "in situ". These applications would not be possible without these capabilities and advantages of this new method.

Our results complement those of Petrovic et al and Hainsworth et al in that we have investigated experimentally the complete dependence of H. U. (Hounsfield Units) on dry bulk density, water content and energy.

Finally we also repeat some of our results obtained, using a non-medical $\mathrm{X}$ and $\gamma$-ray minitomograph of considerable simplicity wich will open new possibilities for the application of the proposed method. 


\section{Í N D I C E}

Capítulo I - INTRODUÇÃo $\ldots \ldots \ldots \ldots \ldots \ldots \ldots \ldots \ldots \ldots \ldots \ldots \ldots \ldots$

Capítulo II - A DINÂMICA DA AGUA NO SOLO: ASPECTOS TEORICOS GERAIS $\ldots \ldots \ldots \ldots \ldots \ldots \ldots \ldots \ldots \ldots . \ldots . \ldots$

2.1. Equação Geral do Fluxo Não-Saturado - Equação de Darcy $\ldots . . .99$

2.2. Infiltração Horizontal em Uma Coluna Infinita de Solo Homogêneo.. 14

2.3. Infiltração Vertical em Uma Coluna Infinita de Solo Homogêneo ... 18

Capitulo III - BREVE REVISÃO DOS PRINCIPAIS MÉTODOS DE MEDIDA DO CONTEÚdo DA ÁGUA E OU DA DENSIDADE GLOBAL, EM COLUNAS DE SOLO, NO LABORATORIO $\ldots \ldots \ldots \ldots .23$

3.1. O Método da Transmissão Direta de Raios Gama Monoenergêticos ... 24

3.2. Utıl1zação de Um Feixe de Raios Gama de Dupla Energia........ 29

3.3. Parâmetros do Sistema de Radiação, Detecção e Contagem de Raios

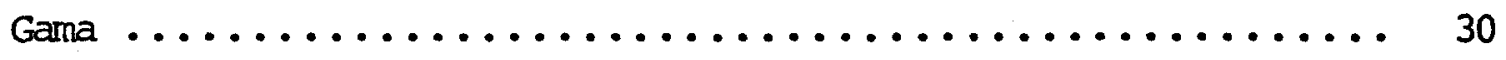

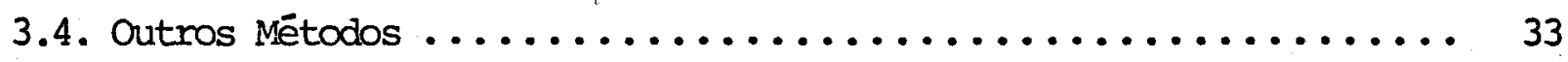

Capítulo IV - A TEORIA DA RECONSTRUÇÃO DA IMAGEM NA TOMOGRA FIA COMPUTADORIZADA $\ldots \ldots \ldots \ldots \ldots \ldots \ldots \ldots \ldots \ldots \ldots$

4.1. Uma Descrição Histōrica e Abreviada da Tomografia Reconstrutiva.. 42

4.2. Os Principais Mētodos Matemáticos de Reconstrução da Imagem .... 45

4.2.1. O Método da Reconstrução Algēbrica (Art). ......... 45

4.2.2. O Método da Transformada de Fourier............... 46

4.2.3. O Método da Convolução ou da Retroprojeção Filtrada ..... 49

4.3. As Bases Matemáticas da Tomografia..$\ldots \ldots \ldots \ldots \ldots \ldots \ldots$. 51

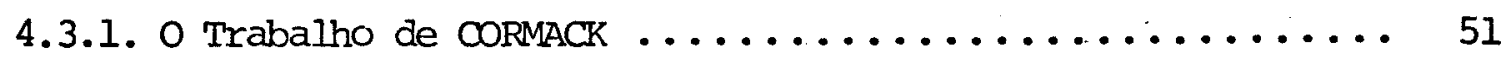

4.3.2. O Teorema da Projeção ..................... 60

4.3.3. Bases Matemáticas do Método da Convolução............ 63

4.3.4. O Mētodo Reconstrutivo da Convolução na Geometria de Feixe Divergente........................... 67

4.3.5. Alguns Comentários Finais $\ldots \ldots \ldots \ldots \ldots \ldots \ldots \ldots, 69$ 
Capítulo V - TOMOGRAFIA COMPUTADORIZADA: UM NOVO MÉTODO PARA ESTUDOS DA FISICA DA AGUA NO SOLO ......72

5.1. Materiais e Metodos $\ldots \ldots \ldots \ldots \ldots \ldots \ldots \ldots \ldots \ldots \ldots \ldots \ldots \ldots .75$

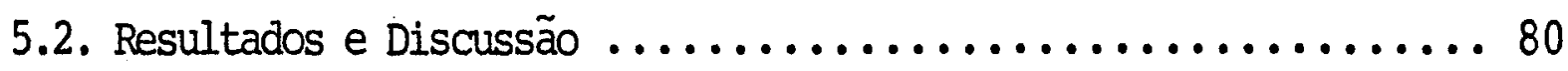

Capitulo VI - OUTROS RESULTADOS DA TOMOGRAFIA COMPUTADORIZADA POSSIVEIS DE SEREM APLICADOS EM ESTUDOS DO SISTEMA ÁGUA-SOLO-PLANTA $\ldots . . \ldots \ldots \ldots \ldots \ldots . . .94$

6.1. Infiltração Vertical: Efeito da Compactação e da Umidade do Solo. 94

6.2. Simulação Dinâmica e Tridimensional de Irrigação por Gotejamento

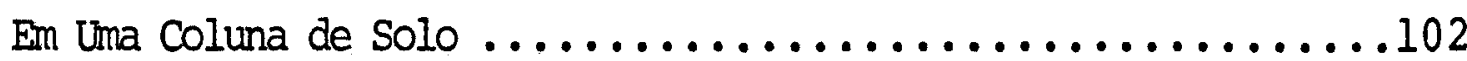

6.3. Método Não-Destrutivo de Observação Dinâmica e Bidimensional da Germinação e Crescimento de Uma Semente Assim Como da Absorção da Água Pelas Raízes ...................................106

Capítulo VII - ALGUNS COMENTÁRIOS E CONCLUSÕES FINAIS ..... 110

APENDICE - O USO DE UM MINI-TOMOGGRAFO PARA MEDIDAS EM FISI CA DA AGUA NO SOLO $\ldots \ldots \ldots \ldots \ldots \ldots \ldots \ldots \ldots \ldots$

REFERENCIAS BIBLIOGRÁFICAS $\ldots \ldots \ldots \ldots \ldots \ldots \ldots \ldots \ldots \ldots \ldots, 129$ 


\section{INTRODUÇÃO}

A presente tese pretende apresentar a Tomografia Compu tadorizada como um novo método para estudos da Física da Agua no Solo. Antes porém, de introduzirmos o assunto tratado assim como os seus objetivos, vamos expor brevemente as origens que motiva ram este trabalho e os meios que tivemos para realizá-10.

Para que pudéssemos chegar à elaboração do plano de trabalho assim como a executá-10, foi necessária a interação e o esforço de diversas pessoas e instituições, que resultaram fundạ mentais.

A formação básica e de pós-graduação fornecida pelo IFQSC-USP, associada ao nosso interesse particular, propiciou as condições para que realizássemos o nosso Mestrado na área de Ópti ca Não-Linear. Durante este período, nos familiarizamos com o tra to de equações diferenciais parciais não-Iineares, resultantes da aplicação da teoria semiclássica da radiação ao estudo da emissão espontânea dos átomos, descritos por um modelo unidimensional ${ }^{(1)}$.

Ao mesmo tempo em que isso ocorria, nos defrontávamos com problemas de natureza mais aplicada, mais especificamente $1 \underline{\underline{i}}$ gados à agricultura (irrigação, por exemplo), pelo fato de estar mos trabalhando em uma região agrícola (Barretos-SP).

Daí, foi natural tentar conciliar a formação em Física Básica com a de Física Aplicada à Agricultura (área multidiscipli nar). Desta forma, no ano de 1981 e 1982, procuramos no DFCM o grupo de Biofísica e iniciamos os primeiros contatos, pois aí já existia uma tradição de trabalho experimental em estudos de Físi Aplicada à Água $(2,3,4)$. 
Por outro lado era necessário localizar bem o problema a ser enfocado de forma a poder manter o trabalho de elevada qua lidade e poder dar uma contribuição em um outro campo que não nos era familiar.

Desta forma se fazia necessária uma maior interação com as instituições e pesquisadores com tradição de pesquisa na á rea de Física de Solos.

Esta oportunidade surgiu e se realizou através do $\underline{\text { a }}$ poio do Projeto de Centros Emergentes do CNPq, coordenado pelo Professor Sérgio Mascarenhas.

A partir disto pudemos elaborar um projeto ${ }^{(5)}$ em convê nio com $\circ$ CNPq e a FINEP, de características multidisciplinares. Pudemos contar com o apoio e a colaboração fundamentais de vários pesquisadores e instituições.

No que se refere à Física de Solos recebemos assesso ria de diversos especialistas. A nível internacional tivemos a co laboração inicial de Edward E. Miller, da Universidade de Winsconsin (EUA), que veio ao Brasil por duas vezes para contri buir na elaboração do plano de trabalho e ministrar cursos especí ficos de treinamento.

Considerando a importância das observações por ele rea lizadas citamos, em seguida, um trecho de seu relatório final ${ }^{(5)}$ que contribui para esclarecer a motivação desta tese.

"... As bagagens do grupo, delineadas acima, a meu ver, possuem dois grandes componentes que posso resumir como (1) competência nas disciplinas fundamentais e (2) "massa crítica". Os Estados Unidos têm muitos bons físicos do solo fazendo bons trabalhos; mas há muito tempo tenho sentido que esta coleção macị ça de talentos e conhecimentos tem sido severamente obstruída em eficácia, por carência exatamente nessas duas áreas especiais. Com poucas exceções, os físicos de solo norte-americanos têm sido 
treinados não em Física, mas como físicos de solo em departamen tos de Solos ou Agronomia. Quando uma pessoa bem treinada em físi ca, a nível de Ph.D., passa para a Física de solos como uma car reira, os aspectos pioneiros das contribuições daquela pessoa po dem ser imensos, como a recente projeção de W. A. Jury, de River side, California. Além disso, mesmo pesquisadores treinados em Fí sica frequentemente não conseguem resolver satisfatoriamente os problemas de Física específicos com que se deparam na Física de Solos.

Vários projetos que eu gostaria de ter explorado foram impedidos por minha impossibilidade de encontrar alguém com trei namento muito mais especializado em certas áreas da Física (es palhamento de neutrons é um relevante exemplo e NMR, um outro), que poderiam ter tomado os aspectos especializados de um problema e chegado a uma conclusão satisfatória. Em são Carlos já existe competência em tais áreas especializadas e parece que as pessoas com tais especializações estão desejosas de cooperar muito mais significativamente do que é norma na América..."

No Brasil, contamos principalmente com a colaboração do pessoal do CENA (Centro de Energia Nuclear na Agricultura) don de destacamós os pesquisadores Reichardt, K., Salati, E. e Libar di, P.L. ${ }^{(6)}$.

A seguir reproduzimos um trecho do relatório(5) do CENA, elaborado pelo professor Klaus Reichardt, a nosso pedido.

$$
\text { "... A Física de Solos estuda os processos físicos e }
$$
físico-químicos que ocorrem na crosta terrestre, principalmente na camada arável de culturas agrícolas, envolvendo o solo, a plan ta e a atmosfera. Estes processos são fundamentais para a produ ção agrícola e na manutenção do meio ambiente. Seu caráter é es tritamente multidisciplinar, sendo que as informações obtidas são de importância fundamental para a fertilidade do solo, microbiolo gia do solo, fisiologia vegetal, conservação do solo, irrigação e 
drenagem, agrometeorologia, etc...

Atualmente, aqui no Brasil e mesmo em muitos países do exterior, a Física de Solos é desenvolvida de forma bastante iso lada e o pessoal envolvido é via de regra de formação puramente agronômica. Com isto as pesquisas desenvolvidas têm apenas descrị to empiricamente situações sem a possibilidade de explicá-las pro fundamente, e assim indicar novos caminhos mais eficientes, econô micos, produtivos e seguros. Existe portanto, a necessidade de $\underline{u}$ ma maior integração entre pesquisadores da área de Física de So los e pesquisadores das áreas básicas de apoio como é o caso da Física, Química, Biologia, Bioquímica, Matemática, Eletrônica. e Instrumentação.

Os processos estudados pela Física de Solos, como por exemplo, o movimento de água no solo, aeração, fluxo de calor no solo, são processos complexos que exigem conhecimentos profundos de Física, modelọs matemáticos, instrumentação adequada. A intẹ gração de pesquisadores nestas diversas áreas possui um enorme potencial para a formação de um grupo de pesquisa que poderá for necer contribuições à agricultura tanto em nível nacional como in ternacional. Existe a possibilidade da emergência de um grupo em condições de fornecer subsídios ná área de física de solos, que poderá prestar uma grande contribuição para a agricultura nacio nal..."

Nesta mesma época fomos convidados a visitar as intala ções da EMBRAPA (CENARGEN, CPAC e o Centro Naciọnal de Hortalí ças), em Brasília, o que também contribuiu para uma importante a proximação nossa com os problemas da pesquisa agropecuária nacio nal.

Neste processo de integração nesta nova área, tentando aplicar as idéias da Física, tomamos conhecimento da importância e também da dificuldade do estudo da equação de Darcy. Conforme podèrá ser visto no Capítulo II, esta equação governa o movimento 
da água no solo. É uma equação diferencial, parcial, fortemente não-linear e tridimensional.

Devido a esta alta não-linearidade não é possível en contrar a sua solução analítica, no caso geral, mesmo quando sob condições de contorno apropriadas.

Os métodos numéricos existentes e citados no texto mos tram que as soluções são normalmente de natureza unidimensional e só se aproximam dos resultados reais em situações muito particula res.

Por outro lado, medidas experimentais como a da densi dade global, a do conteúdo da água, a da condutividade e difusivi dade hidráulica do solo, fornecem resultados muito importantes tais como no acompanhamento da frente de molhamento, na distribui ção da água no solo, no seu tempo de escoamento horizontal e ver tical.

No entanto, dos métodos experimentais existentes para medidas em laboratório, como nos mostra o Capítulo III, o de transmissão direta de raios $\gamma$ (de única ou dupla energia) é o mais eficiente. Porém, as medidas são unidimensionais, não é sen sível a heterogeneidades, não é suficientemente rápido para. medi das de velocidades altas da frente de molhamento, impedindo-o, den tre outras coisas, de realizar estudos bi e tridimensionais em tempo real (medidas simultâneas do espaço e do tempo).

A nossa idéia inicial foi enfrentar este problema ten tando utilizar a radiação- $\mathrm{X}$, empregando um sistema densitométrico apropriado, conforme o trabalho citado na referência 7 . Os primei ros experimentos foram realizados no Hospital são Jorge, em Bar retos e no Raio-X do DFCM. Embora os resultados obtidos tivessem sido estimulantes, eles demonstraram as dificuldades em se obter imagens de boa resolução e nitidez suficientes para mostrar o con traste solo seco-solo úmido(*).

(*) No Capítulo IV explicamos as razões das dificuldades de se ob ter bons resultados de imagem, utilizando a radiografia de Raios- $X$. 
A partir disto (1982), surgiu a idéia que resultou nes ta tese, ou seja, usar a Tomografia Computadorizada para investị. gações da Física da Agua no Solo. Os primeiros resultados obti dos com o tomógrafo do Hospital das Clínicas de Ribeirão Preto, embora não convincentes, mostraram-se alentadores. Em 1983, tivemos a oportunidade de finalizar o nosso trabalho de Mestrado e em seguida participar de um Curso de Física de Solos realizado em Trieste, na Itālia, sob os auspícios do ICTP ${ }^{(*)}$. Durante este tempo foi possível conviver e discutir com especialistas, as pos sibilidades e a relevância da utilização da Tomografia computadọ rizada em Física de Solos. A idéia foi muito bem aceita e outras sugestões foram acrescentadas por Nielsen, D.; Gabriels, D.; Rei chardt, K. e Vachaud, G. ${ }^{(8)}$

Coincidentemente com o término do Curso de Física de Solos foi iniciada uma reunião de Física Médica no mesmo ICTP. Nesta oportunidade, foi possivel permanecer por mais tempo no ICTP, graças ao apoio e incentivo do Professor Abdus Salam seu Diretor. Assim, pudemos realizar sob orientação do Professor Sēr gio Mascarenhas e com a colaboração do Professor Roberto P. Muc celi e Klaus Reichardt, uma série de experimentos iniciais com $\circ$ tomógrafo do Hospital da Universidade de Trieste. Os resultados foram muito positivos e pudemos publicā-los ${ }^{(9)}$ após discutí-los com a equipe especializada em Física de Solos, do Professor Geor ge Vachaud, da Universidade de Grenoble, na França, onde estivemos a seu convite.

(*) Participamos do "College on Soil Physics", patrocinado pelo ICTP (International Centre for Theoretical Physics), pela Agencia Internacional de Energia Atômica e pela UNESCO. Nesta oportunidade aceitamos o convite de colaborar diretamente com a EMBRAPA, no Brasil, através da UEPAE ( Unidade de Execução de Pesquisa de Âmbito Estadual de São Carlos) e posteriormente contribuir para instalar a UAPDIA (Unidade de Apoio à Pesquisa e Desenvolvi mento de Instrumentação Agropecuāria), onde hoje nos encontramos. 
Em 1984, tivemos a oportunidade ${ }^{(* *)}$ de retornar à Itālia, onde pudemos voltar a trabalhar no Hospital de Trieste e estudar junto da Universidade de Roma, a possibilidade da utilização do minitomógrafo lá existente para fins biomédicos', em Física da $\underline{\AA}$ gua no Solo (apresentado no Apêndice). Nesta oportunidade pudemos consolidar os resultados já obtidos e acrescentar outros que serão mostrados e comentados no Capítulo V, VI e Apêndice desta tese. Estes novos resultados serão publicados através da referência 10 . A seguir, fornecemos uma explicação resumida do conteú do de cada capítulo.

No Capítulo II, apresentamos a Equação de Darcy que a coplada à equação da continuidade resulta em uma equação espaço-temporal tridimensional que governa o escoamento da água no so 10. Aplicamos esta equação, a uma dimensão, ao estudo de duas sị tuações específicas de interesse: à infiltração horizontal e à in filtração vertical da água no solo. Discutimos algumas possibili dades de solução e alguns resultados possíveis de serem alcança dos em função das condições iniciais e de contorno utilizadas.

No Capítulo III, apresentamos e discutimos os princi pais métodos experimentais existentes de medida da Física da Água no Solo, em colunas de laboratório.

No Capítulo IV, desenvolvemos a Teoria Reconstrutiva da Imagem a partir da Tomografia convencional até a Tomografia Computadorizada dos dias de hoje. Destacamos os principais méto dos de reconstrução da imagem assim como os fundamentos matemátị cQs básicos que julgamos pertinentes.

No Capítulo V, aplicamos os resultados apresentados no Capítulo IV (Teoria Reconstrutiva da Imagem) ł̀s medidas experimen tais apresentadas nos Capítulos II e III. Os resultados obtidos

(**) Esta oportunidade surgiu através do convite que recebemos para participar do "Programa de Treinamento e Pesquisa em Laboratórios Italianos" organizado pelo ICTP. 
mostraram a viabilidade do novo método proposto, na medida da densidade global e do conteúdo da água no solo, além de outras medidas adicionais de importância no estudo da Física da Agua no Solo. E o caso de medidas bi e tridimensionais, dinâmicas e ca pazes de distinguir heterogeneidades presentes no solo e na dis tribuição da ăgua no mesmo solo.

No Capitulo VI, aplicamos a metodologia desenvolvida no Capitulo $\mathrm{V}$ a algumas situações de interesse prātico, onde pre tendemos mostrar algumas das potencialidades do novo método. 0 caso do estudo da infiltração vertical da água em um solo úmido e compactado, da simulação de irrigação por gotejamento, da ger minação de uma semente e no crescimento e absorção de água pelas raízes de uma planta.

No Capítulo VII, apresentamos alguns comentārios e conclusões finais incluindo algumas sugestões de trabalhos futuros.

No Apênaice, mostramos a viabilidade de se utilizar um mint-tomógrafo de Raios X ou $\gamma$ em estudos da Física da Água. no solo. 


\section{CAPÍTULO II}

\section{A DINÂMICA DA ÁGUA NO SOLO: ASPECTOS TEÓRICOS GERAIS}

Apresentaremos, no decorrer deste capítulo, uma visão sucinta da teoria que governa o fluxo da água em solos homogêneos, considerando tanto o regime estacionário como o de transien te. Vamos estudar o caso mais geral do fluxo em solo' homogêneo não-saturado e estabelecer a sua equação geral correspondente.

Em seguida, vamos aproveitar este resultado para aplicá-lo ao estudo teórico da infiltração horizontal (livre da influ ência gravitacional) e da infiltração vertical (onde muitas vezes, o efeito gravitacional adquire importância fundamental). Estes processos são de muito interesse em Física de Solos e em particular, no manejo da água e do solo. Lembramos ainda que uma des crição mais detalhada dos processos dinâmicos que ocorrem no sistema água - solo - planta - atmosfera e de forma mais restrita no sistema água - solo pode ser encontrada em HILLEL ${ }^{(11,12)}$, REICHARDT $(13,14)$, MILLER e KLUTE ${ }^{(15)}$, VERPLANCKE ${ }^{(16)}$ e HENIN ${ }^{(17)}$.

Deixaremos para o próximo capítulo o tratamento dos principais métodos e técnicas experimentais que julgamos de inte resse à presente tese.

\section{1 - EQUAÇÃO GERAL dO FLUXO NÄO-SATURAdO - EQUAÇÃO DE DARCY}

A primeira publicação de que se tem notícia ${ }^{(18)}$ segundo HUBBERT $^{(19)}$ (1956), que relaciona o fluxo da água com o gradiente do potencial, advém de 1856 e é de autoria do hidrologista francês HENRY DARCY, após um estudo empírico da filtragem da água em arei as saturadas existentes nos chafarizes públicos de Dijon, na Fran ça.

Em 1899, SLICHTER ${ }^{(20)}$ generalizou a Lei de Darcy para um meio saturado, escrevendo uma equação diferencial macroscópica 
tridimensional da forma:

$$
\overrightarrow{\mathrm{q}}=-\mathrm{K}_{\mathrm{S}} \stackrel{\vec{\nabla}}{\mathrm{H}}
$$

onde, a partir de agora, utilizaremos a denominação comumente em pregada em Física de Solos e denotaremos com $q$ a densidade de flu xo da água no solo $\left(\mathrm{cm}^{3} / \mathrm{cm}^{2} \mathrm{seg}\right)$, com $\vec{\nabla}_{\mathrm{H}}^{(*)} \circ$ gradiente da carga hidráulica $(\mathrm{cm} / \mathrm{cm})$, com $\mathrm{K}$ a constante chamada condutividade $\mathrm{h} \underline{\mathrm{i}}$ dráulica $(\mathrm{cm} / \mathrm{s})$ e c índice s lembrará saturação.

RICHARDS ${ }^{(22)}$, em 1931, postulou que o conceito de SLICL TER poderia ser estendido aos meios porosos não-saturados. Para isto, ele supôs que a condutividade hidráulica $K$, dependia univo camente de uma outra função $\psi$ denominada potencial matricial de sucção. Por sua vez é possível relacionar experimentalmente esta função $\psi$ com a umidade do solo $\theta^{(* *)}$ através da chamada curva cá racterística da umidade do solo. Assim, conforme a conveniência, pode-se obter a curva da condutividade hidráulica como função da umidade $\theta$.

No entanto, em 1956, MILLER e MILLER ${ }^{(23)}$ Chamaram a aten ção de que a Equação de Richards tornava-se falha quando a histe rese era considerada. Devido a isto, estenderam a Equação de $\mathrm{R} \underline{\underline{i}}$ chards incluindo a histerese na relação de condutividade. Dessa forma, (II-1) passou a ser escrita como:

$$
\vec{q}=-K_{h}(\psi) \vec{\nabla} \quad H
$$

onde o índice h lembra histerese. A relação $\mathrm{K}_{\mathrm{h}}(\psi)$ para solos é

(*) Uma discussão bastante detalhada e recente da aplicação do conceito de potencial ao estudo do equilíbrio e do transporte da água no solo pode ser encontrada em COREY e KLUTE (1985)(21).

(**) Definimos umidade volumétrica ou conteúdo da água no solo $\theta$, como o quociente do volume da água existente no mesmo solo pelo volume total (que inclui o volume da parte sólida, o volume da parte líquida e o volume da parte gasosa) do solo. 
altamente não linear e histerética, complicando sobremaneira e mesmo impossibilitando, na maioria dos casos (condições de contor no), a solução numérica da equação (II-2) .

Devido a este fato, não consideraremos em nossos estudos a presença da histerese, procedimento muito comum nos estudos de Física de Solos. Com isto, abandonaremos o índice $h$ em (II-2), ou seja, trabalharemos com a Equação de Richards que chamaremos de Equação de Darcy conforme é normalmente designada na literatura e que se escreve como:

$$
\vec{q}=-K(\psi) \vec{\nabla} H=-K(\theta) \vec{\nabla} H \quad \ldots \ldots \ldots \ldots \ldots(I I-3)
$$

Apesar das limitações, (II-3) é a equação que melhor representa a Lei do Fluxo da Água no solo, em se considerando os aspectos práticos e as dificuldades matemáticas. Convém observar que mesmo abandonando a histerese, a equação (II-3) apresenta ain da uma complexidade matemática bastante elevada, principalmente devido à alta não-linearidade presente na condutividade hidráulica $K(\psi)$ ou $K(\theta)$.

Vamos, a partir deste ponto, obter a equação geral do fluxo, acoplando para isto a equação da continuidade (que provém da Lei da Conservação da Massa) com a equação (II-3). A equação da continuidade fica escrita, de acordo com a notação adotada, co mo:

$$
\frac{\partial \theta}{\partial t}=-\dot{\vec{\nabla}} \cdot \vec{q}
$$

e que de acordo com (II-3) é possível concluir que:

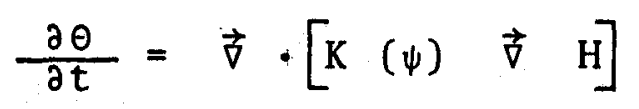

Comumente, o potencial $\mathrm{H}$ pode ser escrito como função de suas componentes $\psi$ e $Z$ (veja por exemplo, a referência 13), on- 
de $z$ é o chamado potencial gravitacional, significando uma medida ao longo do comprimento na vertical (profundidade), e o termo - $\psi$ é denominado sucção matricial.

Com isto, (II-5) se escreve como:

$$
\frac{\partial \theta}{\partial t}=-\vec{\nabla} \cdot\left[\begin{array}{lll}
K(\psi) & \vec{\nabla} & (\psi-z)
\end{array}\right]
$$

No caso de fluxo horizontal ( $z$ constante) $\vec{\nabla} z=0$, e no caso de fluxo na vertical $\vec{\nabla} z=1$, então $(I I-6)$ assume a seguinte forma:

$$
\begin{aligned}
& \frac{\partial \theta}{\partial t}=-\vec{\nabla} \cdot[K(\psi) \vec{\nabla} \psi]+\frac{\partial K}{\partial z} \ldots \ldots \ldots \ldots \ldots \ldots(I I-7) \\
& \text { No caso em que } \circ \vec{\nabla}_{z} \text { (gradiente gravitacional) é despre }
\end{aligned}
$$
zível comparado com o gradiente de sucção matricial $\vec{\nabla} \psi$ a equação (II-7) fica escrita como:

$$
\frac{\partial \theta}{\partial t}=\vec{\nabla} \cdot[K(\psi) \quad \vec{\nabla} \psi]
$$

ou para o caso de um sistema unidimensional horizontal, que utili zaremos mais adiante, obtemos que:

$$
\frac{\partial \theta}{\partial t}=\frac{\partial}{\partial x}\left[K(\psi) \frac{\partial \psi}{\partial x}\right]
$$

onde a variável $x$ é indicativa da dimensão horizontal.

A esta altura, convém voltar à equação (II-3) a uma dị mensão (sem a componente vertical $z$ em $H$ ) e relacionar $\bigcirc$ fluxo com $\circ$ gradiente da umidade $\theta$ e não com o gradiente de suçãa $\psi$. $\underline{U}$ sando para isto a regra da cadeia e definindo capacidade especí fica da água como $c(\theta)=\frac{d \theta}{d \psi}$ (tangente a curva $\theta \times$ obtida expe rimentalmente) é possível escrever (II-3) como:

$$
q=K(\theta) \frac{\partial \psi}{\partial x}=-\frac{K(\theta)}{c(\theta)} \quad \frac{\partial \theta}{\partial x}
$$


CHILDS e COLLIS - GEORGE ${ }^{(24)}$, em 1950, definiram:

$$
D(\theta)=\frac{K(\theta)}{c(\theta)}=K(\theta) \frac{d \psi}{d \theta}
$$

onde a função $D(\theta)$ é chamada de difusividade hidráulica.

Se substituirmos (II-11) em (II-10) obteremos:

$$
q=-D(\theta) \frac{\partial \theta}{\partial x}
$$

que é análoga à primeira Lei da Difusão de Fick, que estabelece que a taxa da difusão é proporcional ao gradiente da concentração. No caso de $K(\theta)$ constante (solo saturado) a equação (II-10) possui a mesma forma matemática de outras duas equações de transporte da Física Clássica, quais sejam: a Lei de Ohm (a corrente é proporcional ao gradiente do potencial elétrico) e a Lei de FOURIER (a taxa de condução de calor é proporcional ao gradiente de temperatura).

No entanto, convém observar que embora seja possível fazer uma analogia com as leis citadas, as complexidades matemáti cas presentes nas equações (II-10) ou (II-12) são muito superiores, pois $K$ depende de $\theta$ no caso do solo não-saturado, além da não-linearidade e no caso mais geral depende da histerese, como já ressaltamos anteriormente. Além do mais, a presença da gravida de no caso da infiltraçao vertical é uma característica muito especial do transporte da água no solo, acrescentando novas dificul dades.

Voltando agora à equação (II-9) e usando a definição (II-11) podemos escrever que:

$$
\frac{\partial \theta}{\partial t}=\frac{\partial}{\partial x}\left[D(\theta) \frac{\partial \theta}{\partial x}\right]
$$

que é uma equação que envolve somente a variável $\theta$ e não mais $\psi$. Esta equação nos será muito útil no estudo da infiltração horizon 
tal, conforme veremos em seguida.

Passemos, a partir de agora, a estudar analiticamente o processo pelo qual a água entra no solo,denominado infiltração. Por motivo de maior clareza e conveniência, como poderá ser obser vado, vamos separar o estudo da infiltração em infiltração horizontal e vertical.

\section{2 - INFILTRAÇÃO HORIZONTAL EM UMA COLUNA INFINITA DE SOLO HOMOGÊNEO}

Consideremos, conforme a Figura 1 , uma coluna uniforme, horizontal, de seç̧ão transversal e densidade global ${ }^{(*)}$ constantes, comprimento infinito e com uma umidade inicial constan te $\theta_{i}$

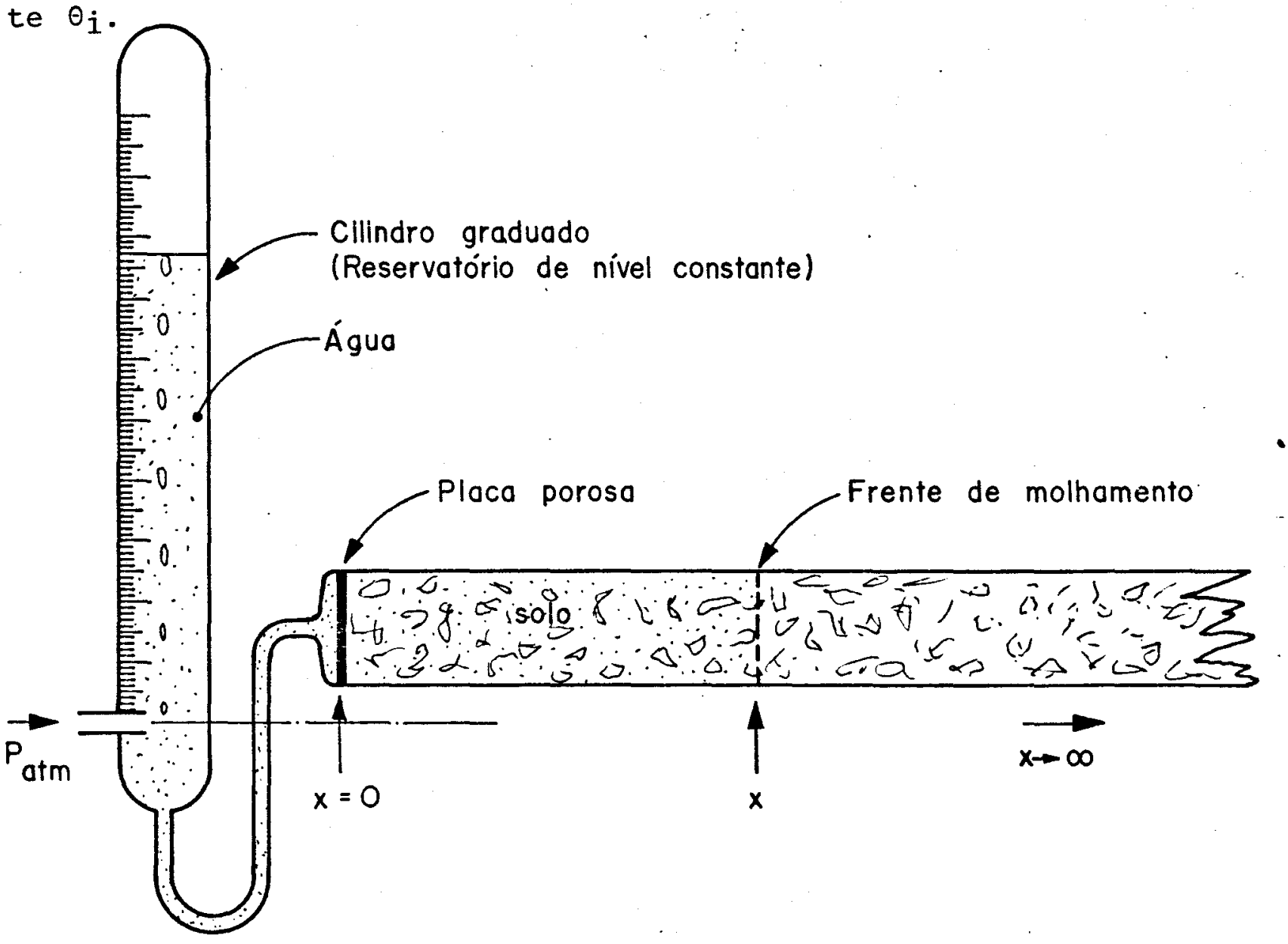

Figura 1 - Ilustração esquematizada de uma coluna infinita de solo homogêneo comumente utilizada en estudos de infiltração horizontal da água no solo.

(*) Definimos densidade global (seca) como o quociente da massa de solo seco pelo volume total de solo seco. 
No instante $t=0$ (início do processo de infiltração), a placa porosa (localizada em $x=0$ ) da Figura 1 é colocada em contacto com a água do reservatório.

Com isto a extremidade $x=0$ permanece com um teor de umidade $\theta_{0}$ constante durante todo o tempo da infiltração. Com a penetração da água no solo, a umidade $\theta$ será uma função do ponto $x$ e do tempo $t$ considerados, ou seja $\theta=\theta(x, t)$.

A equação (II-13) governará este processo, sujeita às seguintes condições de contorno:

$$
\left\{\begin{array}{lll}
\theta=\theta_{i}, & x>0, & t=0 \\
\theta=\theta_{0}, & x=0, & t>0 \\
\theta=\theta_{i}, & x \rightarrow \infty, & t>0
\end{array}\right.
$$

Para resolver a equação (II-13) SWARTZENDRUBER ${ }^{(25)}$ (1969) propôs que $x$ fosse transformada em variável dependente na forma $x=x(\theta, t)$. Utilizando o método da separação das variáveis e es crevendo

$$
x=\lambda(\theta) \cdot \mathrm{T}(\mathrm{t})
$$

onde $\lambda(\theta)$ é uma função que depende somente de $\theta$ e $T(t)$ somente de $t$, é fácil encontrar, utilizando a equação (II-14), que

$$
x=\lambda(\theta) \cdot t^{1 / 2}
$$

A equação (II-16) pode ser reescrita como:

$$
\lambda(\theta)=x \mathrm{t}^{-1 / 2}
$$

que é chamada Transformação de Boltzmann, utilizada pela primeira vez por LUDWIG BOLTZMANN em 1894.

Antes de procurarmos pelo valor de $\lambda(\theta)$ é possivel afirmar que na infiltração horizontal em um solo inicialmente seco 
e estável, o avanço da "frente de molhamento" (avanço $x$ da umidade $\theta$ no interior da coluna) é proporcional à raiz quadrada do tem po. Portanto, no início, a infiltração é rápida tornando-se cada vez mais lenta conforme o tempo avança.

Com a introdução da equação (II-17) na equação (II-13) as condições do contorno (II-14) também sofrem alteração, assumin do a seguinte forma:

$$
\begin{cases}\theta=\theta_{i}, & \lambda+\infty \\ \theta=\theta_{0}, & \lambda=0\end{cases}
$$

Substituindo a transformação (II-17) na equação (II-13) (equação diferencial parcial em $\theta, x$ e $t$ ) obtemos:

$$
\frac{-\lambda}{2} \quad \frac{\mathrm{d} \theta}{\mathrm{d} \lambda}=\frac{\mathrm{d}}{\mathrm{d} \lambda}\left[D(\theta) \frac{\mathrm{d} \theta}{\mathrm{d} \lambda}\right] \ldots \ldots \ldots \ldots \ldots(\text { II-19) }
$$

que passa a ser uma equação diferencial ordinária somente nas variáveis $\theta$ e $\lambda$. Esta equação é não-linear devido à presença de $D(\theta)$, o que requer a busca de soluções numéricas.

Em 1955, PHILIP $(26,27)$ desenvolveu um procedimento iterativo para a solução numérica de (II-19) sujeita às condições. de contorno (II-18). Em 1971, PARLANGE ${ }^{28)}$ introduziu uma técnica quase analítica, DE WIT e VAN KEULEN ${ }^{(29)}$ em 1972 e ELRICK e LARYEA $^{(30)} \mathrm{em}$ 1979 desenvolveram procedimentos baseados em simulação por computador. LIBARDI, REICHARDT et al ${ }^{(31)}$ também contribuíram com métodos para estimar a condutividade hidráulica do solo em condições de campo.

Uma técnica para determinar a difusividade. hidráulica $D(\theta)$ a partir de distribuições de umidade obtidas experimentalmen te $[i . e ́ ., \theta(\lambda)]$ da infiltração horizontal foi publicada em 1956 por BRUCE e KLUTE ${ }^{(32)}$.

Integrando-se (II-19) em $\theta$ entre os limites $\theta_{i}$ e um va- 
lor de $\theta$ qualquer, obtemos:

$$
\int_{\theta_{i}}^{\theta} \lambda d \theta=-2 D(\theta) \frac{d \theta}{d \lambda}
$$

BRUCE e KLUTE explicitaram $D(\theta)$ a partir de (II-2ø) encontrando:

$$
D(\theta)=-\frac{1}{2 t_{0}} \frac{d x}{d \theta} \int_{\theta_{i}}^{\theta} x \mathrm{~d} \theta
$$

uma vez que o tempo $t$ é uma constante num dado instante de observação $t_{0}$.

Com isto, conhecida a curva de $\theta$ em função de $x$ experi mentalmente, para um dado $t_{0}$ como pode ser visto de forma genérica na Figura 2, é possível determinar $D(\theta)$ em $t$ para qualquer $\theta$ entre $\theta_{j}$ e $\theta_{0}$ através da equação (II-21). Resultados típicos das curvas $\theta$ em função de $x$ para diversos solos podem ser encontrados em LIBARDI e REICHARDT ${ }^{(33)}$ ou em POPI ${ }^{(34)}$ que estudou um solo da região de São Carlos (Represa do Lobo).

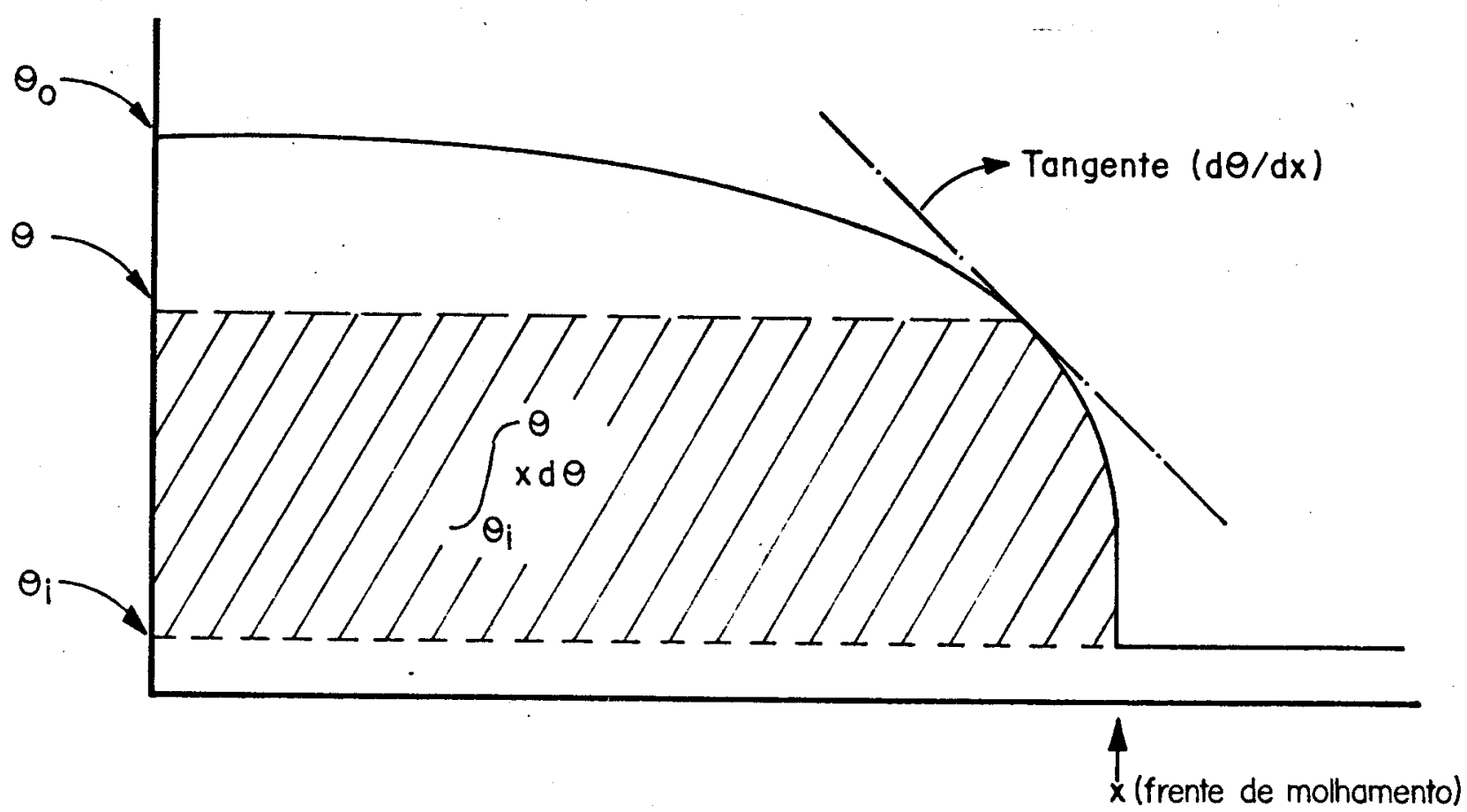

Figura 2 - Curva típica da umidade $\theta$ em função de $x$ (posição da frente de molhamento) para um dado instante arbitrário to durante a infil tração horizontal num solo estável e homogêneo de umidade inicial $\theta_{j}$. Em $t=0$, a água é introduzida no plano $x=0$ (placa porosa da Fig. I) e instantaneamente a umidade do solo atinge o valor $\theta_{0}$. A tangente à curva $\theta$ em função de $x$ nos fornece $d \theta / d x$ e a área riscada corresponde ao valor da integral $\int_{\theta_{i}}^{\theta} x \mathrm{~d} \theta$. Com isto $D(\theta)$ pode ser calculado 


\section{3 - INFILTRAÇÃO VERTICAL EM UMA COLUNA INFINITA DE SOLO HOMOGÊNEO}

Consideremos uma coluna idêntica à da Figura 1, posicio nada na vertical. Da mesma forma, no instante $t=0$ a placa porosa é colocada em contacto com o solo em $z=0$.

As condições de contorno existentes são:

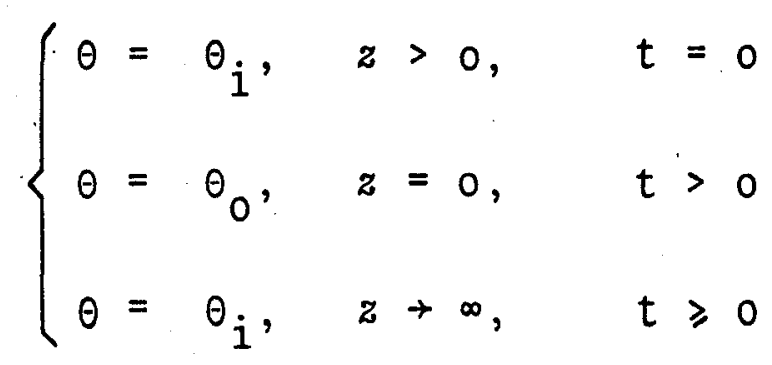

A Equação de Darcy (II-3) para a infiltração vertical, onde $\mathrm{H}=-(\psi+z)$, fica:

$$
\mathrm{q}=\mathrm{K}(\psi) \frac{\mathrm{d} \psi}{\mathrm{d} z}+\mathrm{K}
$$

e a equação (II-7) em uma dimensão assume à seguinte forma:

$$
\frac{\partial \theta}{\partial t}=-\frac{\partial}{\partial z}\left[K(\psi) \frac{\partial \psi}{\partial z}\right]-\frac{\partial K}{\partial z}
$$

Se a umidade do solo $\theta$ estiver relacionada $\operatorname{com} \psi$ de for ma única e se definirmos agora a capacidade específica ou diferen cial da água como $\mathrm{C}(\theta)=-\frac{\partial \theta}{\partial \psi}$ então é possível, usando a regra da cadeia, obter de (II-24) que:

$$
\begin{aligned}
& C \frac{\partial \psi}{\partial t}=\frac{\partial}{\partial z}\left(K \frac{\partial \psi}{\partial z}\right)+\frac{\partial K}{\partial z} ; \ldots . \\
& \frac{\partial \theta}{\partial t}=\frac{\partial}{\partial z}\left(\frac{K}{C}\right) \frac{\partial \theta}{\partial z}-\frac{\partial K}{\partial z} \quad \text { ou } \\
& \frac{\partial \theta}{\partial t}=\frac{\partial}{\partial z}\left(D \frac{\partial \theta}{\partial z}\right)-\frac{\partial K}{\partial z}
\end{aligned}
$$

ondè $D=K(\theta) / C(\theta)$ e que é o correspondente da função anterior- 
mente chamada de difusividade hidráulica.

As equações (II-24), (II-25) e (II-26) podem ser todas consideradas como diferentes formas da Equação de Richards (22).

Destas mesmas três equações é fácil observar a presença de dois termos nos seus respectivos lados direitos, o primeiro fornecendo a contribuição do gradiente da sucção ou umidade e o segundo a contribuição do gradiente gravitacional. A importância maior de um sobre o outro depende essencialmente das condições iniciais, das condições de contorno e do estágio do processo consi derado. Se tomarmos, como exemplo, a infiltração que tem início num solo seco, o termo de sucção predominará sobre o gravitacional e nesta situação a taxa de infiltração vertical tende a se comportar inicialmente da mesma maneira que a de infiltração hori zontal. Assim, a infiltração num sulco seco tende a ocorrer com a mesma velocidade, tanto na direção horizontal como na vertical, resultando que a frente de molhamento descreve, no início, arcos de círculo. Depois de um certo tempo pode ocorrer que o potencial de sucção decresça. e o potencial gravitacional prevaleça. A Figu ra 3 ilustra, para um caso típico, o que acabamos de afirmar.

Figura 3 - Infiltração típica que ocor re em um sulco de irrigação onde o so lo encontra-se inicialmente seco. A frente de molhamento é mostrada em três instantes de tempo diferentes $\left(t_{1}<t_{2}<t_{3}\right)$. Hote no início a pre dominância do termo de sucção (até o instante $t_{1}$ ) e no final a predominân cia do termo gravitacional.

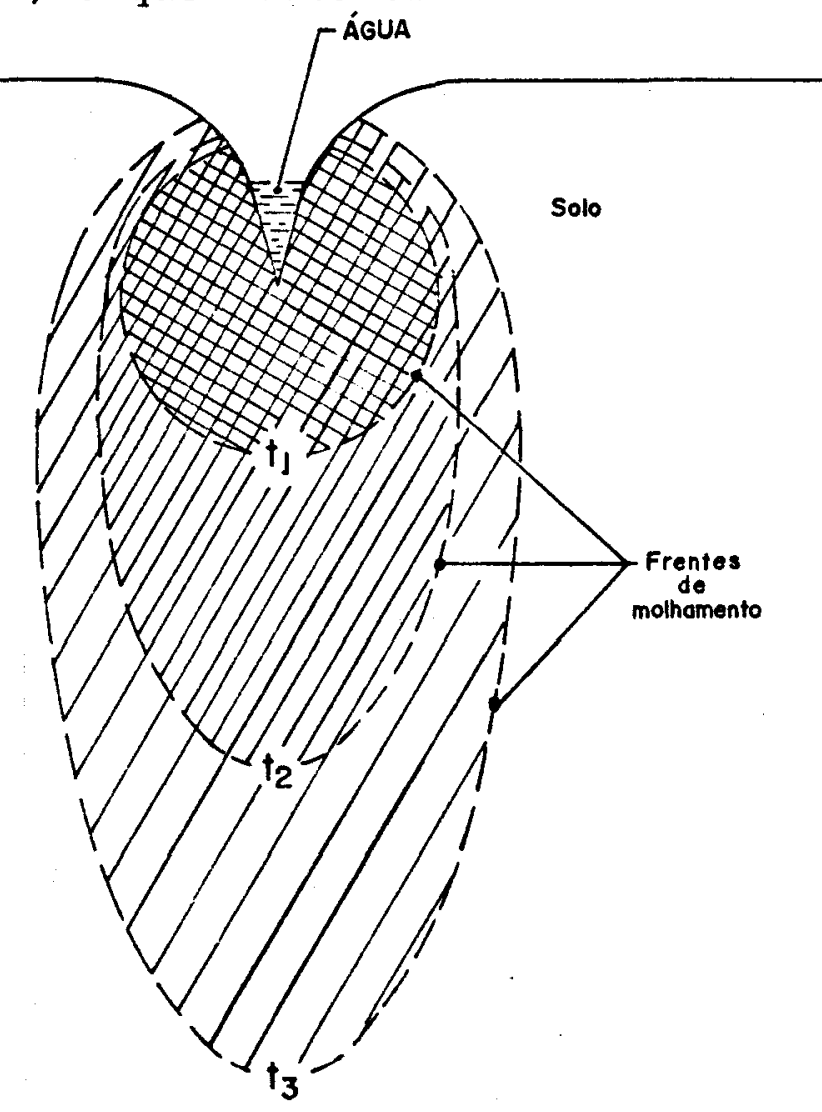


Por outro lado, quando a infiltração ocorre num solo $\underline{i}$ nicialmente molhado, o termo referente ao gradiente de sucção é pequeno, tornando-se rapidamente desprezível, predominando o ter mo referente ao potencial gravitacional, conforme ilustra generi camente a Figura 4, em comparação com a Figura 3.

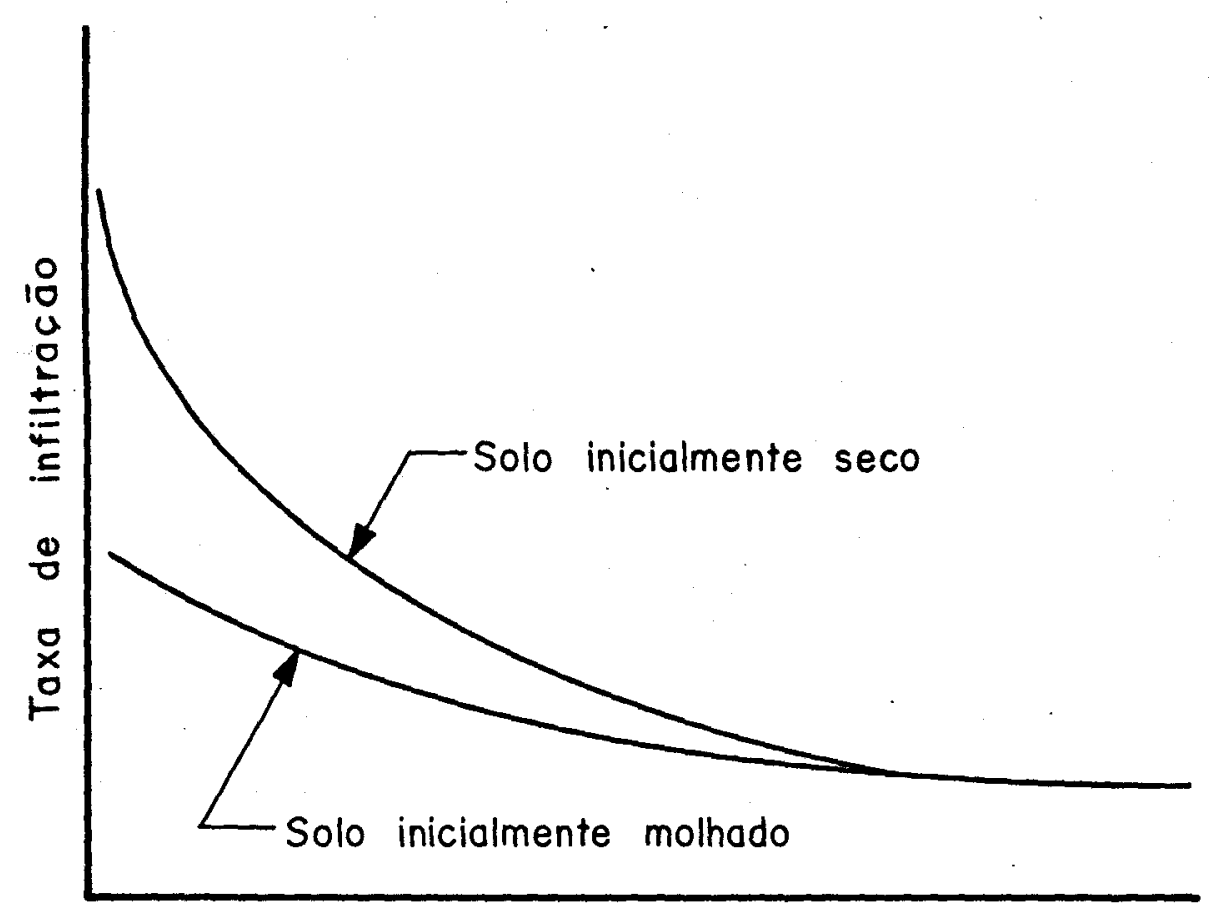

Tempo

Figura 4 - 0 volume da água que penetra no solo por unidade de tempo (taxa de infiltração) para um mes mo solo em duas condições iniciais diferentes: seco e úmido.

Para finalizar, vamos rapidamente discutir a solução da equação (II-26) sob as condições de contorno (II-22).

Como una primeira aproximação, vamos considerar somen te os primeiros instantes do avanço da frente de molhamento. Rees crevendo (II-26) na forma:

$$
\frac{\partial \theta}{\partial t}=\frac{\partial}{\partial z}\left[D \frac{\partial \theta}{\partial z}-K\right]
$$

é fácil verificar que $D \frac{\partial \theta}{\partial z} \gg K$ quando $t \rightarrow 0$, permitindo-nos desprezar. K. Com isto $(I I-27)$ se reduz a (II-13) (basta trocar $z$ 
por $x$ ), que foi usada para estudar o fluxo horizontal, admitindo por conseguinte a solução:

$$
z=\lambda(\theta) \cdot t^{1 / 2}
$$

- que demonstra que nos primeiros instantes da infiltração não há diferença considerável entre a infiltração horizontal e a verti cal (ou seja, a componente gravitacional não é relevante). É o que ocorre na Figura 3, conforme já discutimos. Da experiência, é sa bido que o tempo em que os dois processos coincidem varia confor me o solo. Em geral, esse tempo é maior para solos de texturas $\mathrm{f}_{\underline{1}}$ nas do que para solos de texturas grossas (menor capacidade de retenção da água).

A solução de (II-27) para tempos mais longos, exige maiores investigações. Uma técnica comumente adotada na resolução de equações diferenciais é expandir $z(\theta, t)$ em uma série infinị ta. Façamos isto:

$$
z(\theta, t)=\stackrel{\Sigma}{\Sigma}=0_{i} f_{i}(\theta) t^{i m}
$$

sendo m um número positivo. Se (II-29) é uma solução geral de (II-26) ou (II-27) sob as condições de contorno (II-22), então e la deve coincidir com (II-28) quando t tender a zero. Com esta condição, desprezemos em (II-29) os termos em que $i>1$ e compare mos o resultado com (II-27).

Com isto, concluímos que $f_{0}(\theta)=0, f_{1}(\theta)=\lambda(\theta)$ e $m=\frac{1}{2}$ Logo, voltando a (II-29) podemos escrever:

$$
z(\theta, t)=\lambda(\theta) t^{1 / 2}+f_{2}(\theta) t+f_{3}(\theta) t^{3 / 2}+f_{4}(\theta) t^{2}+\ldots \quad(I I-30)
$$

PHILIP (35), em 1957, apresentou uma solução numérica (baseado no Método das Diferenças Finitas) para a determinação de 
$\lambda(\theta), f_{2}(\theta), f_{3}(\theta), f_{4}(\theta) \ldots$ conhecidos $D(\theta)$ e $K(\theta)$. Para tem pos muito longos o avanço da frente de umidade (infiltração verti cal) atinge uma taxa constante $\frac{\left(K_{0}-K_{i}\right)}{\left(\theta_{0}-\theta_{i}\right)}$, onde $K_{0}$ e $K_{i}$ são as condutividades para os valores da umidade na superfície molhada $\left(\theta_{0}\right)$ e para a umidade inicial $\left(\theta_{i}\right)$ do solo, respectivamente.

Finalmente, queremos observar que não é nosso objetivo nesta tese, discutir mais detalhadamente este assunto. No en tanto, recentes progressos têm sido possíveis neste campo através de métodos como o da solução integral por função de Green realizạ do por CHENG ${ }^{(36)}(1984)$ ou outros conforme avaliados por STEPHENS e REHFELDT (37)(1985) no cálculo da condutividade hidráulica de uma areia fina. 


\section{CAPÍTULO III}

\section{BREVE REVISĂO DOS PRINCIPAIS MÉTODOS DE MEDIDA DO CONTEÚDO DA ÁGUA E OU DA DENSIDADE GLOBAL, EM COLUNAS DE SOLO, NO LABORATÓRIO}

Do capítulo anterior é evidente a importância da medi da, em laboratório, do conteúdo da água no solo $\theta$ e em muitos casos também de sua densidade global $\rho_{\mathrm{g}}$, se quisermos entender as propriedades de transmissão e retenção da água no solo. É o caso, por exemplo, da construção da curva da umidade volumétrica $\theta$ em função da posição da frente de molhamento (ou de umidade) $x$ da Fị gura 2, em um determinado instante escolhido. Tal curva nos permi te calcular a difusividade hidráulica $D(\theta)$ para a infiltração horizontal. Ou, de modo análogo, na infiltração vertical é preciso acompaninar a frente de molhamento em diferentes instantes, confor me nos mostram as Figuras 3 e 4 .

Dentre os vários métodos de medida direta ou indireta ora existentes $(38,39)$ a técnica de atenuação de raios gana $(\gamma) .41,42)$ que descreveremos a seguir tem ocupado um papel de destaque, quan . do se pretende estudar com precisão o fluxo da água nos materiais porosos e am particular no solo, em colunas de laboratório. Esta técnica é não-destruciva, rápida, possui boa sensibilidade e já possui cerca de 30 anos de uso. Acredita-se que tenha surgido ins pirada no experimento de RUTHERFORD, que em 1911, conforme é do conhecimento geral, propôs o seu modelo de estrutura atômica baseado no estudo da interação das partículas alfa com os núcleos de uma placa fina (lâmina) de ouro.

Em 1950, BELCHER ${ }^{(43)}$ e outros realizaram experimentos u tilizando a moderação de neutrons para medir a umidade do solo e - espalhamento de raios gama para medir.a densidade global. Poste riormente, os métodos nucleares e em particular, a radiação gama 
foram estendidos a outros fins. É o caso da determinação do nível de fluído em tanques, da densidade do concreto, da concentração de sólidos em fluídos, da concentração de metais pesađos em soluções aquosas, do estudo da uniformidade de vários materiais diferentes, etc.

FERRAZ ${ }^{(44)}$, em 1983, fez um levantamento retrospectivo bastante interessante do progresso do uso do método da atenuação do raio gama. Atualmente, em função da disponibilidade de novas fontes de radiação gama, das facilidades da automação, dos avanços dos equipamentos eletrônicos de detecção e contagem, o referi do método tem se tornado em uma das mais importantes ferramentas científicas de medida.

No Brasil, no caso das aplicações na agricultura, o método tem sido sistematicamente empregado no CENA (Centro de Energia Nuclear na Agricultura), em Piracicaba, pelos pesquisadores CERVELLINI， SALATI, REICHARDT, FERRAZ, LIBARDI e NASCIMENTO, entre outros. ${ }^{(6)}$.

Embora ainda existam outros métodos (como o gravimétrico, o TDR, etc.) usados em Física de solos para medidas em laboratório, conforme veremos no final deste capítulo, daremos . destaque ao método da atenuação da radiação gama no solo, devido às razões expostas.

Reforçamos ainda esta escolha sabendo que faremos compa rações entre este método e o novo método que iremos apresentar nos capítulos $V$ e VI desta tese.

\section{1 - 0 MÉTODO DA TRANSMISSÃO DIRETA DE RAIOS GAMA MONOENERGÉTICOS}

A interaçăo da energia radiante, no caso dos fótons da radiação gama com a matéria (átomos) constituída pelo solo (material poroso) é um processo físico relativamente complexo pois en- 
volve os efeitos da absorção, da emissão, do espalhamento e da aniquilação dos fótons. Na região de energia considerada na maioria dos experimentos que envolvem a radiação gama (até 1,4 Mev), os efeitos que prevalecem são conhecidos e chamam-se efeito fotoelétrico (absorção), efeito Compton (absorção e espalhamento) e produção de pares (aniquilação). O Espalhamento Raylegh, a exemplo de outros, também presentes nos processos de interação da radiação com a matéria tem contribuição desprezível no caso que estamos estudando.

A somatória destes efeitos pode ser expressa no que definimos como coeficiente de atenuação de massa $\left(\mathrm{em} \mathrm{cm}^{2} / \mathrm{g}\right)$. A Figu ra 5, como um exemplo típico, nos mostra o coeficiente de atenuação de massa do chumbo em função da energia dos fótons, donde podemos observar a contribuição relativa dos três efeitos principais citados. É evidente a preponderância do efeito fotoelétrico sobre os demais em baixas energias enquanto que o efeito Compton e o de produção de pares cresce em importância em altas energias, quando praticamente desaparece o efeito fotoelétrico. 


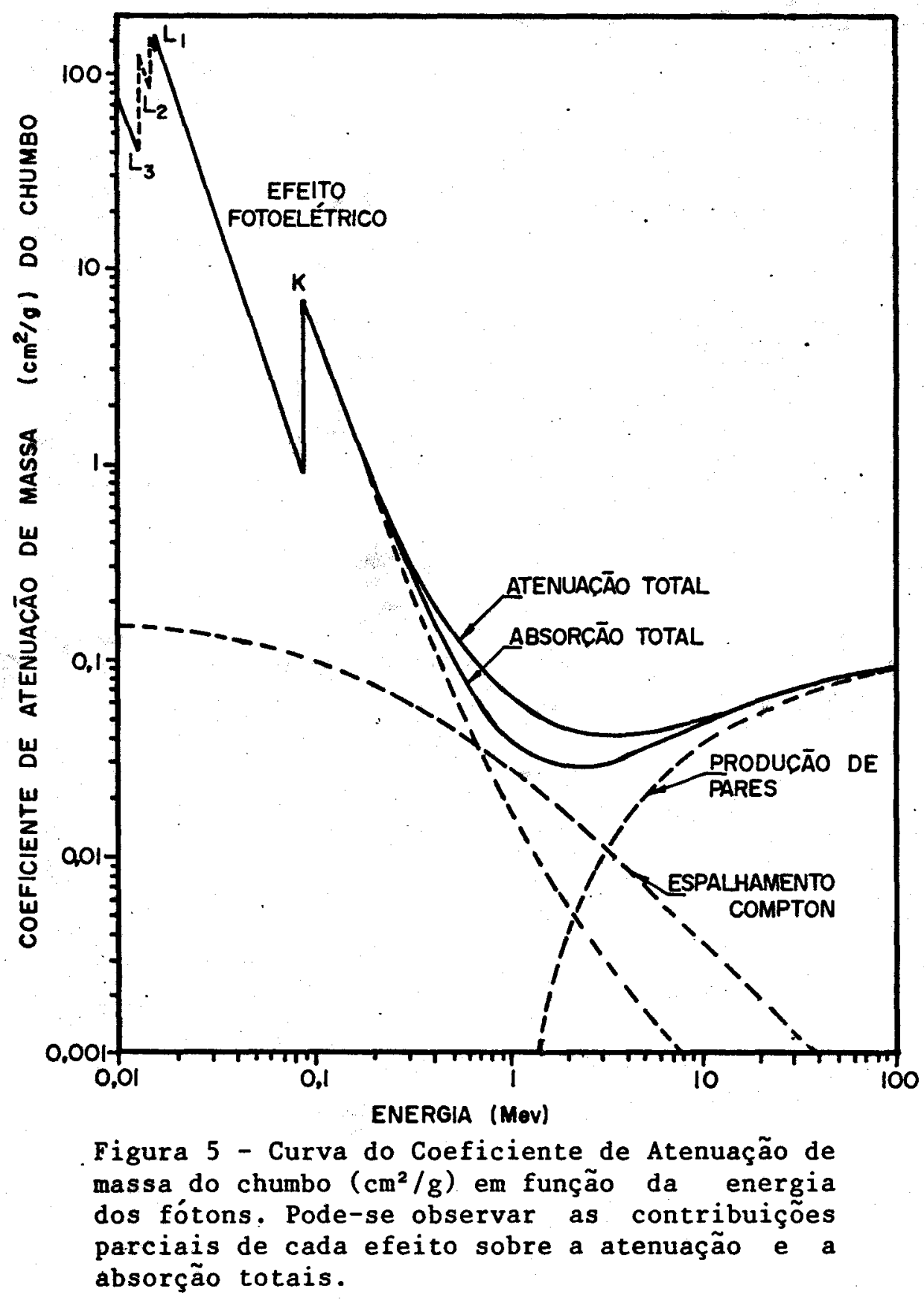

Observemos agora a Figura 6 , que traz um esquema exper $\underline{i}$ mental comumente utilizado em estudos da radiação $\gamma$ com amostras de solo. De forma genérica, o solo é constituído de uma parte sólida (sólidos do solo), de uma parte líquida (água) e de uma parte gasosa (ar). Ao caminhar da fonte ao detetor, os raios $\gamma$ colimados e monoenergéticos atravessarão o ar, as paredes iguais e paralelas do recipiente que contém a amostra de solo e a amostra de solo propriamente dita, que pode encontrar-se tanto úmida como seca. Em nosso estudo, não iremos considerar a contribuição do ar, pois o seu coeficiente de atenuação da radiação gama é cerca 
de $10^{3}$ a $10^{4}$ vezes menor que a contribuição dos outros constituin tes considerados na trajetória dos fótons. Denotaremos respectivamente por $x_{S}, \mu_{S}, \rho_{S} ; x_{W}, \mu_{W}, \rho_{W}$ e $x_{r}, \mu_{Y}, \rho_{r}$ as dimensões $I_{\underline{i}}$ neares $\left(\mathrm{em} \mathrm{cm}\right.$ ), os coeficientes de atenuação de massa (em $\mathrm{cm}^{2} / \mathrm{g}$ ) e as densidades volumétricas $\left(\mathrm{em} \mathrm{g} / \mathrm{cm}^{3}\right.$ ) das partes sólida ( $\mathrm{s}$ ) e líquida $(w)$ do solo e $(r)$ caracterizará o recipiente.

Com isto, a Equação de Lambert-Beer (equação que relaciona exponencialmente a intensidade do feixe emergente com a do incidente) para o esquema mostrado na Figura 6 se expressa como:

$$
I=I_{o i} e^{-\left[2 \mu_{r} \rho_{r} x_{r}+\mu_{s} \rho_{s} x_{s}+\mu_{w} \rho_{w} x_{w}\right]} \ldots \ldots \ldots(\text { III-1) }
$$

onde I é a intensidade do feixe emergente (número de fótons por $\mathrm{cm}^{2}$ por segundo que atingem o detetor após atravessar o recipiente com solo) e $I_{o i}$ é a intensidade do feixe incidente (número de fótons por $\mathrm{cm}^{2}$ por segundo que atingem o detetor sem a presença do recipiente com solo).

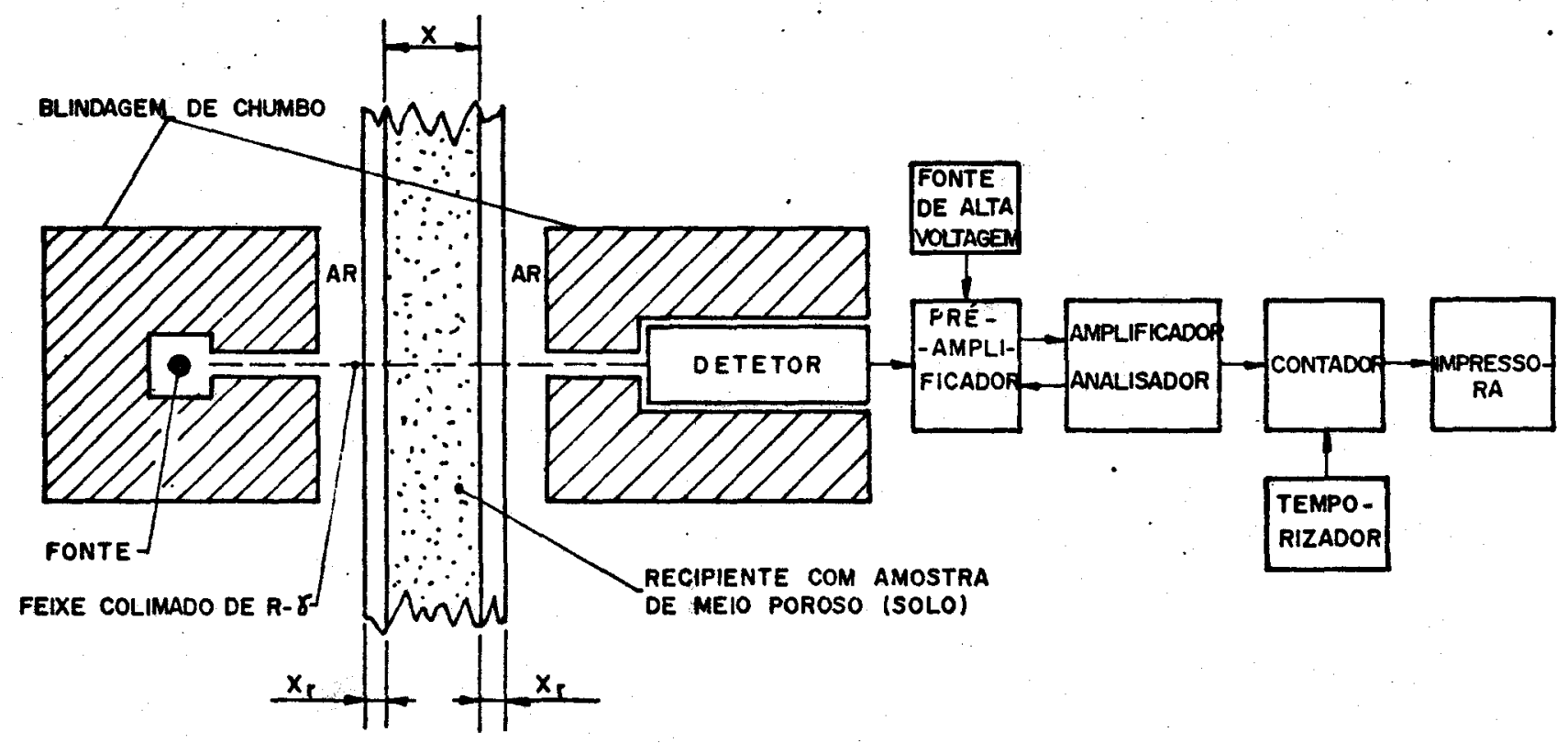

Figura 6 - Esquema de um experimento típico de medida do conteúdo da água e ou da densidade global de um solo utilizando fótons de raios $\gamma$ colimados e monoenergéticos percorrendo a trajetória reti línea da fonte ao detetor, atravessando o ar, as paredes do recipiente e a amostra do solo. Em seguida ilustramos o diagrama dos componentes do sistema de contagem e coleta de dados. 
Em geral, as medidas de I são feitas em várias posị ções, usando a mesma geometria e o mesmo recipiente. Devido a este fato, é possível fazer desaparecer o termo da equação (III-1) que contém a contribuição do recipiente. Como o mesmo é sempre constante, se fizermos inicialmente uma medida de $I$ com o recí piente vazio (que denotaremos por $I_{0}$ ) obtemos:

$$
I_{0}=I_{0 i} e^{-2 \mu} \rho_{r} x_{r}
$$

Dividindo-se (III-1) por (III-2) encontramos que:

$$
I=I_{0} \mathrm{e}^{-\left(\mu_{s} \rho_{s} x_{s}+\mu_{w} \rho_{w} x_{w}\right) \ldots \ldots \ldots \ldots(I I I-3)}
$$

com a contribuição do recipiente contida agora no termo Io.

Em estudos de água no solo, a equação (III-3) é usual mente escrita de outra forma. Para reescrevê-la nesta forma mais adequada, considèremos que a água é pura e portanto $\rho_{\mathrm{W}}=1 \mathrm{~g} / \mathrm{cm}^{3} \mathrm{e}$ sabendo-se que a densidade volumétrica da parte sólida os ${ }^{\left({ }^{*}\right)}$ multị plicada por $x_{\mathrm{S}}$ nos fornece $\rho_{\mathrm{g}} x$ e que $x_{\mathrm{w}}$ é igual a $x \theta^{(* *)}$ então (III-3) fica:

$$
\begin{aligned}
& I=I_{0} e^{-}\left[x\left(\mu_{s} \rho_{g}+\mu_{w} \theta\right)\right] \ldots \ldots \ldots \ldots \text { (III-4) } \\
& \text { Conhecidos os valores de } x, \mu_{s} \text { e } \mu_{w} \text { (dependem da enex }
\end{aligned}
$$
gia dos fótons com $\mu_{S}$ dependendo ainda do solo) podemos determi nar a densidade global $\rho_{g}$ a partir de (III-4) se previamente co

(*) Definimos densidade dos sólidos ou densidade média das partículas $\rho_{S}$ como sendo a fração entre a massa dos sólidos e o volume dos mesmos. Daí é fácil verificar que $\rho_{s}=\rho_{g}\left(1+\frac{x_{w}}{x_{s}}\right)$, ou seja, $\rho_{s} x_{s}=\rho_{g} x$, onde $\rho_{g}$ foi definida no rodapé do Capítulo II, na página 14.

(**) Da definição de $\theta=\frac{V_{W}}{V_{t}}$ (ver rodapé do Capítulo II, na pági na 10) -- $V_{t}$ é o volume total que é a soma do volume da parte líquida $V_{W}$ com o volume da parte sólida $\mathrm{V}_{\mathrm{S}}$-- é evidente o resultado. 
nhecermos o valor de $\theta$, que geralmente é a umidade residual do solo (solo seco ao ar) denotado por $\theta_{0}$. Ou seja,

$$
\rho_{g}=\frac{1}{x \mu_{s}}\left[\ln \left(\frac{I_{0}}{I}\right)-x \mu_{w} \theta_{0}\right]
$$

Por outro lado, supondo que a densidade global $\rho_{\mathrm{g}}$ perma neça constante durante a variação de $\theta$ (solo não-expansivo) podemos calcular os valores que a umidade $\theta$ vai adquirindo no decorrer do processo de escoamento (infiltração horizontal e ou vertical) da água no solo. Deste modo, a partir da equação (III-4) poo demos expressar a equação de $\theta$ em função de $\rho_{g}$, obtendo:

$$
\theta=\frac{1}{x \mu_{\mathrm{W}}} \quad\left[\ln \left(\frac{\mathrm{I}_{\mathrm{o}}}{\mathrm{I}}\right)-x \mu_{\mathrm{s}} \rho_{\mathrm{g}}\right]
$$

Portanto, através das equações (III-5) e (III-6) podemos calcular $\rho_{g}$ ou $\theta$, desde que uma destas variáveis seja anteriormente conhecida. No entanto, este método não possibilita determinar $\rho_{\mathrm{g}}$ e $\theta$ ao mesmo tempo. Para isto, vamos descrever, em seguida, o método do feixe de dupla energia que nos permitirá me-. dílas simultaneamente. Uma descrição e resultados mais detalhados podem ser encontrados no trabalho de STROOSNIJDER e DE SWART $^{(45)}$ (1974).

\section{2 - UTILIZAÇÃO DE UM FEIXE DE RAIOS GAMA DE DUPLA ENERGIA}

$$
\text { Como acabamos de observar, a equação (III-4) possui }
$$
duas incógnitas: $\rho_{g}$ e $\theta$. É possível obter um sistema de duas equações a duas incógnitas ao invés das equações (III-5) ou (III-6). Com isto, é possível estudar, sob determinadas condições, meios porosos não rígidos, como por exemplo, os solos expan sivos ${ }^{(45,46)}$. Consideremos o mesmo esquema da Figura 6 onde agora o feixe de raios gama é fornecido por duas fontes de energias di- 
ferentes. Vamos usar os índices a e $\underline{b}$ para distinguir as duas energias que o feixe possui. A partir de (III-4), conhecidos os va lores dos coeficientes de atenuação $\mu_{S}$ e $\mu_{W}$ para cada energia, é possível obter um par de equações que adquire a seguinte forma ma tricial:

$$
\left[\begin{array}{c}
\ln \left(\frac{I_{o a}}{I_{a}}\right) \\
\ln \left(\frac{I_{o b}}{I_{b}}\right)
\end{array}\right]=x\left[\begin{array}{cc}
\mu_{s a} & \mu_{w a} \\
\mu_{s b} & \mu_{w b}
\end{array}\right]\left[\begin{array}{c}
\rho_{g} \\
\theta
\end{array}\right]
$$

Experimentalmente, as medidas das intensidades dos dois feixes são feitas separadamente.

É fácil observar de (III-7) que pelo método da atenuação da radiação gama de dupla energia que estamos descrevendo, os erros $^{(47)}$ cometidos nas medidas de $x, \rho g$ e $\theta$ se propagam, permitindo que a imprecisão cresça. Em princípio, podemos usar outras energias ( 3 por exemplo) e considerarmos também o parâmetro $x$ em (III-4) como desconhecido. Embora isto seja possivel teoricamente, do ponto de vista experimental o aparato de fontes, detetores e respectivos mecanismos de movimento e ajustes torna-se mais com plicado e caro, além do agravamento do problema da interferência mútua da deteç̧ão da radiação de uma fonte sobre outra, conforme será ressaltado na próxima secção.

\section{3 - PARÂMETROS DO SISTEMA DE RADIAÇÃO, DETECÇÃO E CONTAGEM DE RAIOS GAMA}

Vamos fazer aqui algumas considerações a respeito das fontes de radiação gama assim como da geometria, deteç̧ão e contạ gem do sistema da Figura 6. Deste modo, pode-se ter uma idéia mais precisa das facilidades e dificuldades inerentes ao método da radiação gama. 
observados na escolha da fonte de radiação: ${ }^{(44)}$

a) ESPECTRO MONOENERGÉTICO. O espectro de radiação pre cisa possuir um pico principal de energia bastante pro nunciado numa região livre da radiação interferente, pois na maioria dos experimentos emprega-se o detetor de $\mathrm{NaI}(\mathrm{Tl})$ cintilante, que embora possua alta eficiência possui baixa resolução.

b) MEIA-VIDA. A meia-vida do radioisótopo utilizado de ve ter pelo menos o mesmo tempo de duração dos experí mentos programados de forma a evitar correções decorren tes dos decaimentos. Além disso, o custo também precisa ser considerado.

C) ATIVIDADE. Neste caso, a atividade total e a ativida de específica da fonte são importantes, devido à nature za caótica da desintegração radioativa. Um grande núme ro de fótons deve alcançar o detetor, sendo que o núme ro real de fótons contados é uma função da atividade da fonte, da atividade específica, da geometria e da coli mação. Em geral, uma fonte com 100 a $200 \mathrm{mCi}$ é usada pa ra produzir um feixe colimado no laboratório, mas cer tos pesquisadores usam fontes mais fortes (maiores que $250 \mathrm{mCi}$. A alta atividade fornece altos valores de in tensidade do feixe, e isto embora seja bom para a estą tística de contagem, por outro lado aumenta os erros provenientes do tempo "morto" do equipamento eletrônico.

d) ENERGIA. A espessura da amostra; sua densidade e a $\underline{e}$ nergia da radiação gama, determinam as condições ótimas de experimentação ${ }^{(48)}$. o produto da densidade pela espes sura determina a melhor energia a ser usada. Para a 
maioria dos solos recomenda-se $0^{241} \mathrm{Am}$ ( $60 \mathrm{Kev}$ ) quando a espessura das colunas variarem entre 4 e $8 \mathrm{~cm}$ e recomenda-se $\circ{ }^{137} \mathrm{Cs}(662 \mathrm{Kev})$ quando as mesmas variarem en tre 15 e $25 \mathrm{~cm}$ ou quando o material for muito denso, como no caso de rochas ou de concreto. Em alguns casos es peciais utiliza-se $0{ }^{60} \mathrm{Co}(1170$ a $1310 \mathrm{Kev})$ ou $0^{22} \mathrm{Na}$ (1250 Kev). No caso de amostras muito finas e materiais leves emprega-se raios $\mathrm{X}$ e energias muito baixas como a do ${ }^{55} \mathrm{Fe}{ }^{(49,50)}(5,9 \mathrm{Kev})$. No método do feixe de dupla energia são necessárias duas energias bastante distintas. Estas energias devem fornecer os coeficientes de a tenuação de massa para o material poroso (solo) e o fluído (água), de modo a obter-se uma boa resolução no cálculo das equações simultâneas. Um exame cuidadoso de uma tabela de radioisótopos mostra que somente alguns destes preenchem as considerações feitas, o que constitui um fator limitante da técnica de atenuação de raios gama.

Hoje a maioria das investigações que utilizam o mé todo do duplo feixe para medir a densidade global e. o conteúdo da água no solo é feita com fontes de raios gama provenientes do ${ }^{241} \mathrm{Am}$ e do ${ }^{137} \mathrm{Cs}$.

Quanto à geometria e detecção, temos a destacar a impor tância da colimação, principalmente quando utilizamos a técnica do feixe duplo de energia. Do ponto de vista prático, não é fácil colimar o sistema devido às limitações de ordem geométrica e de a tividade da fonte. O que se busca sempre é um feixe fino e de alta intensidade, o que exige do experimentador muita habilidade na montagem. A área da seç̧ão reta por onde passa o feịe varia de experimento a experimento. Vai desde 2 ou $3 \mathrm{~mm}^{2}$ a 80 ou $100 \mathrm{~mm}^{2}$ no caso de secção circular ou no caso de secções retangulares valo- 
res menores que $1 \mathrm{~mm}^{2}$ ou maiores que $100 \mathrm{~mm}^{2},(51,52)$.

Para a detecção do feixe emergente é comum empregar-se um cristal de Na I (TI) cintilante acoplado a uma fotomultiplicadora cujos pulsos gerados são analisados e contados por um sistema monocanal conforme já ilustrado na Figura 6. Para fótons de 60 Kev é fácil obter-se uma resolução melhor que $16 \%$ e acima de $10 \%$ para fótons de $662 \mathrm{Kev}$. Os detetores de estado sólido de alta resolução como o de Ge-Li não são usados devido à sua baixa eficiên cia comparada com a do NaI (T1) (cerca de cem vezes menor).

Quanto à contagem, existem erros devido ao tempo finito de medida da intensidade do espectrômetro. Este tempo não pode, por outro lado, ser muito ampliado devido às condições dinâmicas do experimento e também devido às flutuações (perdas de contagem) das medidas feitas pelos equipamentos eletrônicos, ligadas aos seus tempos de estabilidade.

\section{4 - OUTROS MÉTODOS}

Apresentaremos brevemente, em seguida, três outros métô dos de medida do conteúdo da água no solo em colunas de laboratório. Os dois primeiros são bastante clássicos enquanto o último é bastante recente.

a) METTODO GRAVIMETRICO. Este método(11) consiste em medir diretamen te os parâmetros envolvịdos nas definições da densidade global $\rho \mathrm{g}$ e do conteúdo da água no solo $\theta$, através do cálculo da umidade de massa ou gravimétrica $w$, conforme definiremos a seguir.

Para isto, deve-se começar pesando uma amostra de solo recolhida em um recipiente de volume previamente conhecido (por $\underline{e}$ xemplo, usando o Cilindro de Uhland) ${ }^{(13)}$ imediatamente após a sua extração. Dá-se o nome de peso úmido a esta medida. Após este pro 
cedimento deve-se colocar a amostra em um forno a $105^{\circ} \mathrm{C}$ e deixá-la secar por 24 horas. Depois deste período a amostra é novamente pesada obtendo-se o que se chama de peso seco.

Define-se como umidade volumétrica $w$, o quociente do pe so perdido no processo de secamento (diferença entre o peso úmido e o peso secol pelo peso seco. Após. isto, considerando-se que a densidade da água pura é de $1 \mathrm{~g} / \mathrm{cm}^{3}$ e medindo-se a densidade global (seca) os da amostra é possível calcular $\theta$ :

$$
\theta=w \rho_{s}
$$

Este método, embora muito empregado, simples e direto, apresenta uma série de inconvenientes: é destrutivo (não se pode repetir o experimento com o mesmo solo extraído), depende do transporte e da extração da amostra (processos quase sempre sujeí tos a perturbação e compactação), é lento (demora mais que 24 horas), é trabalhoso (necessita de pesagens sucessivas). Após isto tudo, quase sempre a precisão das medidas fica comprometida, podendo invalidar os experimentos que exigem maior rigor. Ainda. mais, determinados tipos de argila contêm água adsorvida ${ }^{(53)}$ em quantidades razoáveis mesmo a $105^{\circ} \mathrm{C}$. Também nesta temperatura é possível haver decomposição e oxidação da amostra de modo que não se pode afirmar com segurança que a perda de peso foi devida somente à evaporação da água. Pode-se, contudo, reduzir o erro até um certo limite, realizando diversas amostragens.

Mas, mesmo assim fica muito difícil não interferir nas características do solo, além do inconveniente de ser um método destrutivo, conforme já frisamos.

b) USANDO A LEI DE ARQUIMEDES. Um outro método também bastante simples, direto e parecido com o que acabamos de descrever (utili za o mesmo princípio) é às vezes empregado. Baseia-se na Lei de 
35.

Arquimedes.

Este método permite medir o volume de uma amostra de so 10, desde que a sua estrutura o permita. Cobre-se a amostra com um filme fino de parafina de tal modo a torná-la impermeável à água. Após isto, mede-se o seu volume através da diferença do seu peso quando "sustentado" no ar e quạdo "sustentado" na água.

c) METODO DO TDR ("TIME DOMAIN REFLECTROMETRY"). Como o método da atenuação de raios gama, é um método indireto para se medir o con teúdo da água $\theta$ no solo ${ }^{(54)}$.

A técnica do TDR aplicada à Física de Solos é relativamente nova ${ }^{(55)}(1980)$.

É uma técnica não-destrutiva, não radioativa e não depende do tipo de solo e nem da sua densidade global. Atualmente também está sendo empregada em medidas no campo ${ }^{(59)}$.

O TDR apareceu com FELLNER-FELDEGG ${ }^{(56)}$ (1969) num esforço de se medir com um só experimento a dependência da frequência com a constante dielétrica dos líquidos. Além disto, foi possível medir os tempos de relaxação moleculares e as condutividades elétri-. cas dos mesmos líquidos.

No caso de solos a constante dielétrica $\varepsilon$ é calculada a partir da medida do tempo que um pulso eletromagnético leva para partir de uma vareta metálica introduzida no solo, caminhar por esta, refletir e retornar. A Figura 7 ajuda a ilustrar $\circ$ que estamos descrevendo. 


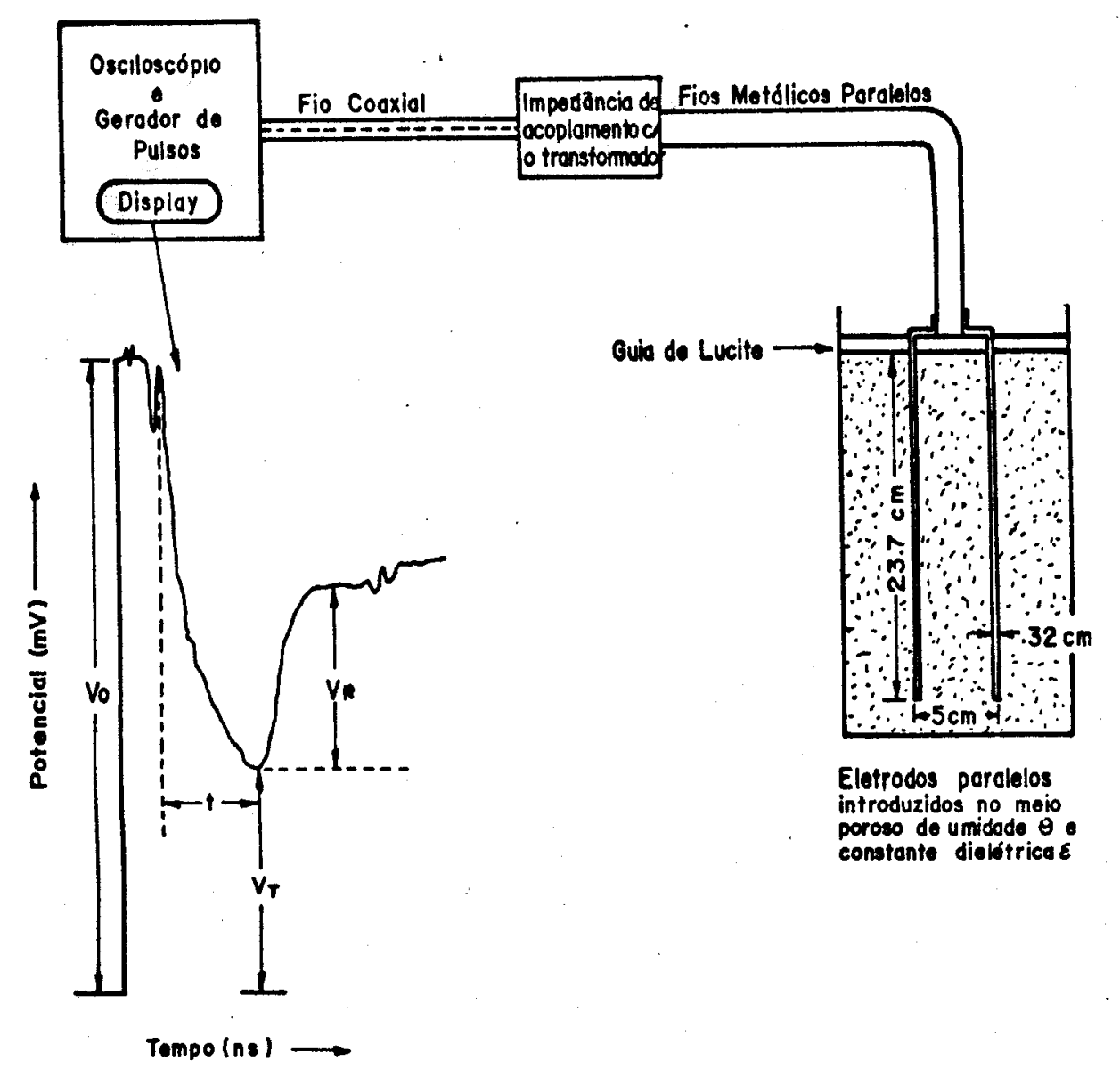

Figura 7 - Diagrama esquemático típico de um Sistema TDR para medir o conteúdo da água no solo e possivelmente a sua condu tividade elétrica. No sinal mostrado é possível identificar facilmente as suas características necessárias parà que as ne didas sejam feitas.

Na Figura 7, $V_{O}$ representa a amplitude do pulso emiti do pelo gerador, $V_{t}$ é a amplitude do pulso que entra na guia de onda de varetas paralelas $e V_{R}$ é a amplitude do pulso refletido quando de volta à mesma posição de partida. Para se distinguir $t$, $V_{R}$ precisa ser maior que zero. $V_{R}$ será igual a $V_{t}$ e facilmente mensurável se o meio não for condutor.

Entretanto, quando o meio é condutor, como num solo sa Iino, a amplitude $\nabla_{t}$ será atenuada na proporção da condutividą de do solo.

Esta atenuação poderá servir para medir a condutivida de elétrica do meio (não-magnético) e daí o seu conteúdo de sal ${ }^{(57)}$.

Para isto é necessário medir no osciloscópio as ampli tudes $V_{t} e V_{R}$, conhecer o comprimento da guia de onda e calcular a constante dielétrica $\varepsilon$ do meio. 
Para se medir $\varepsilon$ é preciso considerar que o pulso emiti do caminha até voltar à posição de partida uma distância igual a duas vezes o comprimento da guia de onda que chamaremos de $L(m)$. 0 tempo de trânsito $t(s)$ medido no osciloscópio fornece a velocidade de propagação $v$ do pulso. Considerando-se que o meio pratica mente é não-dispersivo $\left(v=c \varepsilon^{-1 / 2}\right.$, onde $c$ é a velocidade da luz no vácuo), então podemos calcular a constante dielétrica $\varepsilon$ através da relação:

$$
\varepsilon=\left(\frac{c t}{2 L}\right)^{2}
$$

TOPP et al ${ }^{(55)}(1980)$ relacionaram a constante dielétri ca $\varepsilon \operatorname{com}$ o conteúdo da água $\theta$ para um solo ${ }^{(*)}$ através da relação:

$$
\theta=-0,053+0,0292 \varepsilon
$$

donde $\theta$ poderá ser calculado.

Esta técnica (TDR') é não-destrutiva, relativamente sim ples e tem-se mostrado útil na medida do conteúdo da água no so10, mesmo nas medidas que exigem maior precisão. Estudos comparan . do-a com o método de atenuação de raios gama (58) e com o método gravimétrico ${ }^{(59)}$ têm sido realizados, apresentando resultados bastante positivos, não só no laboratório, mas também no campo. Esta técnica permite alterações $(59,60)$ no arranjo das varetas metálicas colocadas no solo no que se refere a posição (horizontal ou vertí cal), ao tamanho, etc. No entanto, não é possível utilizar o TDR para medir a densidade global (não é suficientemente sensível). Isto, em determinados casos, inviabiliza a técnica. Sabemos que

(*) TOPP et al (1980) estudaram diversos solos inorgânicos. Embo. ra os solos possuíssem grandes variações de densidade e textura, foi possível afirmar que a relação entre o conteúdo de água do solo e a constante dielétri ca permaneceu inalterada. 
38.

na construção de colunas de solo em laboratório é praticamente im possível prepará-las de modo a serem totalmente homogêneas. Ainda mais, em determinados solos (expansivos) a densidade global varia (cresce ou diminui) conforme a água é adicionada ou retirada do mesmo. Nessa situação é fundamental a medida simultânea de $\rho g$ com $\theta$ se quisermos obter sucesso nos resultados do experimento. Ainda outro ponto que está a exigir maiores estudos é a dependência do TDR quando aplicado a solos que possuem alta condutividade elétrica (por exemplo, os salinos), conforme pode ser inferido da leitura das referências (57) e (58).

Finalmente, outros métodos ${ }^{(61)}$ de medida podem ser adotados para a medida da umidade volumétrica $\theta$ ou mesmo da densidade global $\rho g$.

No entanto, as suas principais aplicações encontram-se no campo e não no laboratório, onde particularmente estamos interessados. É o caso da sonda de neutrons ${ }^{(62)}$ (baseado no espalhamen to de neutrons), do psicrômetro(63) (baseado na medida da resistência elétrica de um bloco de gesso, nylon ou fibra de vidro introduzido no solo), do radar ${ }^{(64)}$ (sensoramento remoto de microondas), . da análise do espectro de emissão térmica do solo e outros ${ }^{(65)}$. 


\section{CAPÍTULO IV}

\section{A TEORIA DA RECONSTRUÇÃO DA IMAGEM NA TOMOGRAFIA COMPUTADORIZADA}

Nos Capítulos II e III deduzimos as equações que gover nam o escoamento da água num meio poroso, mais especificamente o solo, assim como os principais recursos existentes de medida do conteúdo da água $\theta$ e da densidade global $\rho_{g}$ do solo acondicionado em colunas de laboratório.

Antes porém, de introduzirmos no próximo capítulo uma nova metodologia de medida de $\theta$ e $\rho_{\mathrm{g}}$, assim como de outros parâme tros, através do uso da Tomografia Computadorizada (T.C.), enten demos como necessário apresentar neste capítulo, os seus funda mentos básicos.

A tomografia não necessariamente precisa do auxílio do computador, embora este esteja sempre presente em todos os tomó grafos comerciais modernos. Devido a este fato é que o termo TAC $^{(*)}$ (Tomografia Auxiliada por Computador) é muitas vezes utili zado e confundido com T.C.. Para dissociarmos a idéia da Recons trução da Imagem da necessidade do emprego do computador, iremos utilizar somente o termo mais geral, Tomografia Reconstrutiva (T.R.)

A T.R. consiste em reconstruir uma dada secção de um corpo, quando um certo número de suas projeções em diferentes di reções é conhecido. A tomografia convencional, conforme esque matizada na Figura 8, foi introduzida por BOCAGE $^{(66)} \mathrm{em} 1921$ e pos sui a grande desvantagem de não conseguir distinguir com nitidez - plano de interesse, permitindo que os demais interfiram so bre este, resultanco em uma imagem "borrada".

(*) Muitas vezes o termo TAC é também usado como Tomografia Axial Computadorizada. Não faremos distinção, neste trabalho, com o termo anterior. 


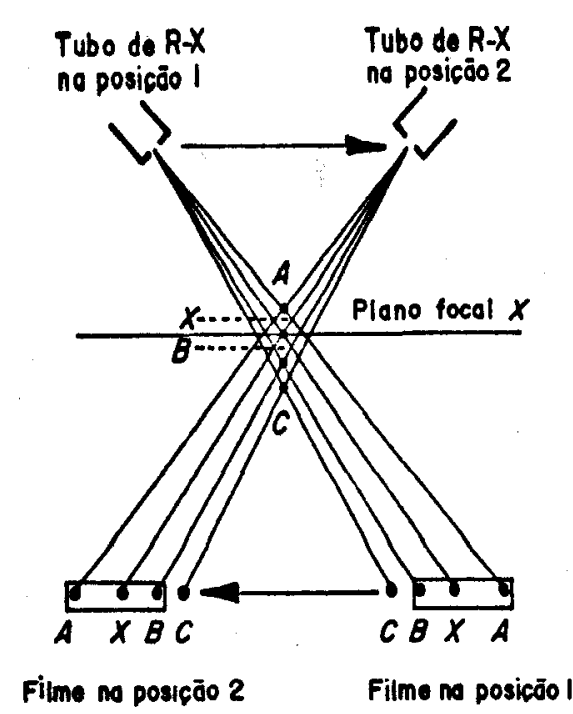

(a)

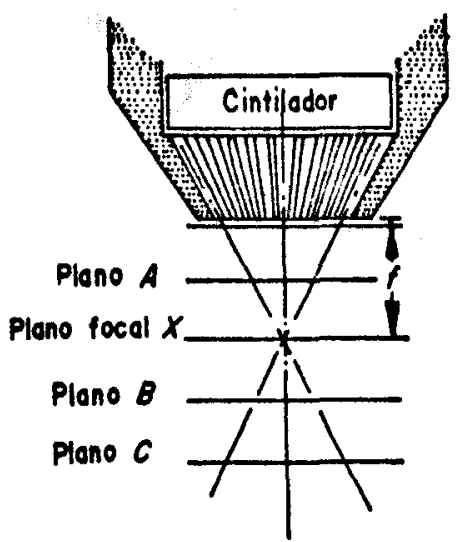

(b)

\begin{abstract}
Figura 8 - Tomografia plano-focal convencional - Na parte (a) o tubo de $\mathrm{R}-\mathrm{X}$ e o filme são movidos em direções opostas, de modo que os pon tos do plano focal $X$ sejam sempre projetados sobre o mesmo ponto do filme, enquanto que os pontos de outros planos (A, B, C) sejam proje tados sobre outras partes do filme, borrando as suas imagens. Na par te (b), na imagem por emissão, utiliza-se um colimador focalizado de modo que para uma dada posição do detetor, somente a radiação de um ponto do plano focal $X$ é detectada, enquanto que a dos demais planos são detectadas em várias posições, borrando as suas imagens.
\end{abstract}

Com a T.R., conforme pode ser visualizado na Figura 9, é possível eliminar os planos indesejáveis, conseguindo-se obter, com isto, maior nitidez da imagem dos planos de interesse. Assim, é possível encontrar a distribuição de coeficientes de atenuação (no caso da tomografia por transmissão) e a densidade de radioisó topos (no caso da tomografia por emissão) do meio observado. 
41.

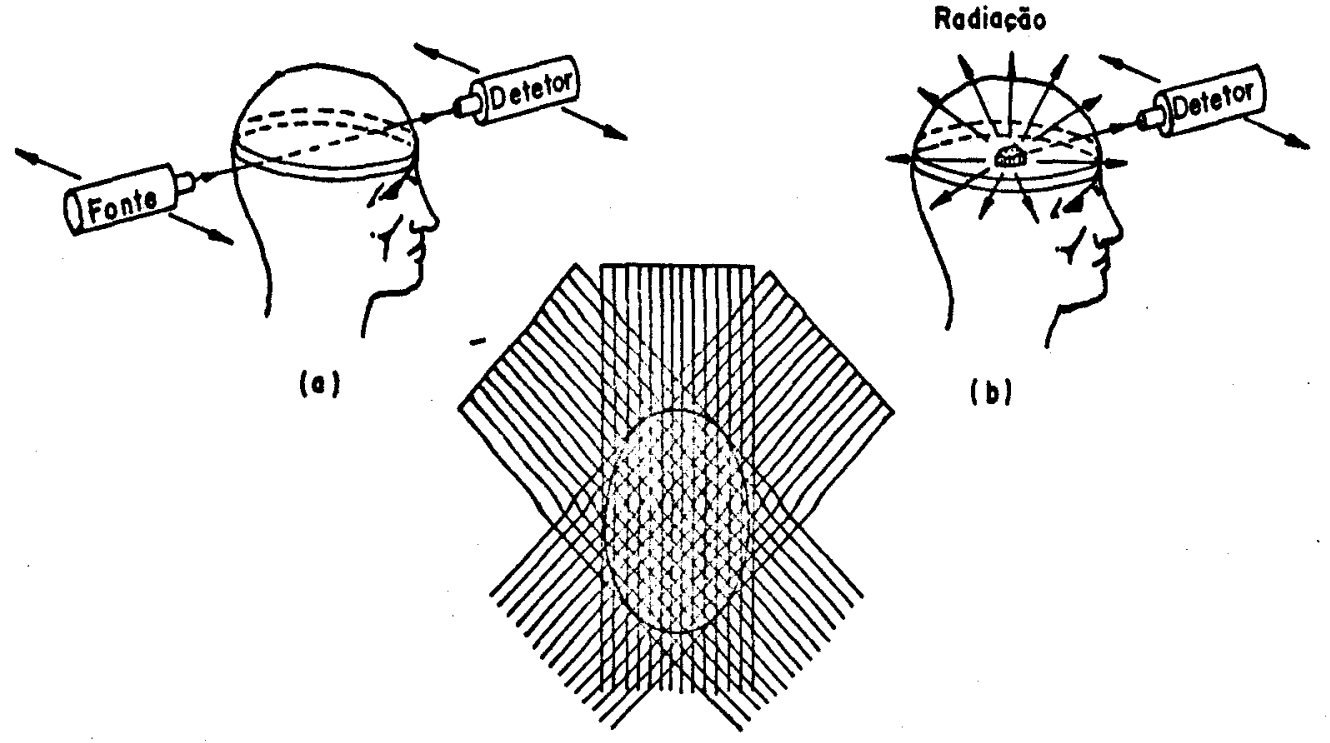

(c)

Figura 9 - Em (a) mostra-se o processo de varredura para obtenção da imagem por transmissão e em (b) por emissão. Em (c), mostra-se um resultado típico de uma série de varreduras realizadas através de sucessivas translações lineares da fonte e do detetor em dife rentes posições angulares (três).

A Reconstrução da Imagem de um objeto a partir do co nhecimento de suas projeções em diversas direções é um problema matemático bastante complexo. Esta é a principal razão do uso do computador, conforme poderemos verificar.

Antes porém, de introduzirmos as bases matemáticas da T.R., vamos apresentar na próxima secção, de maneira bastante a breviada, dentre outras coisas, o seu desenvolvimento histórico. Isto nos permitirá observar que a T.R. da imagem é de natureza altamente multidisciplinar. 


\section{1 - UMA DESCRIÇÃOO HISTÓRICA E ABREVIADA DA TOMOGRAFIA RECONSTRUTIVA}

Uma descrição mais detalhada, embora bastante infor mal, da Tomografia Computadorizada assim como de seus métodos de reconstrução da inagem até o ano de 1976, pode ser encontrada no trabalho de BROOKS e DI CHIRO ${ }^{(67)}$. Os livros de HERMAN ${ }^{(68)}(1980)$ e de NEWTON e POTTS ${ }^{(69)}(1981)$ são também bastante elucidativos.

Nesta secção, em seguida, vamos citar os principais. trabalhos e autores que contribuíram para que a T.R. atingisse o seu atual estágio de desenvolvimento. Como será possível obser var, a T.R. é o resultado do esforço de vários pesquisadores que atuaram em diferentes épocas. Na maioria dos casos, trabalharam de forma independente em diferentes campos da ciência, e não so mente no campo das aplicações médicas onde a T.R. é indubitavelmen te mais usada e conhecida.

Em 1917, O matemático austríaco RADoN ${ }^{(70)}$ foi o primei ro a publicar uma solução matemática das equações da reconstrução da imagem (isto é: a determinação da função distribuição da densị dade da região estudada) através de suas projeções, no campo da • gravitação.

BRACEWELL ${ }^{(71)}$ em 1956, também utilizou a T.R. no campo da radioastronomia, para construir o mapa das regiões solares $\underline{e}$ missoras de microondas. As antenas de microondas existentes não permitiam focalizar um ponto, mas somente pequenas faixas da su perfície solar. A emissão total de cada uma destas faixas ou tị ras podia ser medida e da soma das contribuições de uma série de las foi possível construir o referido mapa.

Na microscopia eletrônica, em estudos de biomoléculas complexas, o problema é bastante similar ao da radioastronomia descrito. Trata-se da reconstrução da estrutura molecular a par 
tir da existência de uma série de micrografias obtidas por trans missão em diversos ângulos. Neste campo, independentemente dos primeiros trabalhos de radioastronomia, DE ROSIER e KLUG ${ }^{(2)}$ (1968), GORDON et al ${ }^{(73)}(1970)$ também desenvolveram métodos de reconstru ção.

As técnicas da T.R. também foram usadas independente mente em aplicações ópticas por ROWLEY ${ }^{(74)}(1969)$, BERRY e GIBBS ${ }^{(75)}$ (1970) e JUNGINGER e VAN HAERINGEN ${ }^{(76)}$ (1972).

Embora a T.R. tenha sido utilizada em todas estas á reas citadas, foi no campo da Medicina, particularmente na Radio logia de diagnósticos, que esta alcançou uma maior projeção.

Foi decisivo, para isto, o lançamento do tomógrafo co mercial ${ }^{(77)}$ de alta resolução ${ }^{(*)}$ patenteado em nome da EMI LTDA. (Central Research Laboratory) da Inglaterra, construído e testado por HOUNSFIELD ${ }^{(78)}$, em 1973.

Entretanto, queremos lembrar que uma série de outros trabalhos e ensaios precederam a construção do primeiro tomógrafo comercial de Raios $\mathrm{X}$.

TAKAHASHI $^{(80)}$ (1957) estudando a tomografia convencio. nal conseguiu eliminar as imagens dos planos indesejados colocan do a fonte da rađiação $X$ sempre no mesmo plano que o filme (atra vés de um movimento de rotação). Mais tarde, em 1961, OLDEN DORF ${ }^{(81)}$ desenvolveu o primeiro aparelho para reconstrução de ima gens por transmissão de Raios $\gamma$ utilizando uma fonte de ${ }^{131} \mathrm{I}$.

De forma independente, KUHL e EDWARDS ${ }^{(82)}$ (1963) desenvol veram um sistema que envolveu uma câmara de detecção com um oscí

(*) Este tomógrafo fazia medida somente da cabeça e os dados eram analisados através de uma técnica iterativa de reconstrução. Em 1974 a Natio nal Biomedical Research Foundation,dos Estados Unidos, projetou outro tomógrâ fo destinado ao exame de qualquer parte do corpo chamado ACTA (Automatic Compu terized Transverse Axial) - LEDLEY et al (79) A técnica de reconstrução utilizáa da foi a chamada convolução da imagem. Tanto a técnica iterativa como a de con volução da imagem será descrita neste capítulo. 
loscópio para processar e armazenar os dados obtidos por emissão. KUHL et al ${ }^{(83)}$, em 1966, estenderam o trabalho anterior e obtiveram imagens por transmissão com uma fonte de ${ }^{241}$ Am.

Estas primeiras tentativas de se obter a tomografia re construtiva, basearam-se na técnica da retroprojeção, que descrẹ veremos na próxima secção. As imagens resultantes eram altamente borradas, devido à imperfeição desta técnica de reconstrução.

A contribuição decisiva foi fornecida por $\operatorname{CORMACK}^{(84,85)}$ em 1963 e 1964, quando este desenvolveu as bases matemáticas da T.R. da imagem. Esta teoria foi aplicada em "phantons" que simula vam corpos simples (por exemplo, a cabeça humana). Devido à sua relevância, vamos apresentar os seus principais resultados na sec ção 4.3.1, deste capítulo.

Para finalizar destacamos ainda que TRETIAK et al (86) (1969), BATES e PETERS ${ }^{(87)}$ (1971) e MUEHLLEHNER e WITZEL ${ }^{(88)}$ (1971) tam bém contribuíram com métodos de tomografia reconstrutiva, utili zando a Transformada de Fourier.

A reconstrução da imagem também tem sido utilizada pa ra outros fins como na radiografia por partículas alfa(89), por. prótons ${ }^{(90)}$, na tomografia de ultrassom ${ }^{(91)}$, na de ressonância nu clear magnética ${ }^{(92)}$ e na tomografia sísmica! ${ }^{(93)}$.

Passemos agora à próxima secção, onde apresentaremos de. forma sucinta os principais algorítmos de reconstrução comumen te empregados na Tomografia Computadorizada e que julgamos serem pertinentes a esta tese. 
45.

\section{2 - OS PRINCIPAIS MÉTODOS MATEMÁTICOS DE RECONSTRUÇÃO DA IMAGEM}

Do ponto de vista matemático, o problema da reconstrú ção está no cálculo de uma função bidimensional desconhecida chạ mada imagem. A partir de uma série destas imagens bidimensionais é relativamente fácil construir a imagem tridimensional.

Na radioscopia a função imagem é a distribuição dos coeficientes de atenuação de uma secção reta. 0 que se conhece são os raios soma (integrais de linha) destes coeficientes, em princípio, para todas as posições e direções. Estas integrais de linha são encontradas a partir de medidas por transmissão de raios $X$.

A partir deste ponto é que os métodos ou algorítmos de reconstrução adquirem um papel crucial. De forma geral, podemos classificar os métodos de reconstrução em três, a seguir descrị tos.

4.2.1. - O MÉTODO DA RECONSTRUÇÃO ALGÉBRICA (ART).

Este método baseia-se no método iterativo ${ }^{(70,94)}$. Através de uma sequência de passos tenta-se estimar uma imagem e a partir de aproximações sucessivas tenta-se obter a imagem correta. 0 princípio utilizado para se saber se a imagem estimada está corre ta é calcular integrais de linha e compará-las com aquelas medi das.

O ART foi utilizado na primeira tomografia da cabeça realizada por HOUNSFIELD, mas após isto não tem sido aplicado co mercialmente. Seus maiores problemas residem na baixa precisão e na sua complexidade computacional. Na presença de dados com ruí do, onde as medidas das projeções não são consistentes com a re construção desejada, os valores reconstruídos (em cada iteração) podem oscilar mais do que convergir para o valor correto. Isto 
faz com que as próximas iterações resultem em resultados até pio res que os anteriores.

Por outro lado, o método ART não requer o conhecimen to do conjunto completo dos dados das projeções. Cada medida é u sada como referência para melhorar a reconstrução estimada. A sim, quando por alguma razão, não se tem acesso a todos os dados das projeções, o ART torna-se útil. É o caso por exemplo, de um objeto que possui um metal opaco no seu interior ou é de geome tria especial.

\subsection{2 - O MÉTODO DA TRANSFORMADA DE FOURIER}

Este método utiliza um princípio fundamental da matemá tica: observadas certas condições essenciais toda função pode ser decomposta em uma soma de funções senoidais de diferentes frequên cias, amplitudes e fases ${ }^{(95)}$. Isto equivale à Transformada de Fou rier (T.F.) da referida função. A operação inversa é conseguida a través do cálculo da T.F. inversa. O mesmo conceito pode ser es tendido às funções bidimensionais como a da Figura 10. Neste caso, a imagem é decomposta em uma soma de ondas seno bidimensionais de diferentes frequências e ângulos.

Assim, se o arranjo de ondas seno bidimensionais puder ser encontrado a partir das medidas das projeções em cada ângulo, a T.F. poderá ser calculada. 
47.
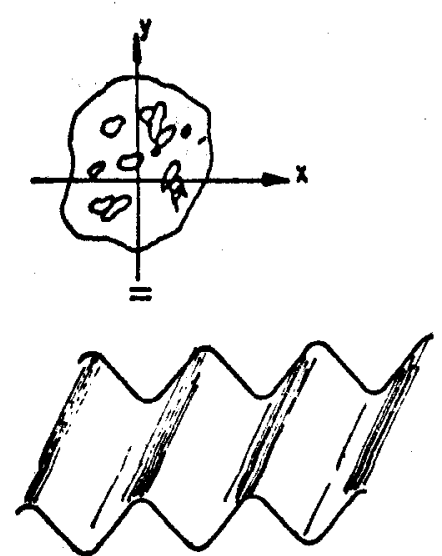

$+$
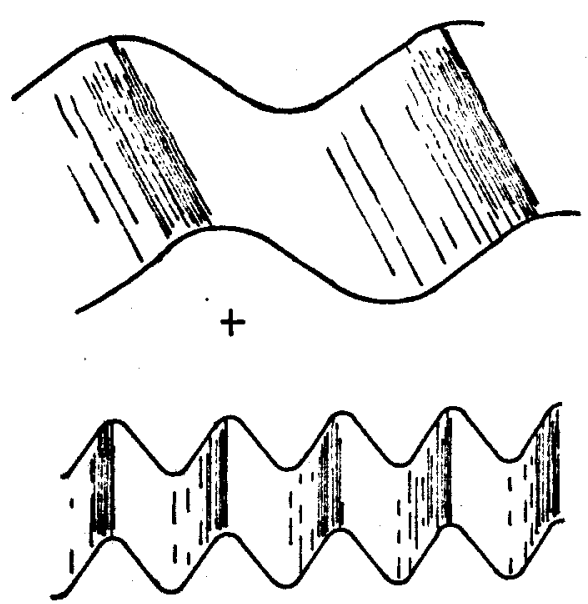

+ Etc.
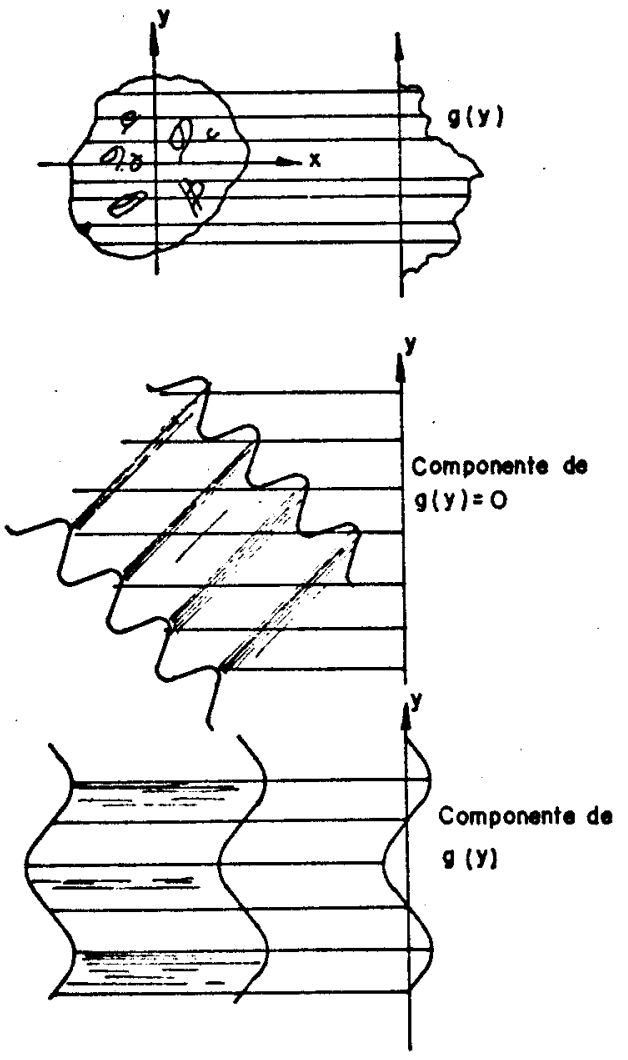

Figura 10 - Decomposição de uma fun ção bidimensional (imagem) em umā combinação de ondas seno bidimensio $n_{a i s}$ em diferentes ângulos e frequências.
Figura 11 - As projeções de uma ima gem reproduzem somente as componentes seno bidimensionais que são pa ralelas ao ângulo de projeção. $\mathrm{Na}$ parte superior é mostrada uma imagem bidimensional projetada na direção $X$. Na parte central é mostrada uma componente seno bidimensional da $\underline{i}$ magem. A projeção na direção indică da é nula devido às contribuições po sitivas e negativas iguais. Na parte inferior da figura é mostrada outra componente seno bidimensional da $\underline{i}$ magem que é paralela aos raios de projeção. Obtém-se portanto uma pro jeção senoidal. Então, a T.F. da pro jeção representa todas as componentes seno bidimensionais, naquele ân gulo de projeção, uma vez que as ou tras em outros ângulos serão nulas. Este é o Teorema da Seç̧ão Central. Quando as componentes seno bidimensionais são determinadas para todos os ângulos, elas podem ser somadas ou transformadas por inversão, para reconstruir a imagem. 
A Figura il ilustra a sequência de obtenção das projẹ çõès de cada componente senoidal da imagem.

Na extremidade superior é realizada uma projeção con vencional da imagem bidimensional na direção indicada, obtendo-se a função unidimensional $g(y)$.

Na parte central e na extremidade inferior da Figura 11, mostramos os efeitos da projeção de outras duas componentes particulares da função seno bidimensional da imagem.

A primeira componente senoidal, para o ângulo de proje ção mostrado, resulta em uma projeção nula. Isto não é difícil de ser entendido, uma vez que cada raio projetado recebe contribui ções negativas e positivas ao atravessar a função seno bidimensio nal. Entretanto, na extremidade inferior, a função seno bidimen sional é paralela aos raios projetados. Nesta caso, o resultado é uma projeção senoidal.

Este exemplo nos leva a afirmar que cada projeção es sencialmente representa as componentes seno bidimensionais somen te daquele ângulo. Esta afirmação possui a validade de um teorema chamado de Teorema da Projeção ou da Secção Central $(71,72,86,96,97,98)$

Em resumo, cada projeção representa a soma das compo nentes senoidais somente naquela direção. Então, a decomposição de cada projeção em senos fornece as componentes da função seno bidimensional naquele ângulo. Repetindo isto para as projeções em todos os ângulos completa-se a T.F. do objeto desconhecido. ES te método será descrito matematicamente na secção 4.3 .2 deste ca pítulo.

o método da T.F. não é usado amplamente, pois na maio ria das vezes é mais complexo do ponto de vista da computação. Es ta complexidade advém da necessidade do cálculo da T.F. bidimen sional inversa e da interpolação bidimensional, uma vez que os dados são adquiridos em coordenadas polares e precisam ser trans formados para coordenadas retangulares. Devido a isto, o método 
49.

da T.F. está sempre procurando aperfeiçoar os métodos de interpo lação (Método da T.F. Rápido), de modo a diminuir o tempo de pro cessamento.

\subsection{3 - O MÉTODO DA CONVOLUÇÃO OU DA RETROPROJEÇÃO FILTRADA}

Comparado com o método iterativo este método é menos susceptível a ruído e é mais rápido, pois a reconstrução é feita diretamente a partir de cada dado coletado. Este método, como o anterior, está na classe dos métodos que se utilizam de soluções analíticas.

Por ora, vamos ilustrá-10 através de representações gráficas, sem envolvimento de maiores complexidades matemáticas, - que deixaremos para fazer nas secções $4.3 .2,4.3 .3$ e 4.3.4.

Comecemos pelo processo de retroprojeção.

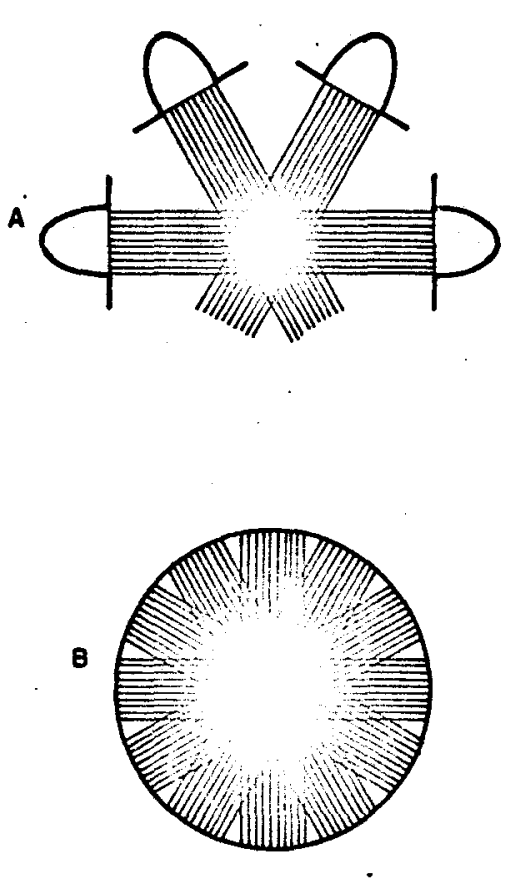

Figura 12 - Em A ilustramos uma retroprojeção simples de quatro perfis de um objeto circular. Em B, mos tramos o "borrão" da imagem ou efe $\underline{i}$ to "estrela" que aparece quando um número finito de perfis são projeta dos sobre o plano da imagem.

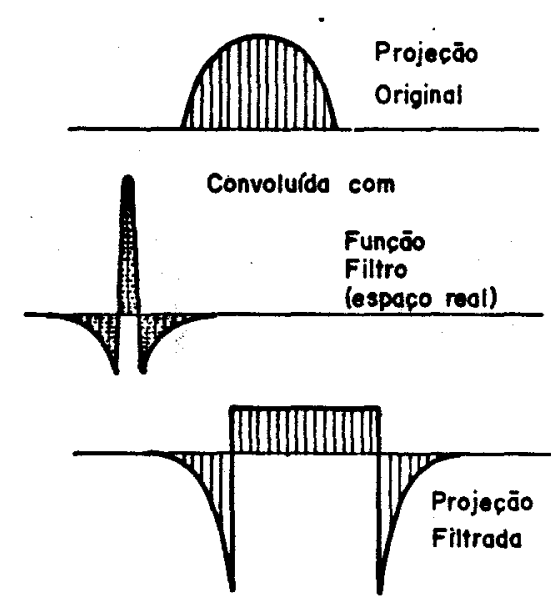

Figura 13 - Esboço idealizado do processo de convolução. Na parte superior mostramos um perfil obtido da pro jeção do objeto circular da Figura 12 -A. A função filtro é mostrada no cen tro. Da multiplicação da função filtro pela projeção obtém-se a figura da parte inferior (Projeção filtrada) onde agora aparecem valores negativos. 

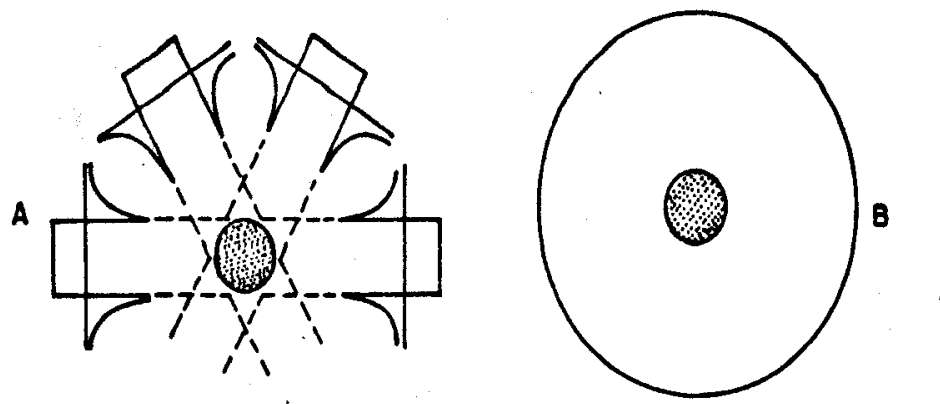

Figura 14 - Em A, ilustramos a retroprojeção filtrada de quatro projeções do objeto circular da Figura 12-A os valores negativos cancelan as contribuições positi vas responsáveis pelo "borrão" ao redor da imagem. Em $B$, mostramos a imagem final livre do efeito "estrela"!

Conforme a Figura 12-A, obtém-se da transmissão dos Rạ ios $X$ uma projeção para um dado ângulo. No processo de simples re troprojeção cada perfil de transmissão obtido é projetado de vol ta, num determinado ângulo, no plano das imagens. Quando esta re troprojeção é completada para todos os ângulos, reobtém-se uma i magem "borrada" do objeto original (ver Figura 12-B). O "borrão" ou estrela, resulta da contribuição de cada perfil projetado de volta sobre a área que circunda o objeto. Para evitar isto, cada perfil precisa ser manipulado (filtrado ou convoluído) antes de se iniciar a retroprojeção. Esta filtragem introduz no perfil va lores negativos que após retroprojetados cancelarão os artefatos ao redor do objeto. A filtragem se faz multiplicando os valores de cada perfil pelo conjunto de valores chamados função filtro (ver Figura 13). Este processo é chamado convolução e a função filtro é chamada de núcleo da convolução. Deste modo, cada perfil é manipulado imediata e independentemente. Com isto pode-se obter (dependerá da potência do computador), a imagem completa do objẹ to, sem "borrões" (Figura 14-B) dentro de poucos segundos. 
Na prática, a retroprojeção é realizada na memória do computador. A cada elemento de área final, chamado pixel, é atri buído um endereço na memória. o valor guardado em cada endereço. durante a retroprojeção é calculado para cada ângulo e somado so bre todos os ângulos para produzir uma matriz de números que é a reconstrução numérica do objeto original.

Após a reconstrução, a imagem digital é transferida da memória do computador para o sistema de disco para armazenagem.

De agora em diante vamos nos ater mais aos aspectos ma temáticos da Teoria Reconstrutiva propriamente dita.

\section{3 - AS BASES MATEMÁTICAS DA TOMOGRAFIA}

O problema matemático fundamentàl da Teoria Reconstrü tiva foi desenvolvido por CORMACK, conforme já dissemos. Devido à sua importância histórica na fundamentação da T.R., vamos sucin tamente apresentá-1o na próxima secção.

Nas secções $4.3 .2,4.3 .3,4.3 .4$ e 4.3.5, vamos respec tivamente apresentar o Teorema da Projeção, As Bases Matemátị cas do Método da Convolução, o Método da Convolução Utilizando a " Geometria de Feixe Divergente e Alguns Comentários Finais.

\subsection{1 - O TRABALHO DE CORMACK}

A equação (III-1) da absorção da radiação $\gamma$ ou $X$ por um meio, quando atravessado por um feixe monoenergético e linear, é válida para materiais homogêneos. No entanto, o problema da de terminação quantitativa da variabilidade do coeficiente de atenua ção em um meio não-homogêneo a partir de medidas externas, 'não hạ via recebido a devida atenção até o trabalho de CORMACK. Mesmo em 
52.

radioterapia, os cálculos de dose a serem ministradas aos pacien. tes eram realizados supondo que o corpo humano se comportava como homogêneo, quando sabemos que isto não é verdade. Principalmente do ponto de vista da radiação que o atravessa (energias da ordem de alguns Kevs, como é o caso do Raio X).

Vamos formular melhor este problema, antes de resol vê-10.

Seja $D$ um domínio finito e bidimensional do espaço constituído de um material absorvente caracterizado por uma fun ção bidimensional chamada coeficiente de absorção linear ${ }^{(*)} \mathrm{g}$, que varia ponto a ponto no interior de $D$ e é nula no seu exte rior, conforme nos mostra a Figura 15-A.
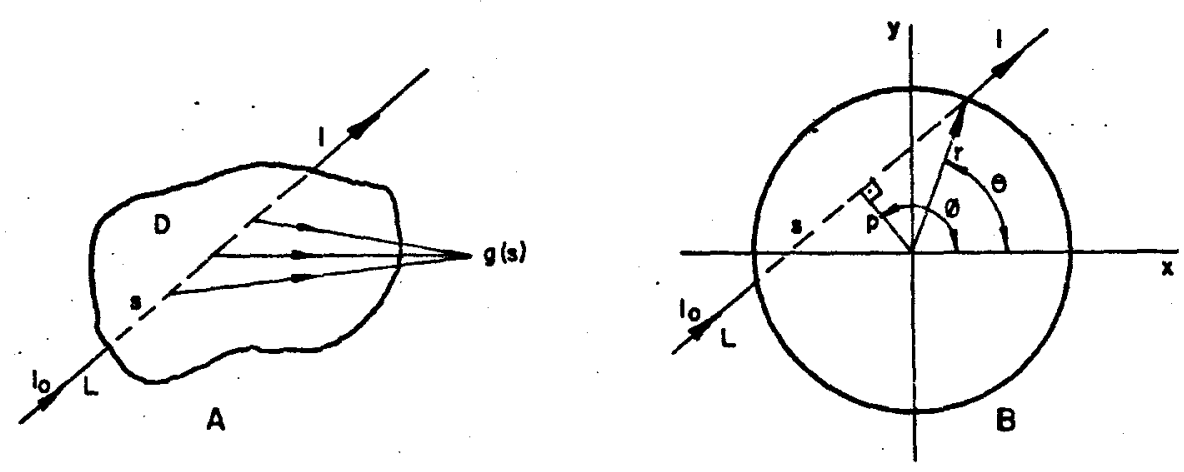

Figura 15 - Esquematizamos em A a transmissão da radiação através de um material não-homogêneo contido no domínio $\mathrm{D}$. I e $\mathrm{I}_{0}$ são res pectivamente as intensidades do feixe da radiação emergente e in cidente; $g(s)$ é o valor do coeficiente de atenuação linear da râa diação, onde $s$ é uma medida de comprimento sobre L. Em B, o domí nio de $\mathrm{g}(\mathrm{s})$ é um círculo unitário, onde $\mathrm{r}, \Theta$ são coordenadas pola res. p e $\phi$ correspondem a definição de outro sistema de coordena das, utilizado no texto.

(*) Corresponde ao valor do coeficiente de absorção de massa $\mu$ multiplicado pelo valor da densidade volumétrica $\rho$ do material em uma dada po sição de observação. 
Suponhamos que um feixe de radiação monoenergético in finitamente fino atravesse $D$ ao longo de uma linha reta $L$, com I sendo a intensidade do feixe emergente $e I_{0}$ sendo a intensidade do feixe incidente em $D$.

Nesta configuração é válido escrever que:

$$
I=I_{0} \exp \left[-\int_{L} g(s) d s\right]
$$

onde s é uma medida de comprimento sobre $L$. Se definirmos $f_{L}=\ln \left(I_{0} / I\right) \quad$ (grandeza possível de ser medida externamente) então:

$$
f_{L}=\int_{L} g(s) d s
$$

cuja integral de linha também é chamada de raio soma.

o problema que se coloca é: Como encontrar g, conhecen do as integrais de linha $f_{L}$, para um número finito de linhas $L$ que interceptam $D$ ?

Para simplificar, embora sem perda de generalidades, vamos supor que o domínio onde g está contido seja um círculo de raio $R$ unitário. Em coordenadas polares, vamos escrever $g$ como $g=g(r, \theta)$, com a origem do sistema escolhido no centro do círcu 10 .

Vamos chamar de $\mathrm{p}$ a distância da linha $\mathrm{L}$ ao centro e de $\phi \circ$ ângulo que a normal de $L$ faz com $\circ$ eixo $\theta=0$, conforme nos ilustra a Figura 15-B.

Desta forma, $f_{L}$ fica escrita em termos das coordenadas polares $(p, \phi)$. O fato de termos escolhido o circulo como domínio de $g$ faz com que o domínio das novas coordenadas seja mantido. A equação $(I V-2)$ se escreve agora como:

$$
f(\ddot{p}, \phi)=\int_{L(p, \phi)} g(r, \theta) \text { ds } \ldots \ldots \ldots \ldots \ldots \ldots \ldots(\text { IV }-3)
$$


Antes porém, de tentarmos encontrar $g(r, \theta)$, convém ob servar que a equação acima é uma equação integral em duas variá veis e que pode ser reduzida a um conjunto de equações integrais de somente uma variável, conforme mostraremos em seguida.

Seja g uma função finita, contínua e bem definida, ex ceto para um número finito de arcos no círculo. Com isto, g pode ser expandida em série de FOURIER:

$$
g(r, \theta)=\sum_{n=-\infty}^{n=\infty} g_{n}(r) e^{i n \theta}
$$

com

$$
g_{n}(r)=\frac{1}{2 \pi} \quad \int_{0}^{2 \pi} g(r, \theta) e^{i n \theta} d \theta
$$

Não é difícil mostrar a partir de (IV-3) e (IV-4) e do cálculo da contribuição do infinitésimo df de dois elementos de arco iguais a ds, da linha $L(p, \phi)$, que:

$$
f(p, \phi)=\sum_{n} e^{i n \phi} 2 \int_{p}^{1} \frac{g_{n}(r) \cos \left[n \cos ^{-1}(p / r)\right] r d r}{\left(r^{2}-p^{2}\right)^{1 / 2}} \ldots(I V-6)
$$

onde consideramos que $s=\left(r^{2}-p^{2}\right)^{1 / 2}$ e $\phi=\operatorname{arc} \cos (p / r)$. Expan dindo $f(p, \phi)$ em série de FOURIER e comparando com (IV-6) é possí vel separar as variáveis $p, \phi$ e obter o conjunto de equações inte grais unidimensionais:

$$
f_{n}(p)=2 \int_{p}^{1} \frac{g_{n}(r) T_{n}(p / r) r d r}{\left(r^{2}-p^{2}\right)^{1 / 2}}
$$

onde $T_{n}(p / r)=\cos \left[n \cos ^{-1}(p / r)\right]$ é o polinômio de Tschebycheff de grau $\mathrm{n}$ em $\mathrm{p} / \mathrm{r}$ (Polinômio de Tschebycheff de la espécie). 
A função $f_{n}(p)$ dada por (IV-7) possui algumas proprie dades que advêm dos Polinômios de Tschebycheff e das restrições sobre $g(r, \theta)$ (Ver a referência 84).

Vamos agora encontrar o valor de $g_{n}(r)$ como função de $f_{n}(p)$ a partir de $(I V-7)$. Para isto multipliquemos ambos os lados da equação $(I V-7)$ por $T_{n}(p / z) \cdot\left(\frac{z}{p}\right) \cdot\left(p^{2}-z^{2}\right)^{-1 / 2}$ e integremos em $p$ de $p=z$ até $p=1$ e utilizemos ainda o resultado:

$$
r z \int_{z}^{r} \frac{T_{n}(p / z) T_{n}(p / r) d p}{\left(r^{2}-p^{2}\right)^{1 / 2}\left(p^{2}-z^{2}\right)^{1 / 2} p}=\frac{\pi}{2}
$$

Após isto, encontramos $g_{n}(r)$ univocamente a partir de $f_{n}(p):$

$$
g_{n}(r)=\frac{1}{\pi} \frac{d}{d r} \int_{r}^{1} \frac{r f_{n}(p) T_{n}(p / r) d p}{\left(p^{2}-r^{2}\right)^{1 / 2} p}
$$

As equações (IV-4) e (IV-9) nos permitem encontrar a naliticamente os valores dos coeficientes de atenuação que consti tuem o corpo D, a partir das medidas das integrais de linha $f_{n}(p, \phi)$ :

Em 1957, na cidade do Cabo (Africa do Sul) CORMACK rea lizou um experimento simples usando uma fonte de raios $\gamma$ do Cobal to-60 e um contador Geiger. Ele obteve bons resultados no cálculo do coeficiente de atenuação de um corpo com simetria cilíndrica (cilindro de madeira com interior de alumínio) utilizando a equa ção (IV-9) que neste caso fica bastante simples (Equação de Abel já conhecida desde 1825).

As equações (IV-7) e (IV-9) podem ser estendidas a to do o plano, bastando para isto mudar os limites de integração do intervalo $0<\mathrm{p}<1$ para $0<\mathrm{p}<\infty \mathrm{e} 0<\mathrm{r}<1$ para $0<x<\infty$. 
A equação (IV-7) pode ser escrita de outra forma muitas vezes mais conveniente, utilizando a Equação de Bessel $J_{2 n}(r t)$ e tomando a Transformada de Fourier cosseno de $f_{n}(p)$ :

$$
f_{2 n}(p)=2(-1)^{n} \int_{0}^{\infty} \cos (p t) d t \int_{0}^{\infty} g_{2 n}(r) J_{2 n}(r t) r d r \quad(I V-10)
$$

que é válida para n par. Uma equação análoga pode ser escrita pa ra $n$ ímpar.

A última integral em (IV-10) é chamada Transformada de Hankel da função $g_{2 n}(r)$. A equação $(I V-10)$ pode apresentar vanta gens sobre a $(I V-7)$, como no caso da expansão de $f_{n}(p)$ em série (conforme faremos a seguir) ou mesmo no caso em que a Transforma da de Hankel estiver tabelada.

Voltemos ao domínio $D$ do círculo unitário ${ }^{(*)}(0 \leqslant r \leqslant 1)$
Vamos supor que $g_{n}(r)$ possa ser escrita em termos dos Polinômios de ZERNICKE ${ }^{(99)}(1934) R_{h}^{1}(r)$ onde:

$$
R_{n}^{\ell}(r)=\sum_{s=0}^{1} \frac{(-1)^{s}(n+2 \ell-s) ! r^{n+2 \ell-2 s)}}{s !(n+\ell-s) !(\ell-s) !}
$$

e utilizemos o resultado obtido por BORN e WOLF ${ }^{(100)}(1959)$ :

$$
\int_{0}^{1} R_{n}^{\ell}(r) J_{n}(r t) r d r=(-1)^{\ell_{t}-1} J_{n+2 \ell+1}(t)
$$

Calculando a Transformada de Hankel e a Transformada de Fourier - cosseno em $($ IV-10) e chamando $p=\cos \psi$, com $0 \leqslant \psi \leqslant \pi / 2$, então é possível obter o sistema de equações para $f_{n}(\cos \psi)$ e $g_{n}(r)$ :

(*) Um tratamento análogo a este que vamos fazer foi também reali zado por CORMACK (1964) no caso do plano todo ( $0<r<\infty)$, utilizando os Poli nômios ortogonais de LAGUERRE e expandindo $f_{n}(p)$ como função dọ Polinômios de HERMITE. 


$$
\left\{\begin{array}{l}
f_{n}(\cos \psi)=2 \sum_{l=0}^{\infty} a_{n}^{\ell} \operatorname{sen}[(n+2 \ell+1) \psi] \text { e } \\
g_{n}(r)=\sum_{\ell=0}^{\infty}(n+2 \ell+1) a_{n}^{\ell} R_{n}^{\ell}(r)
\end{array}\right.
$$

Os valores $a_{n}^{l}$ [da função expandida $f_{n}(\cos \psi)$ ] são ob tidos através das suas relações de ortogonalidade que por sua vez é medida experimentalmente. A partir daí pode-se encontrar $g_{n}(r)$. Utilizando o resultado (IV-13) CORMACK simulou experi mentalmente um cérebro humano com a presença de dois tumores no seu interior, conforme nos mostra a Figura 16.

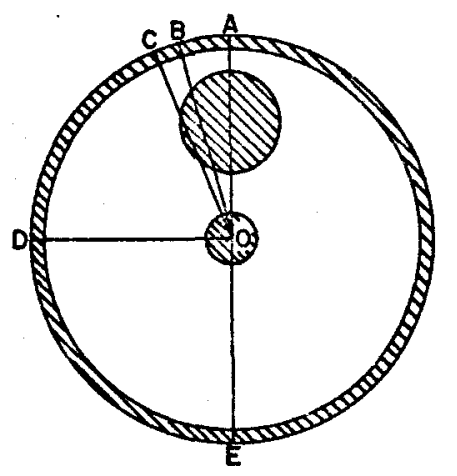

o quociente do coeficiente de absorção linear do Alumí
Figura 16 - Esboço do experimento rea lizado por CORMACK simulando a cabe ça humana com dois tumores no seu in terior. A parte hachurada da figura corresponde ao osso (Alumínio) e aos dois tumores (Alumínio). A parte inte rior não hachurada corresponde ao te cido mole do crânio e é simulado pelo Lucite.

nio pelo coeficiente do Lucite é aproximadamente 2,3 que coincide com relações encontradas entre o tecido doente e o tecido normal, no cérebro.

o cilindro na figura mostrada foi colocado sobre uma mesa capaz de executar movimentos sucessivos de translação e rotạ ção. A fonte de Raios $\gamma\left({ }^{60} \mathrm{Ni}\right)$ e o contador Geiger foram mantidos fixos. A largura do feixe utilizado após colimação foi de $5,3 \mathrm{~mm}$. Para cada valor de $f(p, \phi)$ foram observadas 20.000 contagens e 
58.

160.000 para o cálculo de $I_{0}$, em diferentes tempos.

Considerando a geometria da amostra, o ângulo $\phi$ varrido foi de $180^{\circ}$. Assim para cada $\mathrm{p}$ foram medidos 25 valores de $\phi$ em intervalos regulares de $71 / 2^{\circ}$. Nos casos em que $\mathrm{p} \simeq 1$ foram realizados um número menor de me didas.

$\rightarrow$ Após estas medidas foi possível construir gráficos de $f_{0}(p) \ldots \ldots \ldots \ldots \ldots f_{24}(p)$ em função de $p$. Utilizando crité rios como suavidade das curvas e número de zeros de cada fun ção, CORMACK considerou razoável expandir a função $f_{n}(p)$ até - termo $n=18$. Com esta consideração, 19 valores de $p$ deve riam ser aproveitados (intervaios regulares de $5: 0$ de $\psi$, com $0 \leqslant \psi \leqslant \pi / 2$ ).

No entanto, para $\ell>14$, os erros de computação de acordo com o programa utilizado no cálculo de $\mathrm{R}_{\mathrm{n}}^{l}(r)$ ultrapas savam $1 \%$. Dentro desta precisão, foi possível calcular a fun ção $g(r, \theta)=\sum_{n=0}^{18} g_{n}(r) \cos n \theta$, ou seja:

$$
\begin{aligned}
g(r, \theta)= & \left\{a_{0}^{0}+\ldots \ldots+29 a_{0}^{14} R_{o}^{14}(r)\right\}+\ldots \ldots+ \\
& \left\{19 a_{18}^{0} R_{18}^{0}(r)+\ldots \ldots+\right. \\
& \left.35 a_{18}^{8} R_{18}^{8}(r)\right\} \quad \cos 18 \theta \quad \ldots \ldots \ldots \ldots
\end{aligned}
$$

A figura 17 mostra $g(r, \theta)$ como função de $r$, cal culada através de (IV-14), para valores fixos de $\theta$ corresponden do às linhas $O A, O B \ldots \ldots$ OE da Figura 16. As linhas cheias mostram os valores verdadeiros e as linhas pontilhadas foram cal culadas a partir de (IV-14). 


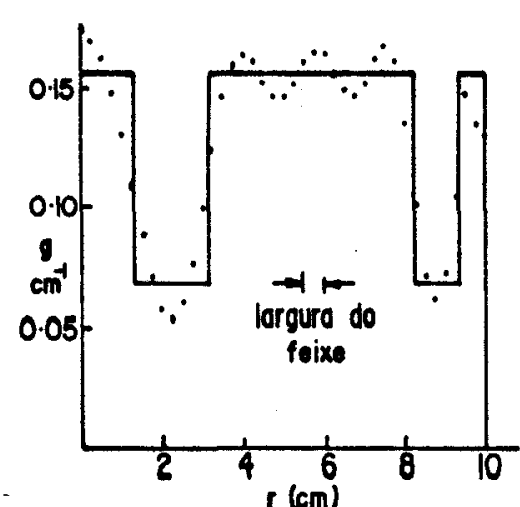

(a)

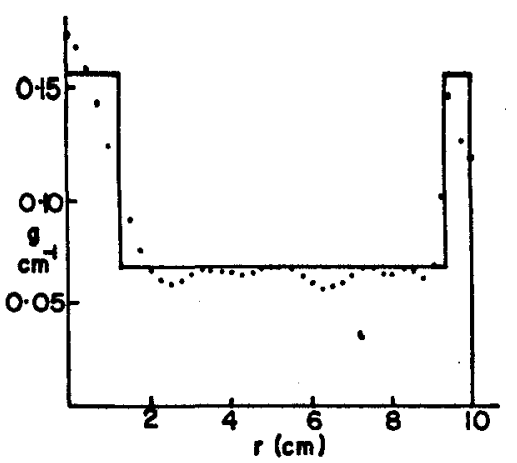

(d)

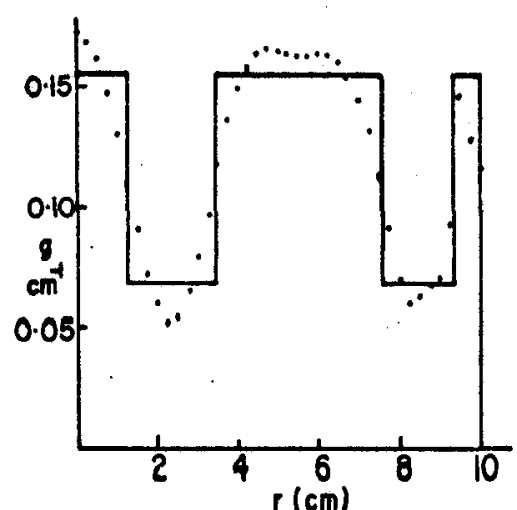

(b)

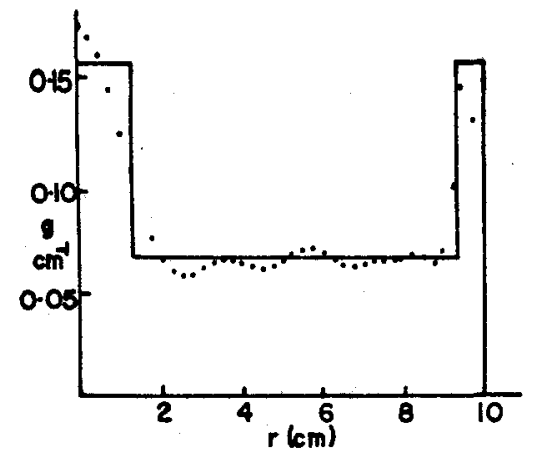

(e)

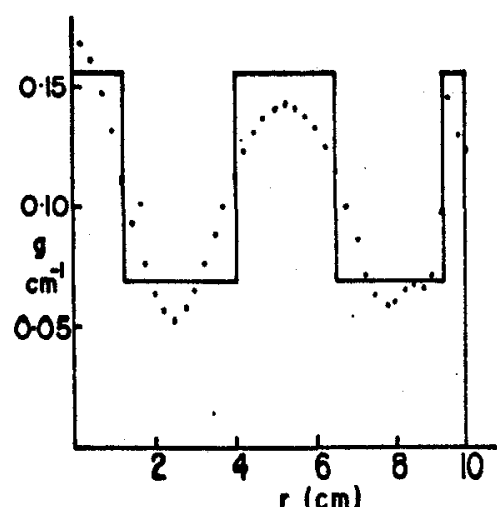

(c)

Figura 17 - Resultados dos cálculos dos coeficientes de atenuação lineares $\left(\mathrm{cm}^{-1}\right)$ realizados através da equação (IV-14) ${ }^{\circ}$ nas dire ções $O A, O B, O C, O D$ e $O E$ da Figura 16 e acima respectivamente in dicados pelas letras (a) até (e).

Obteve-se neste teste uma boa reprodução de resultados com g variando de 0,065 a 0,15 e a zero em uma distância aproxima damente igual à largura do feixe. As oscilações dos valores compu tados. sobre os valores verdadeiros de $\mathrm{g}$ devem-se a interrupção em $\ell=14$ do cálculo dos coeficientes do polinômio de ZERNICKE $\mathrm{R}_{\mathrm{n}}^{\ell}(\mathrm{r})$ utilizado na expansão de $g_{n}(r)$.

Através da realização de alguns testes de influência da estatística de contagem e largura de linha ficou demonstrado que a principal fonte de erros estava presente na limitação do programa computacional. 
Neste ponto, vale a pena ressaltar que com este traba Iho CORMACK estava fazendo a primeira tomografia computadorizada aplicada à medicina, simulando a presença de inohomogeneidades, embora o termo TC só venha a ser adotado mais tarde. Para CORMACK obter uma tomografia axial como nos dias de hoje, ele deveria es tabelecer um padrão cinza e colocar os valores obtidos na tela de um vídeo. Atualmente o método numérico adotado por CORMACK (expan são em série) não é empregado na maioria dos tomógrafos modernos devido a dificuldades e à demora computacional.

\subsection{2 - O TEOREMA DA PROJEÇÃO}

Consideremos, a partir de agora, a geometria da Figura 18, conhecida como Geometria de Raios Paralelos, para formalizar melhor a demonstração do Teorema da Projeção.

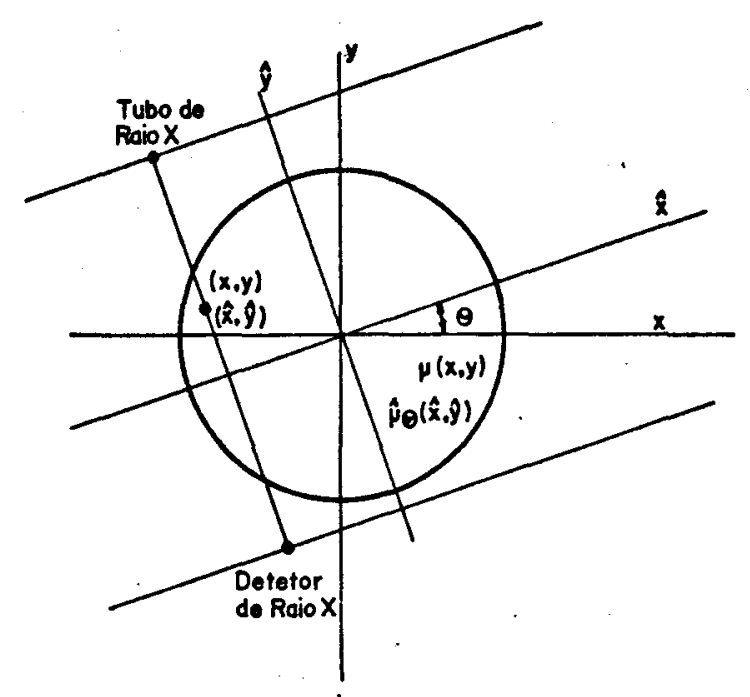

Figura 18 - Geometria do feixe de raios paralelos.

o Sistema de Coordenadas $(x, y)$ é centrado no corpo de coeficiente de absorção Iinear $\mu(x, y)$ enquanto que o sistema fon te - detetor translada e gira ao seu redor (É equivalente ao Sis tema de CORMACK onde o corpo em observação girava e transladava, enquanto o sistema fonte - detetor era mantido permanentemente fi xo). A descrição que estamos fazendo é a empregada no caso dos to mógrafos médicos, pois evita-se o movimento do paciente. 
Seja $\theta$ o ângulo de rotação e $(\hat{x}, \hat{y})$ um sistema de coor denadas de rotação, também centrado na origem, onde $\hat{x}$ representa a posição do detetor e $\hat{y}$ a distância de um ponto em observação ao longo do raio $\hat{y}$ (equivalente a $L$ e s na notação de CORMACK). Qual quer ponto do corpo pode ser representado por $(x, y)$ ou $(\hat{x}, \hat{y})$ que estão relacionados através da transformação rotacional.

0 coeficiente de absorção $\mu(x, y)$ pode ser expresso em termos das coordenadas girantes $(\hat{x}, \hat{y})$, onde $\hat{\mu}_{\theta}(\hat{x}, \hat{y})$ será o coe ficiente de absorção neste sistema. Tomemos respectivamente, as Transformadas de FOURIER biơimensionais de $\mu(x, y)$ e de $\hat{\mu}_{\theta}(\hat{x}, \hat{y})$, obtendo:

$$
\begin{gathered}
\mathrm{U}\left(\mathrm{K}_{x}, \mathrm{~K}_{y}\right)=\int_{-\infty}^{\infty} \int_{-\infty}^{\infty} \mu(x, y) \exp \left[-2 \pi \mathrm{i}\left(x \mathrm{~K}_{x}+y \mathrm{~K}_{y}\right)\right] \mathrm{d} x \mathrm{dy} \ldots \ldots(\mathrm{IV}-15) \\
\mathrm{e} \\
\hat{\mathrm{U}}_{\theta}\left(\hat{\mathrm{R}}_{x}, \hat{\mathrm{K}}_{y}\right)=\int_{-\infty}^{\infty} \int_{-\infty}^{\infty} \hat{\mu}_{\theta}(\hat{x}, \hat{y}) \exp \left[-2 \pi \mathrm{i}\left(\hat{x} \hat{\mathrm{R}}_{x}+\hat{y} \hat{\mathrm{K}}_{y}\right)\right] \mathrm{d} \hat{x} \mathrm{~d} \hat{y} \ldots(I V-16)
\end{gathered}
$$

onde $\mathrm{K}_{x}$ e $\mathrm{K}_{\mathrm{y}}$ são as componentes da frequência $\mathrm{K}$ no espaço recípro co.

Expressando $(x, y)$ em termos de $(\hat{x}, \hat{y})$ em $($ IV-15) e lem brando que $\hat{\mu}_{\Theta}(\hat{x}, \hat{y})=\mu(x, y), d x d y=d \hat{x} d \hat{y}$ e que $\circ$ Jacobiano da transformação rotacional é 1 , após alguns cálculos algébricos sim ples obtemos que:

$$
\begin{aligned}
\mathrm{U}\left(\mathrm{K}_{x}, \mathrm{~K}_{\mathrm{y}}\right)= & \int_{-\infty}^{\infty} \int_{-\infty}^{\infty} \hat{\mu}_{\theta}(\hat{x}, \hat{y}) \exp -2 \pi \mathrm{i}\left[\left(\mathrm{K}_{x} \cos \theta+\mathrm{K}_{\mathrm{y}} \operatorname{sen} \theta\right) \hat{x}+\right. \\
& \left.\left(-\mathrm{K}_{x} \operatorname{sen} \theta+\mathrm{K}_{y} \cos \theta\right) \hat{\mathrm{y}}\right] \mathrm{d} \hat{x} \mathrm{~d} \hat{\mathrm{y}} \quad \ldots \ldots \ldots \ldots \ldots(\mathrm{IV}-1
\end{aligned}
$$

Se chamarmos:

$$
\hat{\mathrm{K}}_{x}=\mathrm{K}_{x} \cos \theta+\mathrm{K}_{\mathrm{y}} \operatorname{sen} \theta \text { e } \hat{\mathrm{K}}_{\mathrm{y}}=-\mathrm{K}_{x} \operatorname{sen} \theta+\mathrm{K}_{\mathrm{y}} \cos \theta
$$


então:

$$
\mathrm{U} .\left(\mathrm{K}_{x}, \mathrm{~K}_{y}\right)=\hat{\mathrm{U}}_{\theta}\left(\hat{\mathrm{K}}_{x}, \hat{\mathrm{K}}_{\mathrm{y}}\right)
$$

- que demostra que as duas transformadas de FOURIER são iguais quando tomamos os eixos $\left(\hat{\mathrm{K}}_{x^{\prime}}, \hat{\mathrm{K}}_{\mathrm{y}}\right)$ como a rotação de $\left(\mathrm{K}_{x}, \mathrm{~K}_{\mathrm{y}}\right)$ por um ângulo $\theta$, no espaço recíproco (espaço das frequências).

É comum designarmos por $\mathrm{p}_{\theta}(\hat{x})$ a projeção do corpo numa dada direção $\theta$, assim definido:

$$
p_{\theta}(\hat{x})=\int_{L} \hat{\mu}_{\theta}(\hat{x}, \hat{y}) d \hat{y} \quad \ldots \ldots \ldots \ldots \ldots \ldots \ldots \ldots(\text { IV-20) }
$$

uma vez que $\widehat{x}$ nos fornece a posição do detetor e $\hat{y}$ a medida da po sição vertical do ponto considerado ao longo do raio que o atra vessa.

Tomando a Transformada de FOURIER unidimensional de (IV-20) no espaço recíproco $K$, é possível: obter:

$$
P_{\theta}(K)=\int_{-\infty}^{\infty} \int_{-\infty}^{\infty} \hat{\mu}_{\theta}(\hat{x}, \hat{y}) \exp [-2 \pi i(K \hat{x}+0 \hat{y})] d \hat{x} d \hat{y} \quad \ldots \ldots(I V-21) .
$$

Lembrando de (IV-16) nos é permitido escrever que:

$$
P_{\theta}(K)=\hat{U}_{\theta}(K, 0)=U(K \cos \theta, K \operatorname{sen} \theta)
$$

A equação (IV-22) expressa o teorema a que já nos refee rimos na Seç̧ão 4.2.2 como Teorema da Projeção. ou seja, calcular a Transformada de FOURIER de uma projeção equivale a obter a área de secção reta central da Transformada de FOURIER da imagem. A maioria dos sistemas tomográficos baseiam-se neste teorema. De ago ra em diante podemos desenvolver todas as operações matemáticas envolvidas na reconstrução da imagem diretamente no espaço recí 
proco. Outra possibilidade é desenvolver expressões equivalentes a que encontramos, só que transformadas para o espaço direto.

Para trabalharmos no espaço recíproco é preciso fazer interpolação dos dados, pois a projeção (IV-22) está na forma po lar enquanto que os "displays" em geral são vídeos onde o sistema de coordenadas é o retangular. Portanto, a opção de trabalhar no espaço recíproco nos leva a fazer transformações de coordenadas. Para evitar isto, vamos utilizar o espaço direto, lem brando que a maioria das máquinas comerciais também o adotam, a través do Método da Convolução.

\subsection{3 - BASES MATEMÁTICAS DO MÉTODO DA CONVOLUÇÃO ${ }^{(*)}$}

Continuemos a adotar a geometria da Figura 19.

Calculemos a transformada inversa de $U\left(\mathrm{~K}_{x}, \mathrm{~K}_{\mathrm{y}}\right)$ em (IV-15) no sistema de coordenadas polares, onde:

$$
\begin{aligned}
& \left\{\begin{array}{l}
x=\mathrm{r} \cos \phi, \mathrm{K}_{x}=\mathrm{K} \cos \theta, \quad \mathrm{K}=\operatorname{sinal} \mathrm{K}_{\mathrm{y}} \sqrt{\mathrm{K}_{x}^{2}+\mathrm{K}_{\mathrm{y}}^{2}} \\
\mathrm{y}=\mathrm{r} \operatorname{sen} \phi, \mathrm{K}_{\mathrm{y}}=\mathrm{K} \operatorname{sen} \theta, \quad \theta=\operatorname{arctg}\left(\frac{\mathrm{K}_{\mathrm{y}}}{\mathrm{K}_{x}}\right) \cdots \cdots(\mathrm{IV}-23)
\end{array}\right. \\
& \operatorname{com} \quad 0<\mathrm{r}<\infty,-\infty<\mathrm{K}<\infty ; 0<\phi<2 \pi, 0<\theta<\pi ; \\
& \mathrm{dK}_{x} \mathrm{dK}_{\mathrm{y}}=|\mathrm{K}| \mathrm{dKd} \theta \text { e } \mathrm{U}(\mathrm{K} \cos \theta, \mathrm{K} \operatorname{sen} \theta)=\mathrm{P}_{\theta}(\mathrm{K})
\end{aligned}
$$

Logo, com a Transformada de FOURIER inversa de (IV-15) e as sub $\underline{\underline{s}}$ tituições (IV-23), obtemos $\mu(x, y)$ :

$$
\mu(x, y)=\int_{0}^{\pi} d \theta \int_{-\infty}^{\infty} P_{\theta}(K)|K| \exp [2 \pi i K r \cos (\theta-\phi)] d K \quad(I V-24)
$$

A integral interna é a transformada inversa do produto da trans formada da projeção do objeto no ângulo $\theta$ pelo termo $|K|$. Seja

(*) Um tratamento mais detalhado e bastante próximo deste que ire mos desenvolver pode ser encontrado nas referências $101,102,103$ e 104. 
$q(x)$ a transformada inversa de $|K|$ que passaremos a chamar de "função" núcleo. $q(x)$ está incluída na classe das "funções genera lizadas" conforme discutiremos adiante, num caso particular.

Utilizando o fato de que a Transformada de FOURIER de um produto de duas funções é igual à convolução das Transformadas de FOURIER das funções (Teorema da Convolução), então é possível escrever a integral interna de (IV-24) como:

$$
g_{\theta}(s)=\int_{-\infty}^{\infty} p_{\theta}\left(s^{\prime}\right) q\left(s-s^{\prime}\right) d s^{\prime} \quad \ldots \ldots \ldots \ldots \ldots(I V-25)
$$

que é a função projeção lida no detetor no ângulo $\theta$ convoluída com a "função" núcleo (equivalente a fazer uma "filtragem" da prô jeção). A integral externa em (IV-24) é chamada de retroprojeção. Usando (IV-25) a equação (IV-24) se escreve como:

$$
\mu(x, y)=\int_{0}^{\pi} g_{\theta}[r \cos (\theta-\phi)] d \theta
$$

As equações $(I V-25)$ e (IV-26) [integrais simples] podem ser escri tas como somas finitas unidimensionais (pois na prática a varredu ra é discreta) e daí o fato de serem calculadas sucessivamente no computador, de acordo com uma precisão previamente escolhida ${ }^{(*)}$. Voltemos à "função" $q(x)$. Para melhor compreendê-la, vamos considerá-la como o limite de uma função "bem comportada". A função $|K| e^{-\varepsilon|K|}$ que se aproxima de $|K|$ quando $\varepsilon \rightarrow 0$ serve co mo um bom exemplo. A Figura 19, mostra o esboço de seu gráfico (no espaço recíproco) assim como a sua Transformada de FOURIER (no espaço direto) para $\varepsilon$ pequeno.

(*) Alguns comentários sobre os métodos de resolução numérica da convolução poderão ser encontrados na seç̧ão 4.3.4. 

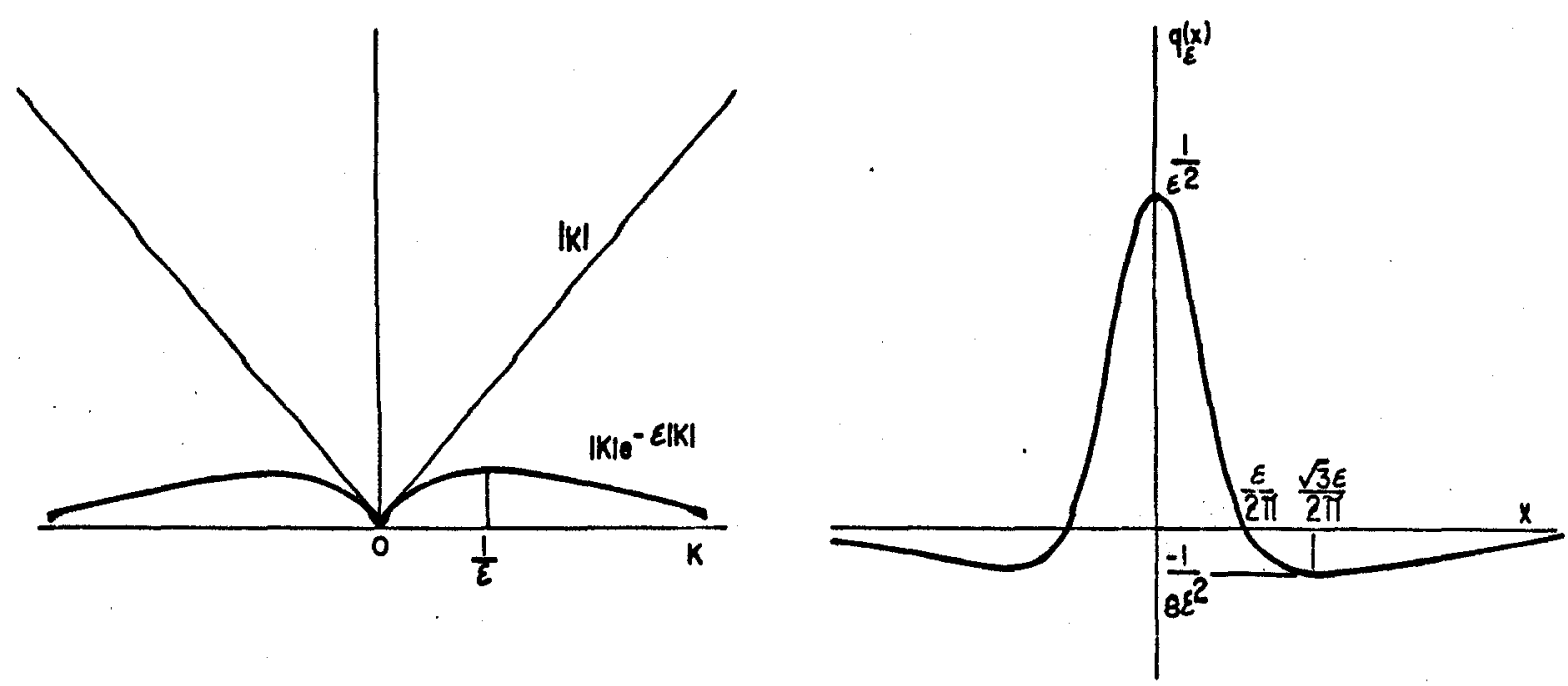

Figura 19 - Esboço de uma função núcleo "bem-comportada" no espaço recíproco e no espaço direto

A transformada inversa de $|K| e^{-\varepsilon|k|}$ é:

$$
q_{\varepsilon}(x)=\frac{\varepsilon^{2}-(2 \pi x)^{2}}{\left[\varepsilon^{2}+(2 \pi x)^{2}\right]^{2}}
$$

Quando $x \rightarrow \infty, q_{\varepsilon} \simeq \frac{-1}{(2 \pi x)^{2}}$. É graças à contribuição negativa de $q(x)$ que após a convolução com os dados projetados o efeito es trela ("borrão" da imagem), a que fizemos alusão na secção 4.2.3, pode ser eliminado durante a operação de retroprojeção.

Convém lembrar que, na prática, o número de projeções é limitado, pois $\theta$ e $x$ são discretos além de que os dados coleta dos precisam ser armazenados no computador e posteriormente prepa rados para o processamento do cálculo da reconstrução da imagem. Devido a isto, duas hipóteses são comumente assumidas em relação aos dados armazenados. A primeira é que $\mu(x, y)$ é limitada por $\underline{u}$ ma frequência espacial $\mathrm{B}\left(\mathrm{cm}^{-1}\right)$ e a segunda é que os dados são coo letados na frequência de NYQUIST, com um espaçamento $a=\frac{1}{2 B}(\mathrm{~cm})$. 
Isto nos leva a uma "função" núcleo $q(x)$ do tipo:

$$
q_{L}(x)=\int_{-\infty}^{B}|K| e^{2 \pi i x K} d K=2 B^{2} \frac{\operatorname{sen} 2 \pi x B}{2 \pi x B}-B^{2} \frac{\operatorname{sen}^{2} \pi B x}{(\pi B x)^{2}}, \ldots(I V-28)
$$

que está esboçada na Figura 20.

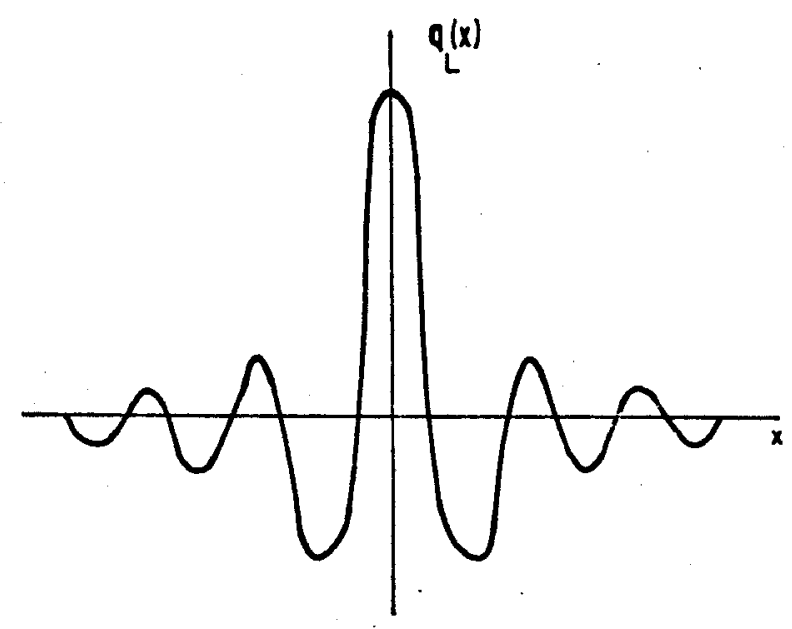

Figura 20 - Esboço da função

núcleo de LAKSHMINARAYANAN

RAMACHADRAN e LAKSHMINARAYANAN ${ }^{(105)}$ foram os primeiros a discutir a "função" núcleo acima.SHEPP e LOGAN ${ }^{(106)}$ e outros defini ram núcleos alternativos, mas suas propriedades não diferem daque las enunciadas até aqui.

Na próxima secção, vamos reobter os resultados princi pais do método da convolução, utilizando a geometria do feixe de raios em forma de leque (feixe divergente), comumente empregada nos tomógrafos de terceira geração. 


$$
\text { HERMAN et al }{ }^{(107)}(1976) \text { foram os primeiros autores a } \underline{a}
$$

nalisarem as modificações introduzidas no algorítmo de reconstru ção da imagem devido à presença do feixe divergente.

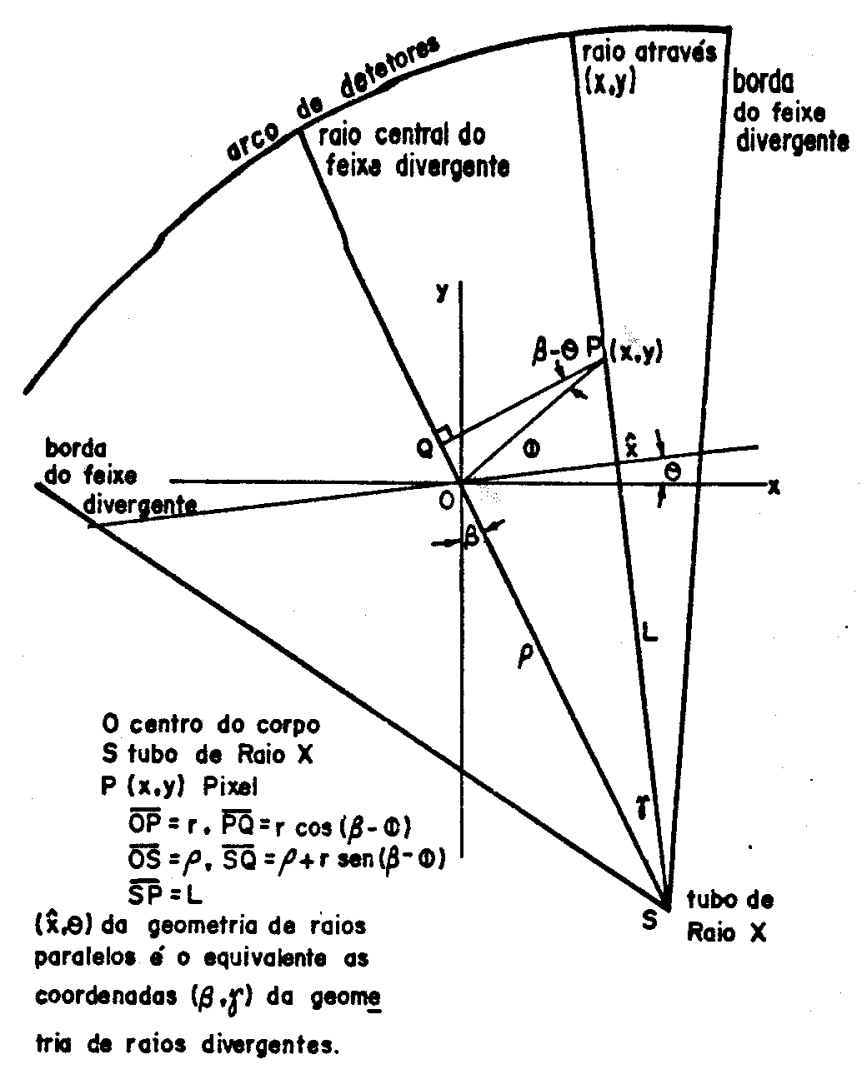

Figura 21 - Geometria do feixe em forma de leque

A partir da equação (IV-25) é possível escrever a equa ção (IV-26) [equações da geometria de feixes paralelos] como:

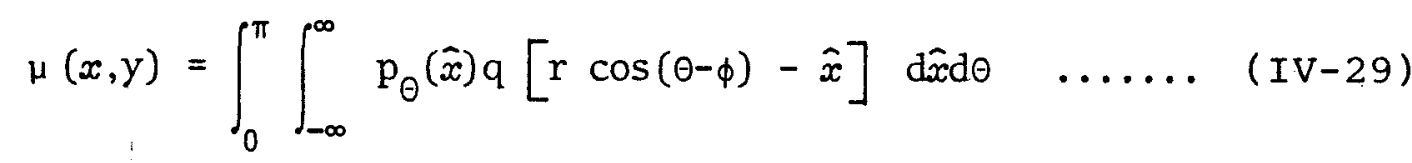

Da geometria da Figura 21 é fácil escrever $\mu(x, y)$ em termos das variáveis $\beta$ (ângulo de projeção. Note que não é o mes mo que $\theta), \gamma$ (ângulo do detetor com o feixe divergente) e $\rho$ (dis tância da fonte ao centro do objeto) que caracterizam o feixe de 
Raios $\mathrm{X}$ em forma de leque. Fazendo a devida transformação de va riáveis (incluindo o cálculo do Jacobiano $\left[\frac{\partial(\hat{x}, \theta)}{\partial(\beta, \gamma)}\right]=\rho \cos \gamma$ ), obtemos:

$$
\begin{aligned}
\mu(x, y)= & \int_{0}^{\pi} \int_{-\gamma_{m}}^{\gamma} p_{(\beta-\gamma)}(-\rho \operatorname{sen} \gamma) q[r \cos (\beta-\gamma-\phi)+ \\
& \rho \operatorname{sen} \gamma] \quad x \rho \cos \gamma d \beta d \gamma \quad \ldots \ldots \ldots \ldots(I V-30)
\end{aligned}
$$

Os limites $\pm \gamma_{m}$ da integral devem-se ao fato de que, na prática, o objeto a ser analisado possui um tamanho finito $T$, on de 0 máximo valor que $\gamma$ adquire é: $\gamma_{\mathbb{m}}=\operatorname{arc} \operatorname{sen}(T / \rho)$.

o termo $P(\beta-\gamma)^{(-\rho \operatorname{sen} \gamma)}$ representa os dados da proje ção coletados na geometria de raios paralelos. Para lembrar a geo metria de feixe divergente, vamos chamá-lo de $h_{\beta}(\gamma)$, ou seja:

$$
h_{\beta}(\gamma)=p_{(\beta-\gamma)}(-\rho \operatorname{sen} \gamma)
$$

que aparece multiplicado pelo fator $\rho \cos \gamma$ em $($ IV-30).

o argumento da "função" núcleo pode ser escrito como $r \cos (\beta-\gamma-\phi)+\rho \operatorname{sen} \gamma=L \operatorname{sen}\left(\gamma_{0}-\gamma\right)$ na geometria do feixe em leque, onde $\mathrm{L}$ é a distância da fonte ao pixel e $\gamma_{0}$ é o ângulo do detetor cujo raio atravessa o par ordenado $(x, y)$. Vamos agora definir algumas variáveis novas que além de caracterizarem a pre sença da geometria de feixe divergente, tornarão a forma das equa ções mais simples e compacta.

$$
\begin{aligned}
& \text { Assim, seja } K^{\prime}=K K^{\prime} \frac{\operatorname{sen} \gamma}{\gamma} \text { e lembrando que: } \\
& \quad \int_{-\infty}^{\infty}|K| \exp (2 \pi j K x) d K \text {, obtemos que: } \\
& q(\operatorname{Lsen} \gamma)=\frac{\gamma^{2}}{L^{2} \operatorname{sen}^{2} \gamma} \int_{-\infty}^{\infty}\left|K^{\prime}\right| \exp \left(2 \pi i K^{\prime} \gamma\right) d K^{\prime}=\frac{\gamma^{2}}{L^{2} \operatorname{sen}^{2} \gamma} q(\gamma) \ldots(I V-32)
\end{aligned}
$$


Vamos também definir a "função" núcleo do feixe em for ma de leque como $\hat{q}(\gamma)=\frac{\gamma^{2}}{\operatorname{sen}^{2} \gamma} q(\gamma)$ e a projeção em leque para os dados coletados no ângulo $\gamma$ da projeção $\beta$ como $\hat{h}_{\beta}(\gamma)=h_{\beta}(\gamma) \rho \cos \gamma$. Com as transformações acima é possível $\mathrm{f}$ nalmente escrever (IV-30) como:

$$
\mu(x, y)=\int_{0}^{\pi} \frac{d \beta}{L^{2}} \int_{-\gamma_{m}}^{\gamma_{m}} \hat{q}\left(\gamma_{0}-\gamma\right) h_{\beta}(\gamma) d \gamma
$$

que é o algorítmo de convolução da retroprojeção como apresentado em (IV-24) ou (IV-26) [geometria de raios paralelos] com a dife rença de que agora aparece o fator "peso" $\frac{1}{\mathrm{~L}^{2}}$ na operação de re troprojeção.

\section{3 .5 - ALGUNS COMENTÁRIOS FINAIS}

Na prática, a resolução das equações (IV-26) ou (IV-33) envolve cálculo numérico feito em computadores digitais.

É comum aproximar $\hat{x}$ ou $\gamma$ por funções degrau (pois o sistema de coleta de dados é feito através de detetores discre tos) assim como as projeções nos ângulos $\theta$ ou $\beta$ são tomadas por rotações também discretas.

A forma mais simples de aproximação é somar os termos discretos das operações de convolução e posteriormente de retro projeção como expressos abaixo, para um pixel qualquer de coorde nadas $\left(x_{m}, y_{n}\right)$ :

$$
\left\{\begin{aligned}
g_{\theta i}\left(\hat{x}_{i}\right)= & \sum_{\theta_{j}} q\left(\hat{x}_{i}-\hat{x}_{j}\right) P_{\theta i}\left(\hat{x}_{j}\right) \Delta x, e \\
\mu\left(x_{m}, y_{n}\right)= & \sum \underset{\theta i}{ } g_{\ominus i}\left[\hat{x}\left(x_{m}, y_{n}, \theta_{j}\right)\right] \Delta \theta
\end{aligned}\right.
$$


A vantagem do método da convolução sobre os demais mé todos de reconstrução do imagem, em termos computacionais, é que simultaneamente à coleta dos $\mathrm{P}_{\theta i}\left(\hat{x}_{j}\right)$, os $g_{\theta i}\left(\hat{x}_{i}\right)$ já são processa dos e em seguida armazenados um a um.

Na operação de retroprojeção, é escolhido o valor $\hat{x}_{j}$ mais próximo do valor real $\hat{x}$ :

$$
\hat{x}=\sqrt{x_{m}^{2}+y_{n}^{2}} \cos \left[\theta_{i}-\operatorname{arctg}\left(y_{n} / x_{m}\right)\right]
$$

que é usado para selecionar o valor de $g_{\theta i}$ que será empregado no cálculo do valor de $\mu\left(x_{m}, y_{n}\right)$.

De forma mais geral, a interpolação linear é frequente mente utilizada para calcular $g_{\theta i}(\hat{x})$, selecionando os valores de $x$ mais próximos de $\hat{x}\left(x_{j}\right.$ e $\left.x_{j+1}\right)$. Deste modo $g_{\theta i}(\hat{x})$ fica escrito como:

$$
g_{\theta i}(\hat{x})=g_{\theta i}\left(\hat{x}_{j}\right)+\left[g_{\theta i}\left(\hat{x}_{j+1}\right)-g_{\theta i}\left(\hat{x}_{j}\right)\right] *\left[\frac{\hat{x}-x_{j}}{x_{j+1}-x_{j}}\right]
$$

Outros tipos de interpolação também são possíveis. De penderá do problema específico. O problema da interpolação pode ser visto mais rigorosamente em trabalhos mais recentes como por exemplo, a análise numérica feita através da interpolação splines cúbica (108)

Da mesma forma que a operação de convolução é feita com os dados projetados através da "função" núcleo (operação de filtragem dos dados coletados) a operação de interpolação também pode ser vista de modo similar. Podemos afirmar isto, porque a 으 peração de convolução é feita no espaço direto como um produto de Transformadas de FOURIER no espaço recíproco. Assim, a operação de interpolação é equivalente a passar os dados convoluídos atrá vés de um "filtro" (a"função" núcleo) ${ }^{(*)}$.

(*) Equivale a fazer dupla filtragen dos dados coletados.

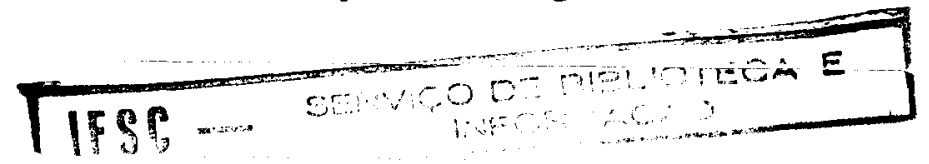


Queremos observar que as duas operações de interpolā ção e convolução podem ser feitas de uma só vez, definindo uma no va "função" núcleo $\tilde{q}(x)$ :

$$
\tilde{q}(x)=\dot{q}(x) * i(x)=\int_{-\infty}^{\infty} q\left(x-x^{\prime}\right) i\left(x^{\prime}\right) d x^{\prime}
$$

onde $i(x)$ é a função interpolação.

De forma análoga, os ruídos ou distorções existentes nos dados das projeções podem ser eliminados através de um proces so de "filtragem" como o da equação (IV-37).

Como parte final deste capítulo, queremos ressaltar que os atuais desenvolvimentos existentes na confecção de instrụ mentos que operam na área de imagem, em especial na tomografia computadorizada, buscam aperfeiçoar a qualidade da imagem, a sua resolução, reduzir os artefatos e abaixar o custo sem perder a qualidade existente.

As medidas em tempo real despertam muito interesse prá tico e futuramente poderão tornar-se realidade. É $\circ$ caso, por e xemplo, da tomografia do coração que poderá permitir a observa . ção das sequências do seu funcionamento, através de seu ciclo de operação.

Outras aplicações da tomografia que demonstram excep cional potencial estão na indústria de turbinas e de aviões à jạ to tais como na inspecção de lâminas e discos. Também na indús tria nuclear como na inspecção de soldas e barras de materiais combustiveis usados nos reatores.

Recentemente, a tomografia computadorizada também tem sido usada para medidas em amostras arqueológicas e biológicas de interesse relevante, através de minitomógrafos especialmente cons truídos para este fim (109). 


\section{CAPÍTULO V}

\section{TOMOGRAFIA COMPUTADORIZADA: UM NOVO MÉTODO PARA ESTUDOS DA FÍSICA DA ÁGUA NO SOLO}

Vamos introduzir, neste capítulo, um novo método de me dida da densidade global og e do conteúdo da água no solo $\theta$. Além disto, será possível constatar a sua extensão contribuindo para estudos estáticos, dinâmicos, tridimensionais e simultâneos des tes parâmetros trazendo, como consequência, diversas outras apli cações conforme serão relatadas no próximo capítulo.

Este novo método baseia-se na utilização da Tomografia Computadorizada, cujos fundamentos estão contidos na Teoria Re construtiva da imagem expressos no Capitulo IV, conforme a nossa descrição anterior.

A sequência a ser desenvolvida neste capítulo no que se refere a Materiais e Métodos e Resultados e Discussão seguirá a mesma que adotamos em nossas publicações $(9,10)$ embora com mais de talhes. Antes disso porém, faremos algumas breves observações re lativas ao Sistema de Reconstrução da Imagem (Sistema TAC) empre gado na realização da série de varreduras tomográficas que iremos apresentar nos próximos capítulos.

o Sistema TAC empregado é apropriado para fins médicos e. a Figura 22 mostra um esquema típico. 
73.

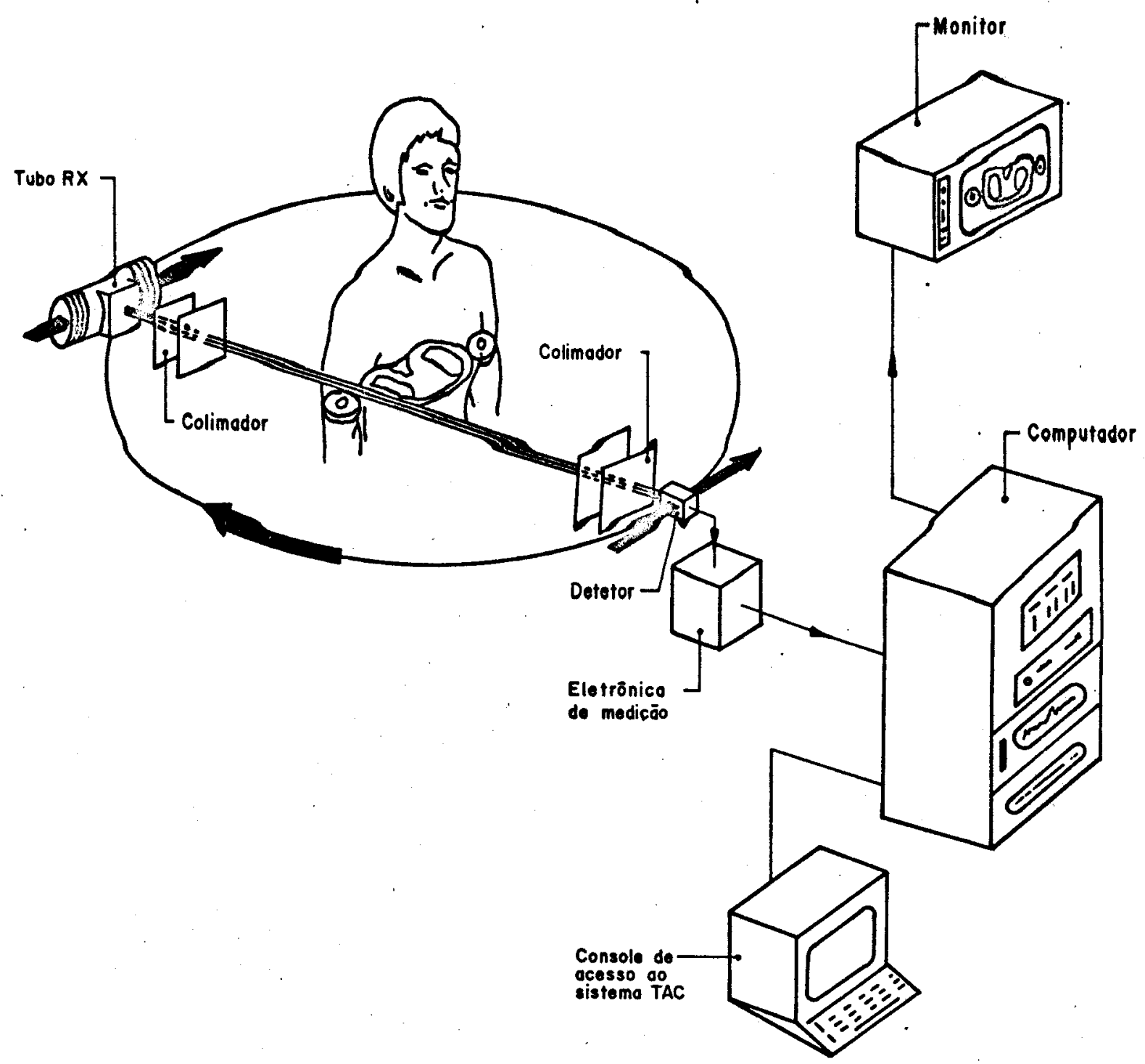

Figura 22 - Esquema típico de um Sistema TAC apropriado para fins médicos, mostrando os seus vários componentes, desde a varredura da região de exame do paciente, a coleta de dados, o seu processa mento até a produção final da imagem.

Na tomografia médica, um dos parâmetros de relevância é o tempo de aquisição de dados. Os fatores referentes à dose re cebida pelo paciente assim como a nitidez da imagem são fundamen tais. No caso da nitidez da imagem deve-se levar em conta que os movimentos do corpo como respiração, batimentos cardíacos, pulsa ções arteriais e outros, podem contribuir para a diminuição da sua qualidade.

Deste modo, os tomógrafos médicos procuram possuir a $\underline{1}$ gorítmos de reconstrução ("softwares") cada vez mais rápidos e de 
maior resolução. Da mesma maneira, são introduzidas implementạ ções no "hardware" do sistema, como modificações no conjunto de fontes, detetores e eletrônica de medida, de forma a aumentar a sua taxa de aquisição de dados. A Figura 23 ilustra estas evolu ções e caracteriza as três gerações de tomógrafos existentes.

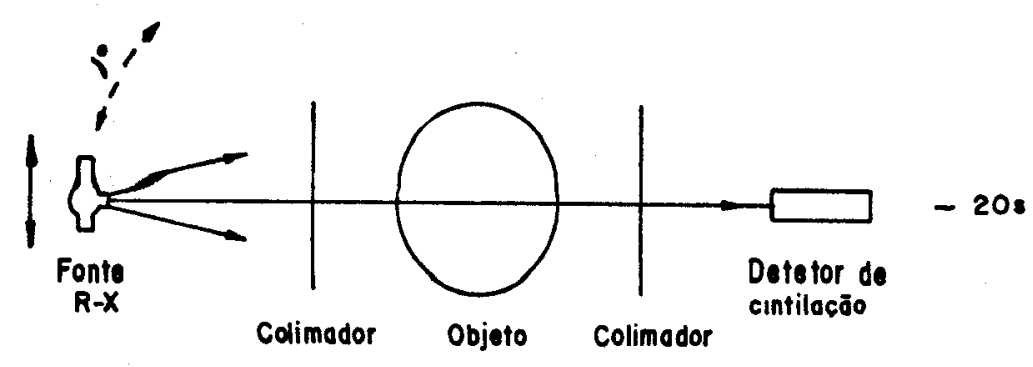

(a)

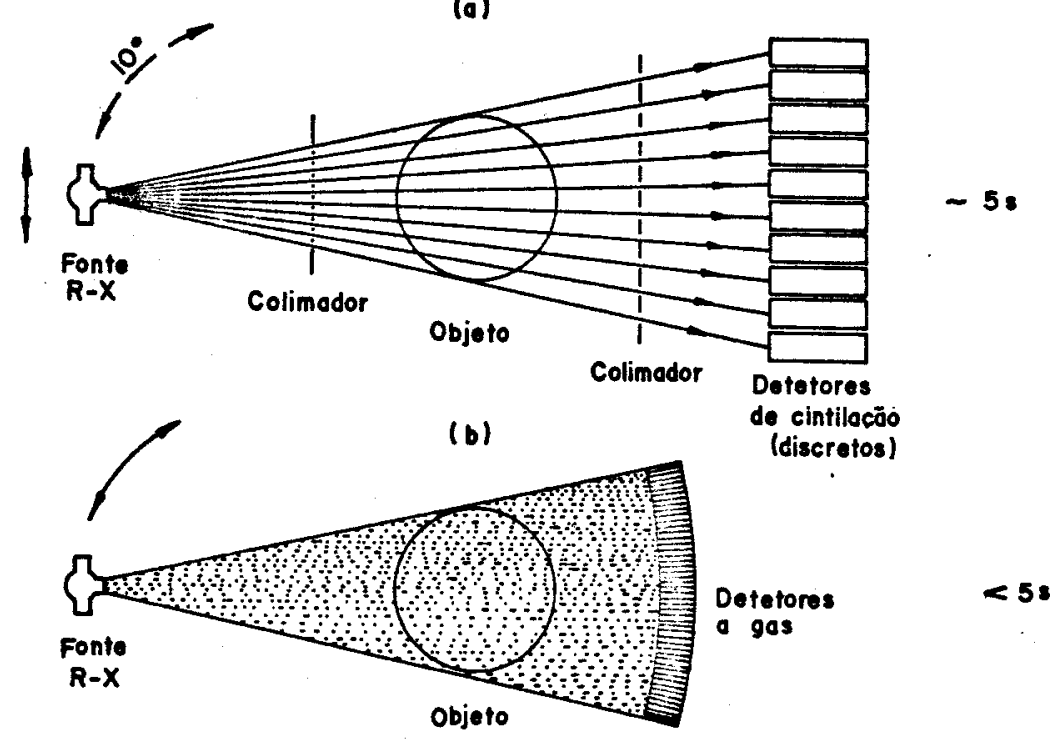

(c)

Figura 23 - São mostrados, de cima para baixo, três gerações de tomó grafos existentes. 0 de $1^{a}$ geração, esquematizado na parte superior da figura, utiliza-se de um único feixe de Raio $X$ (pincel). O de $2^{\text {a }}$ geração, esquematizado na parte central, utiliza-se de um feixe de múltiplos pincéis e o de 3 á geração, utiliza-se da geometria de fei xe em forma de leque (parte inferior da figura). 0 tempo de varredu ra de cada um deles, respectivamente, é de $20 \mathrm{~s}, 5 \mathrm{~s}$ e menor que $5 \mathrm{~s}$ e também estão indicados os seus movimentos de translação e ou de ro tação.

Passemos agora, a uma descrição mais específica do tô mógrafo, assim como das amostras de solo utilizadas nos experimen tos realizados. 


\section{1 - MATERIAIS E MÉTODOS}

\section{A fotografia 1 ilustra o tomógrafo General Electric}

CT/T8800, de terceira geração, pertencente ao Instituto de Radio logia da Universidade de Trieste (Itália), e que empregamos em nossos estudos. $(110,111)$.

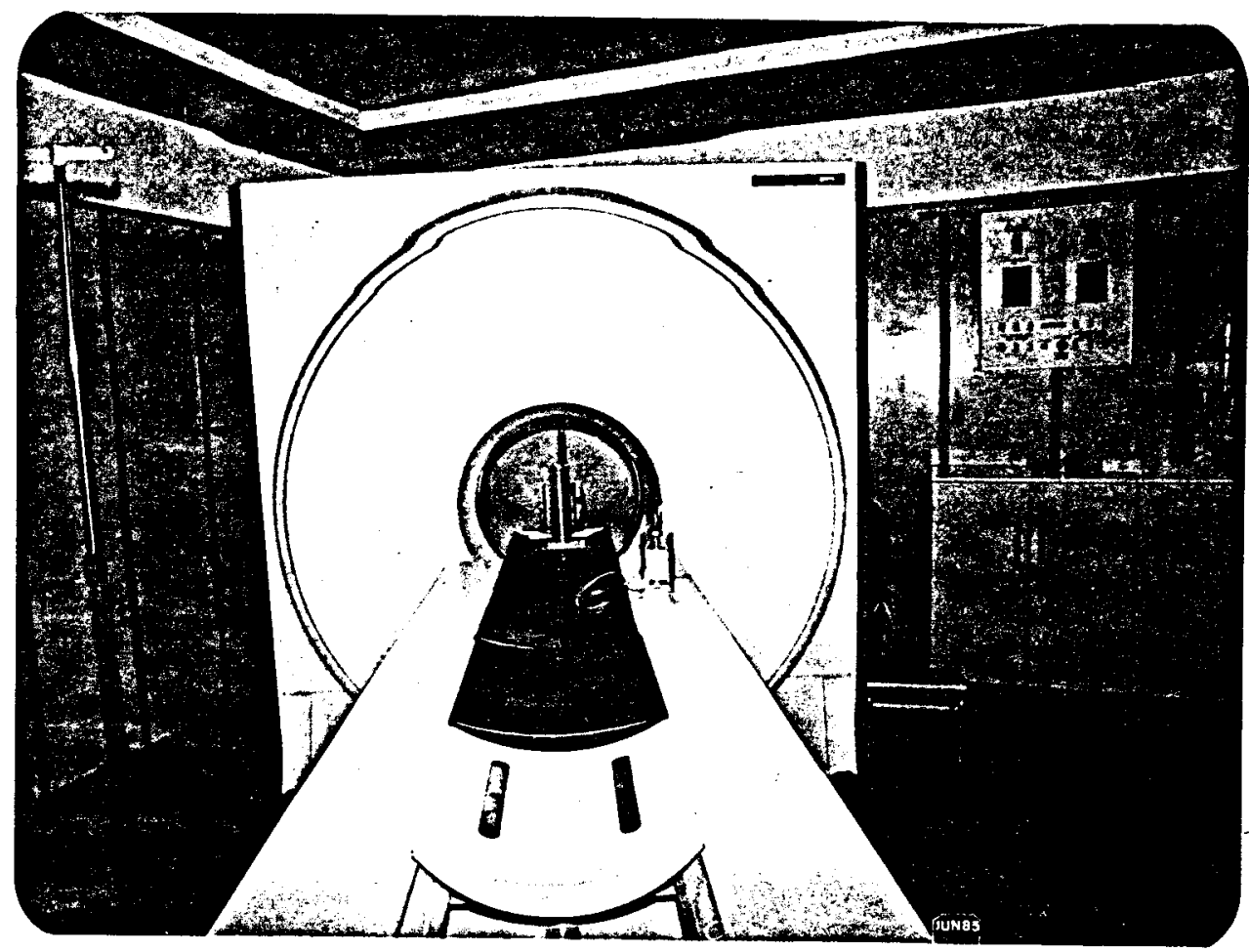

Fotografia 1 - Tomógrafo médico GE CT/T8800, de terceira geração, empregado na série de experimentos realizados. Observe, em primei ro plano, a mesa móvel para posicionamento do paciente. Em segun do plano, pode ser vista a cavidade de exame do paciente com uma coluna de solo no seu interior, utilizada na realização de um ex perimento com planta.

O seu conjunto de detetores consiste de um arco de $30^{\circ}$ que contém 523 detetores de xenônio a alta pressão. o tubo de Raios $\mathrm{X}$ assim como os detetores estão localizados na parte inter na da cavidade de exame dos pacientes.

As características de operação do tubo são de $120 \mathrm{KV}$ quanto que a intensidade da corrente pode variar entre 20 e 500 mA. A mAs depende do tempo de varredura e pode variar entre 30 mAs a 1152 mAs. Nos experimentos realizados tentamos sempre utili 
zar a máxima mas disponível pelo instrumento, conforme os parâmetros empregados (varreduras dinâmicas ou não e espessura da fạ tia ou secção do corte tomográfico $\left.{ }^{(*)}\right)$. A abertura disponível no local onde o paciente é examinado (cavidade) é de $60 \mathrm{~cm}$ de diâme tro. O tempo de varredura pode variar entre 5,7 a 11,5 segundos. O intervalo entre duas varreduras sucessivas é de cerca de 30 se gundos podendo ser reduzido a 1 segundo quando a técnica dinâmica é empregada. A varredura dinâmica consiste de uma série de varre duras executadas na mesma posição do corte tomográfico da amostra (em tempos diferentes) ou em diferentes posições da mesma. A téc nica dinâmica permite obter gráficos da variação da densidade com - tempo, do objeto em exame. As espessuras das fatias tomográfí cas podem ser de $1,5 \mathrm{~mm}, 5 \mathrm{~mm}$ e $10 \mathrm{~mm}$. Os círculos-padrões de recons trução da imagem comumente usados para estudos do cérebro são de $25 \mathrm{~cm}$, enquanto que de $35 \mathrm{~cm}$ e $42 \mathrm{~cm}$ para estudos do corpo. O tama nho da matriz é de 320 por 320 pixels. A Figura 24 ilustra os con ceitos de pixel, largura de raio, etc.

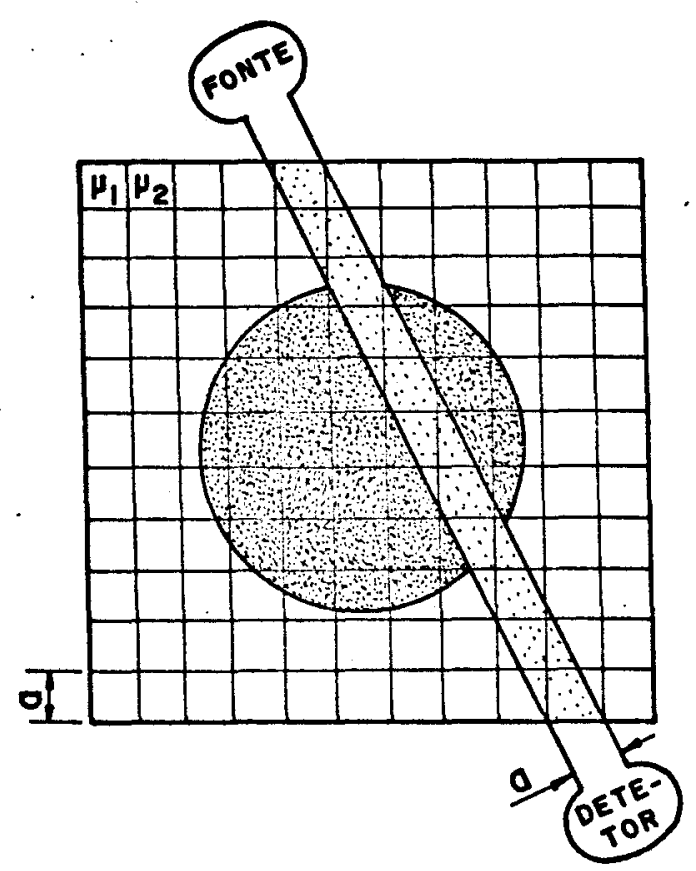

Figura 24- A figura mostra es quematicamente um plano de um corte tomográfico. Mostra-se a sua divisão em uma malha de cé lulas quadradas de lado a, que coincide com a largura do raio. Os valores dos coeficientes de atenuação lineares $\mu_{1}, \mu_{2}$ são calculados em pontos dis cretos. Tais pontos são chama dos células ou pixels.

(*) Não faremos distinção entre os dois termos. 
o tamanho de cada pixel depende dos círculos de recons trução da imagem $(25 \mathrm{~cm}, 35 \mathrm{~cm} \mathrm{e} 42 \mathrm{~cm})$ e é respectivamente de 0,8 ; I e $1,2 \mathrm{~mm}$. A dimensão do pixel pode ser ainda mais reduzida até a tingir $0,25 \mathrm{~mm}$ através do recurso disponível neste tomógrafo chama do de reconstrução de imagem de alta resolução. o algorítmo de re construção (tanto o comum como o de alta resolução) atribui a ca da pixel na matriz imagem o coeficiente de atenuação linear da rạ diação $X$ relativo ao volume do material do objeto representado pe 10 referido pixel. Esses coeficientes são convertidos em números correspondentes às unidades medidas pelo tomógrafo (Unidades Hounsfield - U.H. $)^{(*)}$ antes da imagem ser vista. A escala normal de números do tomógrafo varia entre -1000 U.H. (ar) a +1000 U.H. (osso). O valor zero U.H. é atribuído à agua. Caso se queira ob servar densidades maiores que $1000 \mathrm{U} . \mathrm{H}$. pode-se utilizar o recur so da escala ampliada ou estendida, que permite fazer com que a escala dos números do T.C. passe a variar no intervalo de -1000 a +3000 U.H.

Passemos, de agora em diante a descrever os materiais e métodos referentes propriamente aos experimentos de água e solo em que as varreduras tomográficas foram realizadas.

Quanto às amostras de solo, trabalhamos com diversas texturas extraidas do horizonte $A_{p}$ de um solo argilo-arenoso de Trieste - Itália e de um solo limo-arenoso de Barretos - Bra $\operatorname{sil}^{(* *)}$. Quanto ao acondicionamento das referidas amostras, utili zamos dois tipos de colunas cilíndricas de acrílico.

(*) As Unidades Hounsfield (U.H.) são definidas como:

$$
\text { U.H. }=1000 \frac{\left(\mu-\mu_{W}\right)}{\mu_{W}}
$$

onde $\mu_{W}$ é o coeficiente de atenuação da água. Comunente é utilizada uma escala. relativa onde o $\mu_{W}$ é tomado como nível de referência e igualado a zero (consi derado como valor padrão).

(**) Conforme Urquiaga (112), o solo argilo-arenoso de Trieste (entis solo) é constituído de minerais primários como quartzo, feldspato, mica e argi la (principalmente montmorilonita). 0 solo limo-arenoso de Barretos é um LVAFa (Latossolo Vermelho-Amarelo fase arenosa) e é constituído de minerais se cundários como a caolinita, óxidos de ferro como a geotita e a hematita, assim como óxicios de Alumínio. 
Para o estudo do fluxo horizontal utilizamos seringas de $5 \mathrm{~cm}$ de diâmetro e $20 \mathrm{~cm}$ de comprimento e para o fluxo vertical utilizamos cilindros de $10 \mathrm{~cm}$ de diâmetro por $30 \mathrm{~cm}$ de altura. Algu mas destas colunas verticais foram divididas ao meio (internamen te) através de uma parede fina de acrílico, de forma a permitir (durante as varreduras) comparações simultâneas entre o solo sẹ co e o solo úmido.

As colunas foram posicionadas no interior da cavidade do tomógrafo na forma mais criteriosa possível de modo a evitar artefatos. Inclusive cobrimos as amostras que se destinavam a ob tenção de resultados quantitativos (por exemplo: curvas de cali bração) com uma bolsa de água apropriada. Além disto, escolhemos os parâmetros como $\mathrm{KV}_{\mathrm{p}}$, mAs, tempo de varredura e espessura da fá tia de acordo com as conveniências previamente discutidas.

o fluxo de água foi adequadamente introduzido através de diferentes formas: carga hidráulica, molhamento direto e conta to de um algodão molhado.

Na obtenção das curvas de calibração do coeficiente de atenuação em U.H. em função da densidade global do solo (Figura. 25), utilizamos várias amostras de densidades globais médias obti das de solos de Barretos e Trieste, variando no intervalo de 1,10 a $1,4 \mathrm{~g} / \mathrm{cm}^{3}$. Calculamos previamente o valor da absorção média (U.H.) sobre a secção de corte de cada uma (como por exemplo é mostrado na Tomografia 2), em diferentes posições. Após isto, sele cionamos as melhores amostras (as mais homogêneas) e realizamos novamente várias tomografias antes de construir as curvas da Figu ra 25 .

o solo (seco ao ar) foi passado através de uma peneira de $1,0 \mathrm{~mm}$ e posteriormente acondicionado nos cilindros de acríli co. Para a preparação das amostras de solo no que se refere ao preenchimento das colunas assim como no que se refere as suas res pectivas compactações, foi adotada a metodologia padrão comumente 
usada em Física de Solos (Veja por exemplo, a referência 34 ).

Na obtenção das curvas de calibração das U.H. em fun ção do conteúdo da água no solo (Figura 26) utilizamos diversas a mostras de solo de Trieste e Barretos uniformemente peneiradas (peneira de $1 \mathrm{~mm}$ ) e também acondicionadas nas colunas conforme a metodologia padrão. No caso do solo de Barretos escolhemos para a confecção do gráfico pelo menos três densidades globais médias calculadas a partir da Figura $25\left(\bar{\rho}_{\mathrm{g}}=1,23 \mathrm{~g} / \mathrm{cm}^{3}, \bar{\rho}_{\mathrm{g}}=1,29 \mathrm{~g} / \mathrm{cm}^{3}\right.$, $\bar{\rho}_{\mathrm{g}}=1,34 \mathrm{~g} / \mathrm{cm}^{3}$ e $\left.\bar{\rho}_{\mathrm{g}}=1,39 \mathrm{~g} / \mathrm{cm}^{3}\right)$.

Os pontos graficados na Figura 26, são resultantes dos mesmos procedimentos realizados com a série de amostras da Figura 25. Na tomografia 2, é mostrada uma das tomografias utilizadas no cálculo do valor médio das U.H., donde as amostras não homogêneas e com artefatos, foram posteriormente eliminadas.

Na preparação de cada amostra de solo úmido, foi adi cionada uma quantidade de água bem definida a um volume previamen te conhecido deste solo seco ao ar. Após a observação de que o $\underline{\text { }}$ quilíbrio da água com o solo foi atingido e que a sua distribui ção era uniforme (cerca de dez dias após), preparamos amostras. com umidades volumétricas compreendidas no intervalo de $0 \%$ a $66,67 \%$. No entanto, houve saturação em amostras na faixa de 40 a $50 \%$, não sendo portanto consideradas aquelas que ultrapassaram es tes valores. A operação de preparação de amostras úmidas (com umi dades precisas) é relativamente delicada e exige muita atenção. É preciso introduzir a água de tal modo a evitar a formação de a gregados, de rupturas, de mudanças da densidade global, etc. Sabe mos que de forma mais ou menos intensa o fenômeno do "inchamento" do solo está quase sempre presente no processo de molhamento. Daí a necessidade de introdução da água no solo de forma lenta e gra dativa. Além disto, quando estes efeitos ocorreram gravemente fo ram devidamente eliminados através da seleção das amostras. 
Finalmente, cabe observar que todos os procedimentos

referentes à preparação das amostras foram realizados no próprio loçal do experimento (Hospital). Com isto, pode ser evitada a in terferência de efeitos oriundos de transporte como choques, com pactações e outros.

\section{2 - RESULTADOS E DISCUSSÃO}

Vamos, em seguida, apresentar os principais resultados obtidos através da série de experimentos que realizamos e ao mes mo tempo também discutí-los.

As Figuras 25 e 26 assim como as tomografias ${ }^{(*)} 1,2$ e 3 indicam a conveniência do uso da T.C. para a medida da densida de global e do conteúdo da água no solo. Selecionando uma área a propriada na imagem, podemos medir diretamente a atenuação em U.H. no console do vídeo.

Depois disso a conversão de U.H. para a densidade glo bal ou para o conteúdo de água no solo pode ser feita através das curvas de calibração das Figuras 25 e 26.

Indicadores de geometria e área variáveis como círcu los (tomografia 1) ou retângulos (tomografias 2 e 3 ) fornecem 0 valor da atenuação numa dada região de interesse ("ROI BOX"). O sistema também fornece as coordenadas, a área e $\circ$ desvio pạ drão ${ }^{(\star \star)}$ da atenuação conforme a região de interesse escolhida.

(*) Rigorosamente, as tomografias que aparecerão nesta tese foram obtidas do console do vídeo ou de um filme radiológico e não na forma de foto grafias conforme serão mostradas. No entanto, para destacar a técnica utilizä da iremos propositalmente confundir, no texto, a fotografia da tomografia, com a tomografia em si.

(**) As origens do aparecimento do desvio padrão podem ser vá rias. No entanto, as principais advêm da não uniformidade da região de interes se e ou do seu tamanho, que produzem artefatos na reconstrução da imagem. São interferências de fenômenos como o de Gibbs (que aparece quando há interfaces de descontinuidades), como o endurecimento do feixe (regiões com maior absor ção das baixas energias), etc.. 


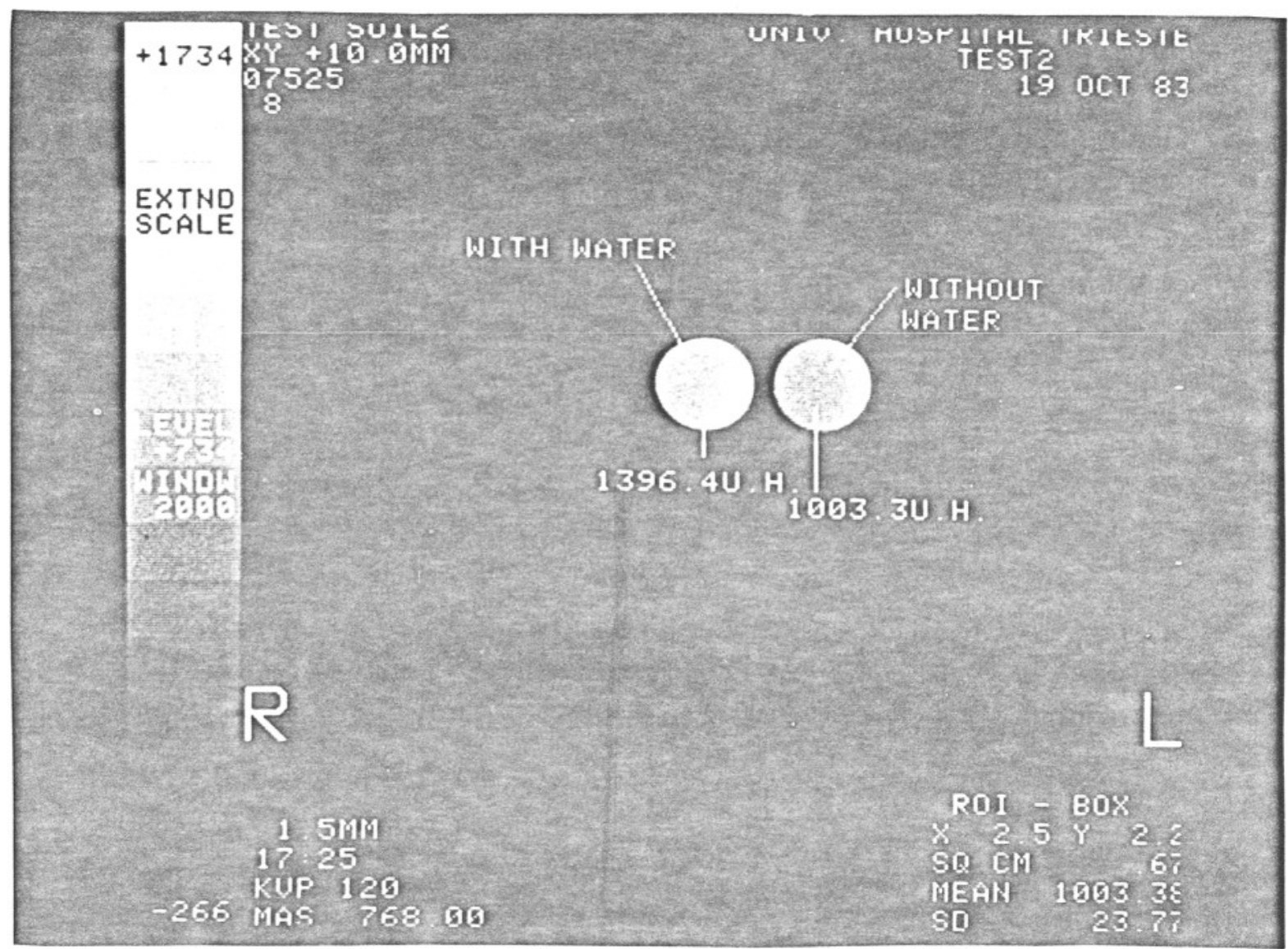

Tomografia 1 - Eficiência do uso da Tomografia para distinguir a água do solo. A diferença entre duas amostras com água e sem á gua e os seus respectivos valores em U.H. são mostrados. Outros dados sobre as condições específicas da realização da tomografia acima estão indicados, assim como as informações do "ROI BOX" e da escala estendida.

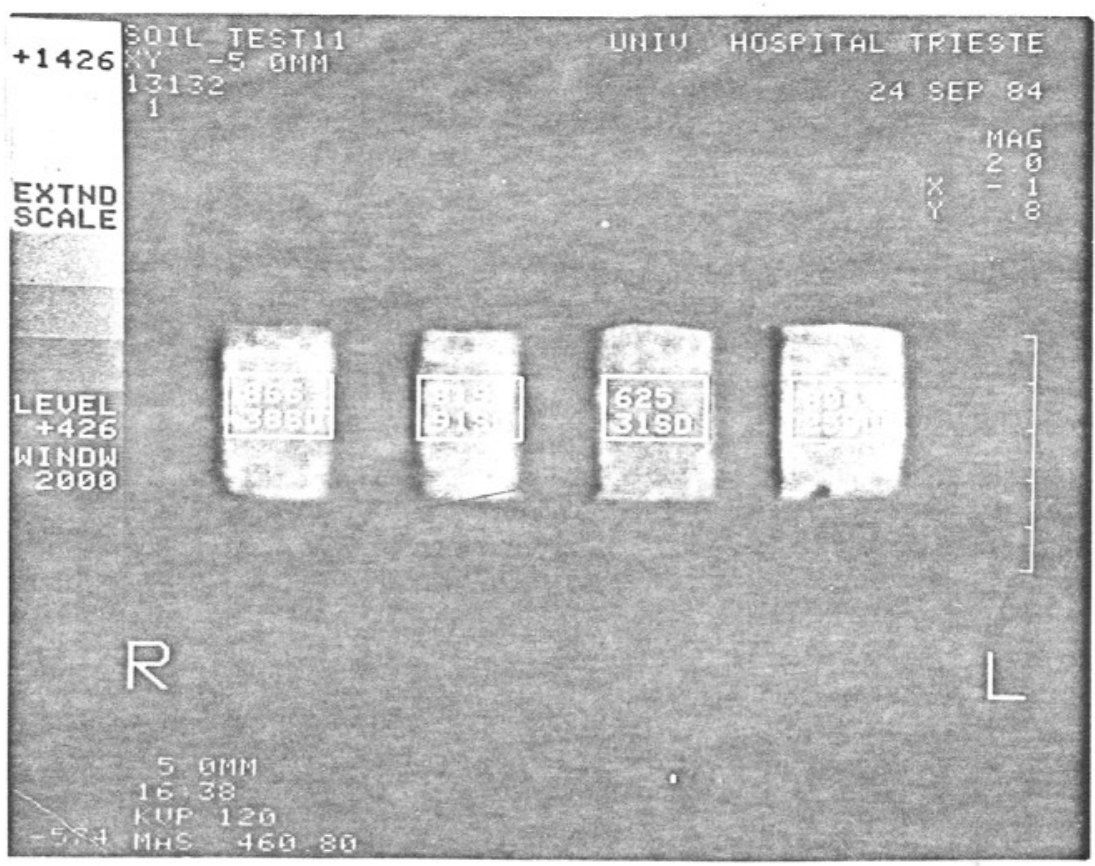

Tomografia 2 - São mostradas quatro amostras de solo seco ao ar, de Barretos, para observações preliminares de possíveis não uniformidades, artefatos, etc. Após este procedimento, pudemos sele cioná-los juntamente com outros e construir a curva de calibra ção das U.H. em função da densidade global $\rho_{\mathrm{g}}$. É possível obser var sobre as amostras a bolsa de água apropriada para evitar ar tefatos. 


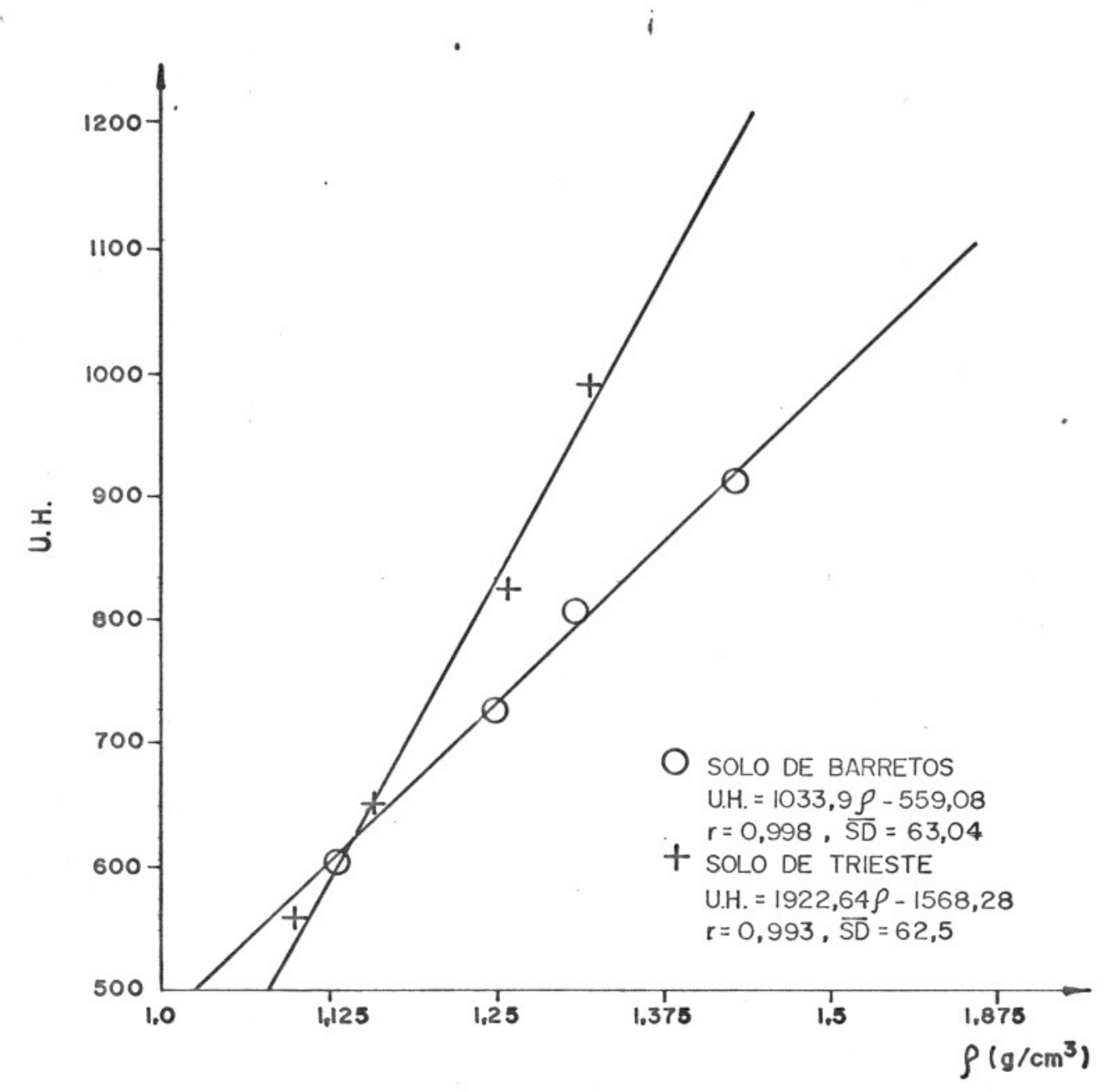

Figura 25 - Curva de calibração linear das Unidades Hounsfield (U.H.) em função da densidade global do solo $\rho_{\mathrm{g}}$ (massa de solo seco dividido pelo seu volume seco). A figura indica os resul tados obtidos com o solo de Barretos e o solo de Trieste.

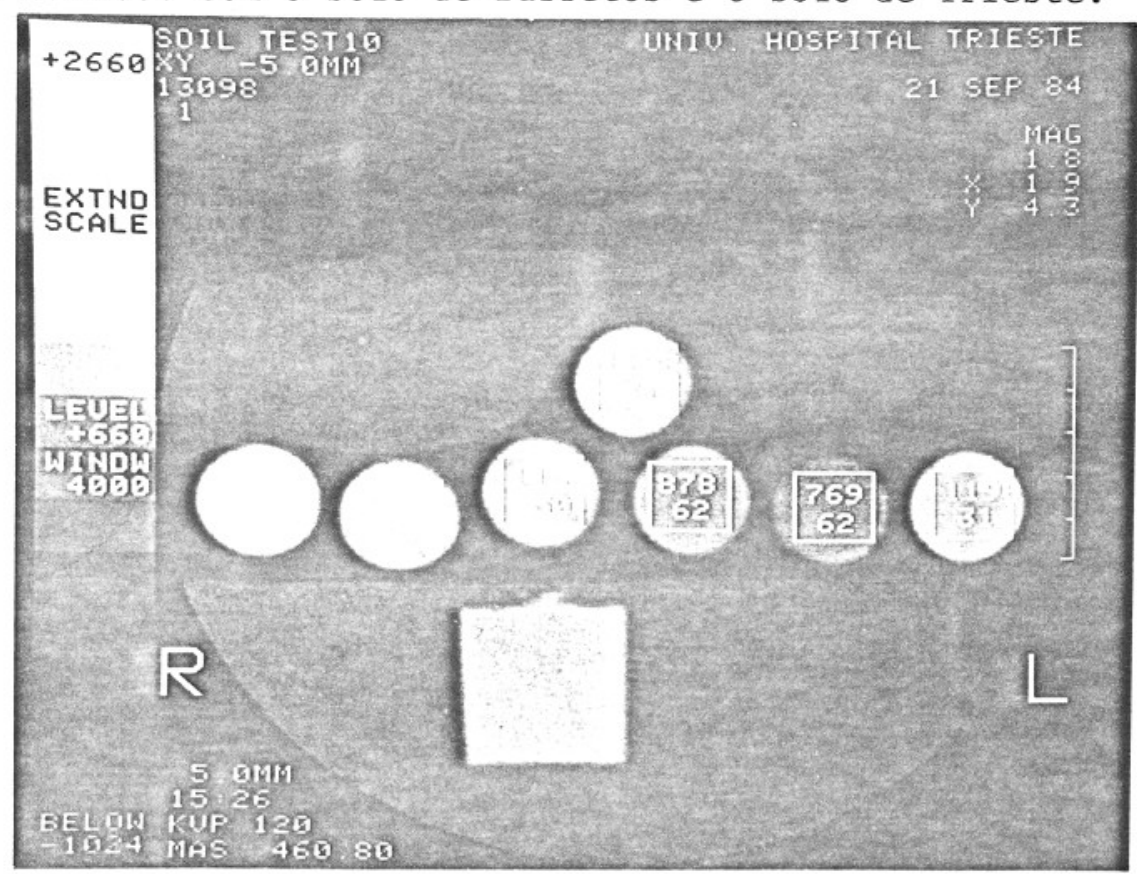

Tomografia 3 - Como na Tomografia 2 são mostradas as imagens de algumas amostras a serem selecionados para a construção da cur va de calibração da Figura 26. Note a presença da bolsa de água sobre as amostras com o fim de evitar artefatos na reconstrução da imagem. 
83.

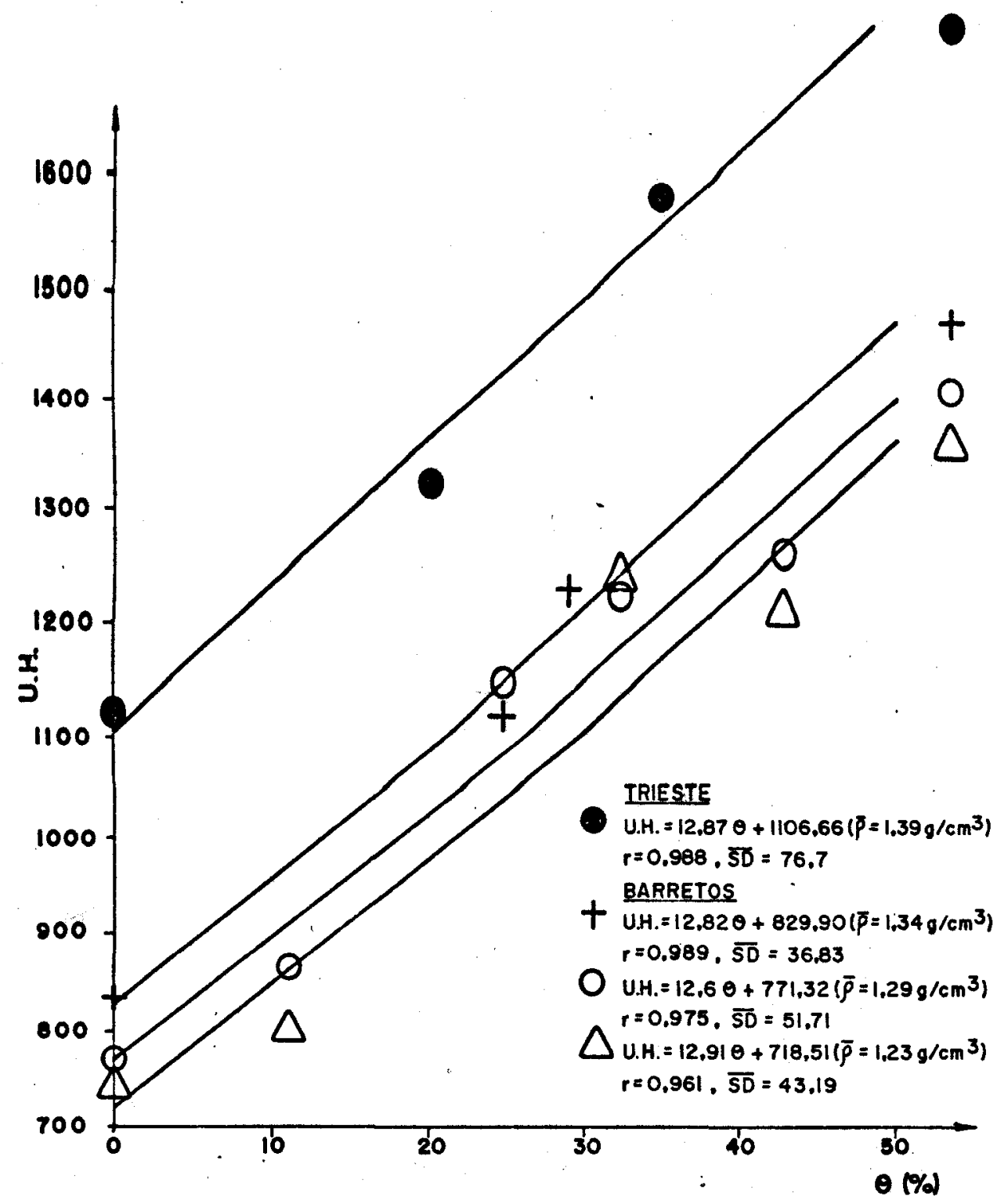

Figura 26 - Curva de calibração linear das Unidades Hounsfield (U.H.) como função do conteúdo de água no solo $\theta$ (volume de á gua pelo volume de solo), em porcentagem. Os valores das densi dades globais médias $\bar{\rho}_{g}$ foram obtidos a partir da figura 25 .

Na Figura 25, mostramos os resultados da curva de cali bração do Sistema TAC expressos em U.H. como função da densidade global. $\mathrm{g}_{\mathrm{g}}$. Encontramos uma dependência linear no caso dos solos de Barretos e Trieste, confirmando os resultados encontrados por PETROVIC et al ${ }^{(113)^{\prime}}$ estudando outro tipo de solo ${ }^{(*)}$. Também é possí vel observar que a curva de calibração depende da constituição de cada solo, como era de se esperar. Este mesmo comportamento ocor re no caso de experimentos de transmissão direta de raios - $\gamma$ e

(*) PETROVIC et al utilizando um tomógrafo AS\&E, Inc.CT Scanner de 4 a geração estudaram amostras coletadas do horizonte Ap de um solo Metea fi no (1imo-arenoso) e também encontraram uma dependência linear entre U:H. e $\rho_{\mathrm{g}}$. 
sonda de neutrons.

Na Figura 26 mostramos os resultados da curva de cali bração do Sistema TAC também expressos em U.H. como função do con teúdo da água no solo.

Como no caso da densidade global, encontramos uma de pendência linear para os dois solos. No caso do solo de Barre tos podemos ver a influência da densidade global calculada a par tir da curva da Figura 25, para os seguintes valores médios: 1,23 $\mathrm{g} / \mathrm{cm}^{3}, 1,29 \mathrm{~g} / \mathrm{cm}^{3}$ e $1,34 \mathrm{~g} / \mathrm{cm}^{3}$. As curvas são paralelas mostrando, dentro de boa concordância, que a densidade global do solo é res ponsável somente pela mudança do ponto de cruzamento da reta de calibração do conteúdo de água no solo, com o eixo das U.H.. I to está em concordância com a Figura 25.

A partir destes resultados, é possível obter diretamen te a densidade global e ou o conteúdo de água de uma imagem com plexa de uma amostra de solo seco ou úmido cuja distribuição de partículas ou mesmo de água não precisa ser necessariamente homo gênea.

Para melhor ilustrar isto, apresentamos em seguida as tabelas I e II impressas a partir de dados obtidos pelo sistema TAC. Estastabelasde 576 números na forma matricial (24 X 24) em U.H.mostram o valor médio da densidade de cada pixel, num dado instante do experimento que será mostrado na Tomografia 5. A tabe la I traz a distribuição de densidades em U.H. para o solo seco enquanto que a tabela II mostra praticamente a mesma distribuição ( $2 \mathrm{~cm}$ abaixo) após a intṛodução de água. Pode ser observado facil mente a não uniformidade das colunas de solo seco e úmido. As tä belas I e II nos fornecem o valor médio das U.H. calculado sobre toda a distribuição. Do confronto da tabela I com a tabela II (por exemplo subtração das imagens: recurso muito comum em tomo grafia médica) pode-se calcular, por exemplo a distribuição de á gua na coluna (na região da tabela). Outras varreduras, em outros 
instantes podem fornecer o avanço da frente de molhamento assim como a da água como um todo no solo.

Realizamos ainda outros experimentos, inclusive dinâmi cos, como aqueles mostrados nas Tomografias 4,5 e 6 . 


\begin{tabular}{|c|c|c|c|c|c|c|c|c|c|c|c|c|c|c|c|c|c|c|c|c|c|c|c|c|}
\hline $24 \times 24$ & $\begin{array}{l}S A x P \\
C \\
143\end{array}$ & $\begin{array}{l}\text { PLE F() } \\
\text { CE ITER } \\
144\end{array}$ & $\begin{array}{l}\text { IR RIJN } \\
-14 \frac{x}{3}\end{array}$ & $=\frac{0752}{146}$ & $\begin{array}{l}27 . S \mathrm{SL} \\
-5, Y \\
147\end{array}$ & $\begin{array}{l}\text { ICE } \\
=\frac{143}{143}\end{array}$ & .2 & 150 & 151 & 152 & .153 & 154 & 153 & 156 & 157 & 158 & 159 & 150 & 161 & 162 & 16.3 & 104 & is5 & 106 \\
\hline 213 & 972 & 1043 & 1082 & 1032 & 1030 & 995 & 995 & $1009^{\circ}$ & 975 & 912 & 866 & 859 & 863 & $857^{\circ}$ & 345 & 829 & 824 & 822 & $800^{\circ}$ & 798 & 841 & 839 & 819 & 353 \\
\hline 214 & 922 & 939 & 981 & 1011 & 967 & 931 & 931 & 940 & 910 & 897 & 861 & 858 & 852 & 822 & 830 & 834 & 827 & 826 & 834 & 827 & 843 & 822 & 842 & 362 \\
\hline 215 & 926 & 923 & 921 & 928 & 914 & 902. & 912 & 397 & 808 & 866 & 865 & 859 & 880 & 855 & 822 & 815 & 818 & 831 & 862 & 849 & 317 & .921 & 350. & 873 \\
\hline 210 & 933 & 933 & 902 & 873 & 870 & 893 & 929 & 912 & 872 & $35 b$ & 862 & 871 & 861 & 346 & 838 & 821 & 825 & 834 & 851 & 332 & 824 & 816 & 336 & 861 \\
\hline 217 & 944 & 919 & 891 & 305 & 866 & 874 & 902 & $\$ 19$ & 891 & 865 & 875 & 895 & 857 & 839 & 870 & 874 & 361 & 851 & 851 & 851 & 854 & 822 & 811 & 834 \\
\hline 213 & 919 & 395 & 395 & 884 & 882 & 885 & 867 & 877 & 884 & 365 & 861 & 884 & 877. & 867 & 882 & 886 & 872 & 870 & 883 & 858 & 854 & 810 & 815 & 905 \\
\hline 219 & 911 & 904 & 92.5 & 909 & 894 & 876 & 855 & 896 & $-902-$ & 362 & 855 & 862 & 379 & $971^{-}$ & $887^{-}$ & 894 & 356 & 854 & $363^{-\cdots}$ & 849 & 362 & 831 & 837 & 395 \\
\hline 220 & 903 & 901 & 921 & 916 & 905 & 809 & 866 & 906 & 906 & 377 & 844 & 843 & 875 & 877 & 873 & 951. & 828 & 843 & 866 & 858 & 365 & 868 & 873 & 881 \\
\hline 221 & 89.3 & 900 & 912 & 924 & 911 & 875 & 854 & 885 & 916 & 903 & $362^{\circ}$ & 853 & 862 & 811 & 368 & 855 & 816 & 857 & 852 & 861 & 390 & 876 & 377 & 880 \\
\hline $222^{\circ}$ & 925 & 915 & 121 & $419^{\circ}$ & $917^{\circ}$ & 899 & 866 & 884 & $918^{-}$ & 904 & 898 & $883^{-}$ & 353 & 842 & $850^{\circ}$ & 849 & 873 & $884^{\circ}$ & 860 & 850 & 803 & 835 & 881 & 375 \\
\hline 223 & 934 & 945 & -951 & 950 & 940 & iil & 859 & 964 & 887 & 881 & 901 & 893 & 845 & 850 & 873 & 362 & 879 & 880 & 868 & 858 & 849 & 881 & 363 & 857 \\
\hline 224 & 512 & 946 & 955 & 903 & 951 & 914 & 862 & 358 & 858 & 368 . & 890 & 881 & 803 & 372 & 894 & 896 & 903 & 867 & 854 & 857 & 84.3 & 544 & 331 & 845 \\
\hline 225 & 953 & $.943^{\circ}$ & 9.47 & 939 & 945 & 913 & 861 & 860 & $878^{\circ}$ & 880 & $879^{\circ}$ & 870 & Bss & 850 & 869 & $878^{-}$ & $-882^{-}$ & 354 & 845 & 855 & 856 & $850^{\circ}$ & $820^{\circ}$ & 337 \\
\hline 225 & 941 & 925 & 914 & 421 & $9 ? 9$ & 901 & 859 & 858 & 859 & 808 & $88 !$ & 853 & $855^{\circ}$ & 816 & 858 & 856 & 858 & 860 & 860 & 873 & 371 & 837 & 819 & 354 \\
\hline 221 & 95.) & 937 & 909 & 901 & 904 & 870 & 853 & 856 & 859 & 300 & 884 & 875 & 852 & 850 & 858 & 859 & 373 & 865 & 845 & 859 & 853 & 835 & 345 & 375 \\
\hline 223 & 902 & 945 & 92.3 & 894 & 882 & 870 & 863 & 373 & $890^{\circ}$ & 371 & 858 & 845 & $827^{-}$ & 855 & 871 & 873 & $831^{-}$ & 855 & 850 & 848 & 350 & 346 & 351 & 357 \\
\hline 227 & 980 & 945 & 912 & 831 & 800 & 867 & 804 & 878 & 915 & 915 & 885 & 857 & 837 & 849 & 869 & 361 & 859 & 841 & 811 & 817 & 834 & 814 & 917 & 822 \\
\hline 230 & 950 & 912 & $8 \times 9$ & 881 & 858 & 850 & 846 & 863. & .896 & 905 & 905 & 835 & 884 & 856 & 849 & 849 & 838 & 827 & 829 & $8 \geq 9$ & 813 & 797 & 776 & 799 \\
\hline 231 & 923 & 903 & B7h & $881^{\circ}$ & 856 & 800 & 855 & $873^{\circ}$ & 896 & $883^{-}$ & $889^{\circ}$ & 893 & 896 & $844^{-}$ & 832 & 348 & 335 & 814 & 819 & 815 & 311 & 799 & 82.3 & 822 \\
\hline 232 & 923 & 911 & 902 & 901 & 867 & 880 & 870 & 877 & 885 & 868 & 876 & 873 & 882 & 828 & 817 & 835 & 342 & 822 & 81.7 & 824 & 823 & 820 & 835 & 809 \\
\hline 233 & 939 & 921 & 903 & 898 & 878 & 835 & .859 & 872 & 882 & 360 & 853 & 864 & 884 & 848 & 836 & 847 & 836 & 833 & 802 & 828 & 816 & 819 & 305 & 777 \\
\hline $234^{\circ}$ & 913 & 904 & 583 & 871 & 850 & 875 & 849 & 844 & 861 & 339 & 816 & 830 & $355^{\cdots}$ & 813 & $843^{\prime \prime}$ & 349 & 838 & 828 & 824 & 343 & 807 & 795 & 808 & 791 \\
\hline 235 & 921. & 908 & 835 & 826 & 835 & 848 & 850 & 358 & 852 & 839 & 309 & 804 & 817 & 796 & 818 & 357. & 858 & 840 & $8 \geq 7$ & 825 & 773 & 785 & 310. & 195 \\
\hline 236 & $\$ 15$ & 900 & 372 & 831 & 829 & 844 & 873 & 1394 & 848 & .947 & 821 & 823 & 320 & 80? & 347 & 885 & 363 & 833 & 819 & 793 & 771 & 503 & 319 & 312 \\
\hline 573 & $\begin{array}{l}\text { CENT } \\
\text { VALU }\end{array}$ & $\begin{array}{l}R^{\prime \prime N} \\
E R:{ }^{R} \\
E S: H E A\end{array}$ & $\begin{aligned} \# & = \\
X & = \\
A N & =\end{aligned}$ & $\begin{array}{r}07521 \\
-870\end{array}$ & $\begin{array}{l}52 \\
103\end{array}$ & & & $\begin{array}{r}C E \#= \\
Y= \\
D E V\end{array}$ & $\begin{array}{l}=2 \\
= \\
=\end{array}$ & 41.00 & & & & $\begin{array}{l}\text { IDAD } \\
\text { NFOR }\end{array}$ & $\begin{array}{l}\text { DA D } \\
\text { COES }\end{array}$ & $P E C$ & $\begin{array}{l}\text { CAO, } \\
\text { ICAS }\end{array}$ & 3 & & TANIF & & & 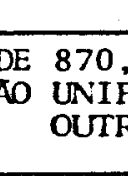 & \\
\hline
\end{tabular}




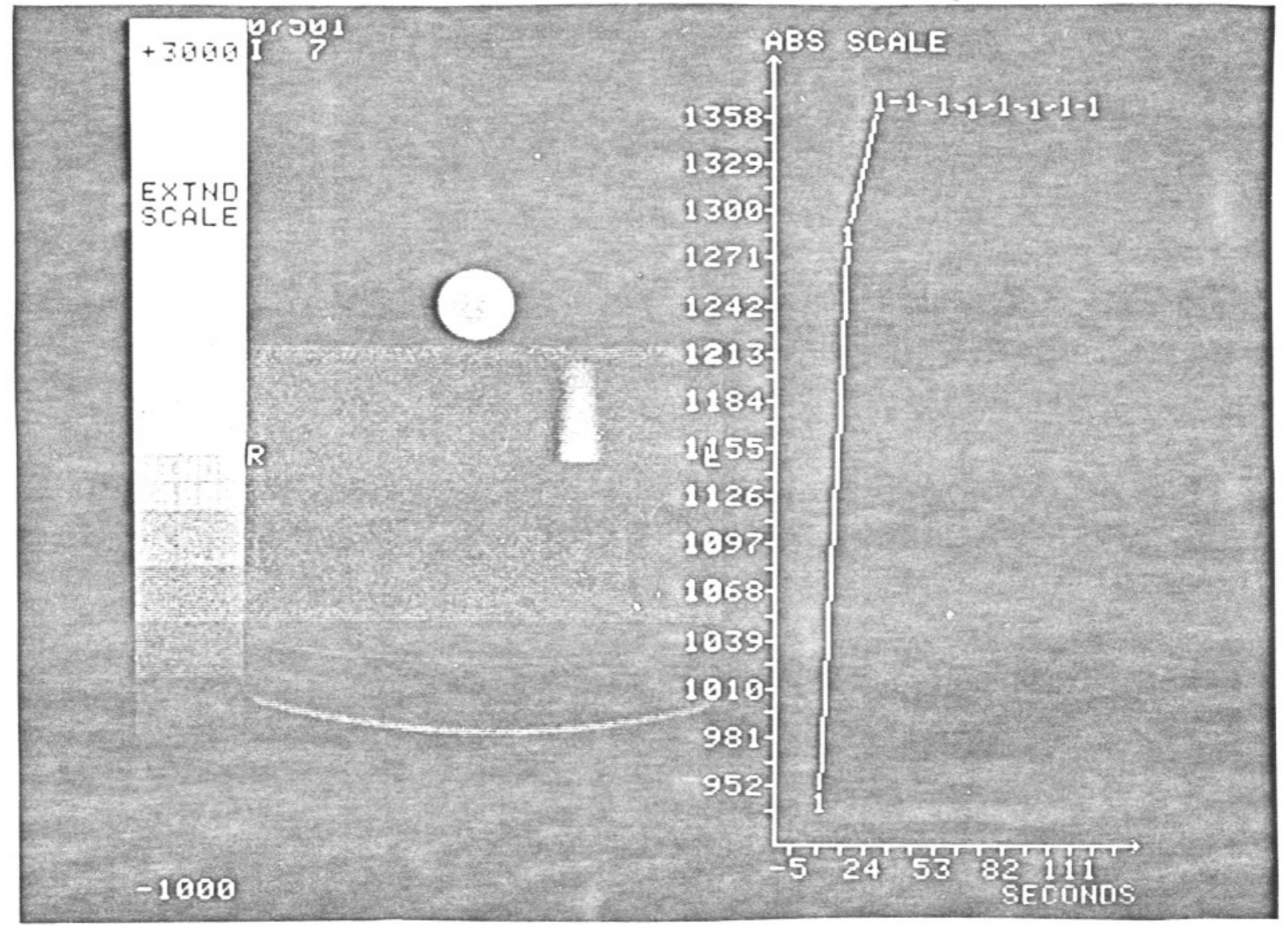

Tomografia 4 - Experimento dinâmico realizado após a introdução de água em uma coluna horizontal onde está sendo mostrada a sua área de secção (corte vertical). São mostradas dez varreduras sequenciais (curva do lado direito) em U.H. (escala absoluta) como uma função do tempo. 0 número 1 representa o ponto indica do na região de interesse.

Na Tomografia 4, vemos a área de secção (corte tomográ fico vertical) de uma seringa horizontal com solo molhado. Fize mos várias varreduras na mesma posição em tempos diferentes (téc nica dinâmica) e escolhemos um círculo para delimitar a região de interesse. 
Utilizando um programa apropriado pertencente ao Siste ma TAC empregado, construímos o gráfico da curva ABS SCALE (em U.H.) em função do tempo (em segundos). o número 1, colocado no interior do círculo indica, na Tomografia 4, a variação do coefi ciente de atenuação ou densidade (em U.H.) com o tempo na área delimitada pelo círculo.

No lado direito, o gráfico mostra através do número 1 , a sequência de varreduras realizadas. Neste experimento, o corte tomográfico ficcu posicionado a 50mm da secção de entrada da água sob pressão na coluna. Isto corresponde a medir uma velocidade mé dia da água no interior da coluna de solo da ordem de $1,6 \mathrm{~mm} / \mathrm{s}$., u ma vez que pela Tomografia 4 é possível observar e medir a rápida velocidade média da frente de molhamento ao atravessar a secção de corte escolhida (cerca de 30 segundos após a introdução da á gua). Empregamos intervalos de varredura de cerca de 5 segundos e espessura da seç̧ão de corte de $1,5 \mathrm{~mm}$.

Também fizemos medidas em diferentes posições e em tem po real (dinâmica) em uma coluna vertical. Neste caso para obter velocidades menores da água, um algodão molhado (embebido com á gua) foi colocado em contato com a extremidade superior (topo) da coluna de solo. Isto pode ser grosseiramente constatado na Tomo grafia 5 . 


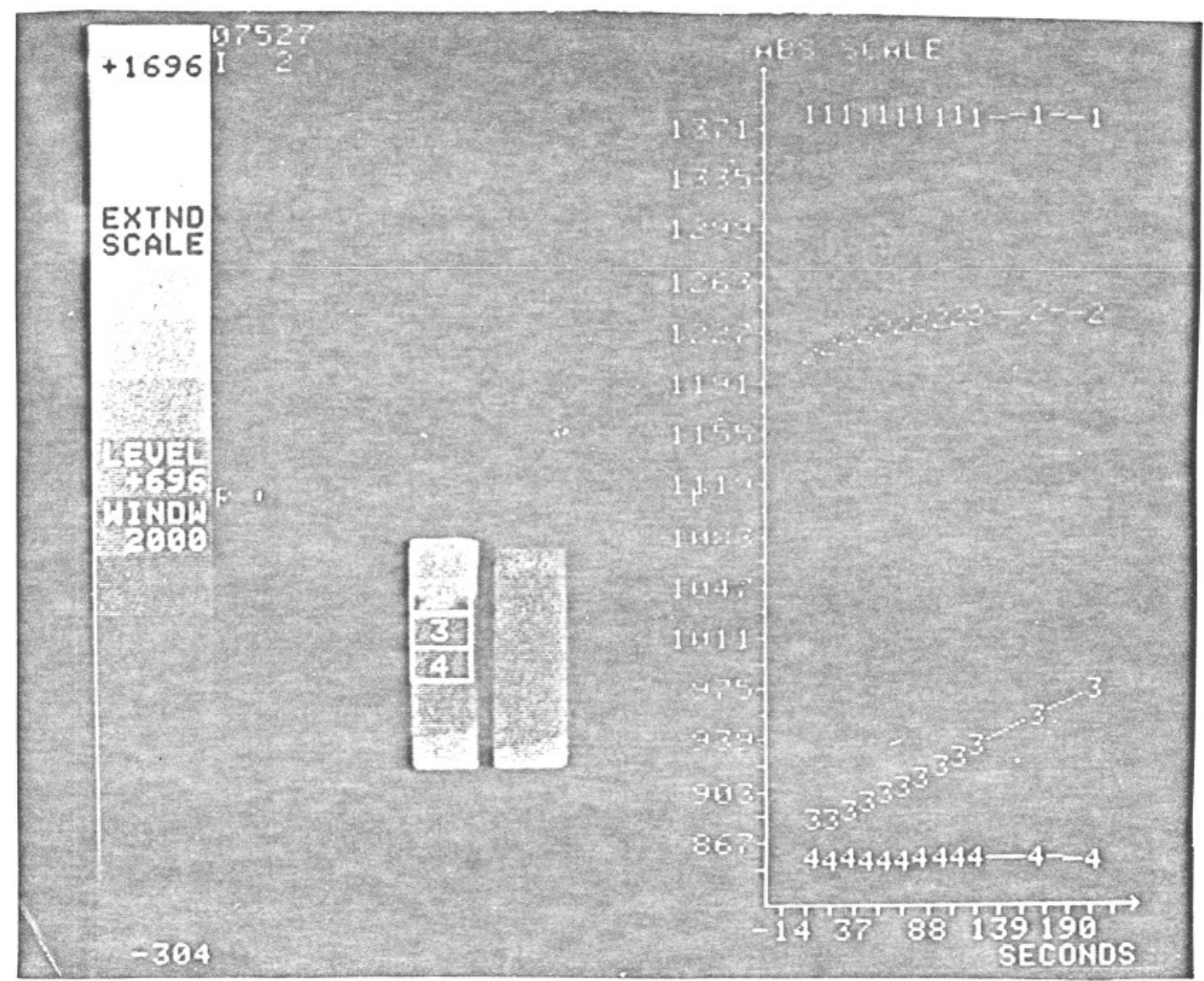

Tomografia 5 - Medida espacial e em tempo real (dinâmica) feita com uma coluna vertical de solo (lado esquerdo) dividida ao meio em di ferentes intervalos de tempo. A atenuação foi medida em diferentes posições mostradas pelas regiões de interesse numeradas por 1,2,3 e 4, de cima para baixo. Do lado direito, graficamos a variação do conteúdo de água (em U.H.) como função do tempo para as diferentes regiões.

A Tomografia 5 mostra que houve um processo de adensa mento do solo localizado na base da coluna. Este efeito foi ob servado e medido. O seu aparecimento é devido ao emprego de um processo diferente de preenchimento da coluna. As partículas mais finas estão localizadas na base, pois o solo foi depositado atra vés do peneiramento direto sobre a coluna e não com um funil, co mo ocorreu no restante dos experimentos e nos aconselha a metodo gia de preenchimento de colunas. Também é possível observar com o auxílio da tabela II que a penetração da água no solo não se dá de forma uniforme, mas apresenta direções preferenciais de movi mento. Da tabela I e Tomografia 5, é possível observar que nestas 
regiões a distribuição de partículas não é homogênea ou é de den sidade diferente (diferente porosidade). Também é interessante ob servar que mesmo tomando todos os cuidados possíveis na prepara ção de uma coluna uniforme (peneiramento do solo, preenchimento com funil, compactação através de pancadas uniformes, bem distribuídas e de mesma intensidade utilizando um martelo de borracha, etc.) isto na prática não ocorre totalmente. Este é um fato impor tante do ponto de vista experimental, pois no método da rađiação $\gamma$ supõe-se, como vimos no Capítulo III, que na medida do conteúdo da água no solo a densidade global seja uniforme e constante.

A Tomografia 5 assim como as tabelas I e II evidenciam claramente o que já havíamos constatado nas Tomografias 2 e 3 e Figuras 25 e 26: as U.H. dependem diretamente de pelo menos dois fâ tores quais sejam a densidade global $\rho_{g}$ e o conteúdo da água no solo $\theta$.

A Tomografia 5 foi realizada a partir de uma série de varreduras na mesma posição e em diferentes intervalos de tempo. Com isto foi possível medir a atenuação em diferentes regiões da coluna, partindo-se do topo para a base, com as regiões de inte resse indicadas pelos números $1,2,3$ e 4 .

Na Tomografia 5 (lado direito), mostramos um gráfico da variação do conteúdo da água (em U.H.) como função do tempo pa ra as diferentes regiões. A Figura 27, construída a partir destes dados, ilustra o movimento da frente de molhamento em três tempos diferentes. Com isto, reproduzimos um resultado real conforme ilustrado genericamente na Figura 2 (Capítulo II) e que nos permite calcular a difusividade hidráulica do solo num deter minado instante. Embora a Figura 2 ilustre a infiltração horizon tal, não se nota diferença da Figura 27. Nesta, a água foi intrô duzida sob pressão, anulando assim a influência do termo corres pondente ao gradiente gravitacional. 


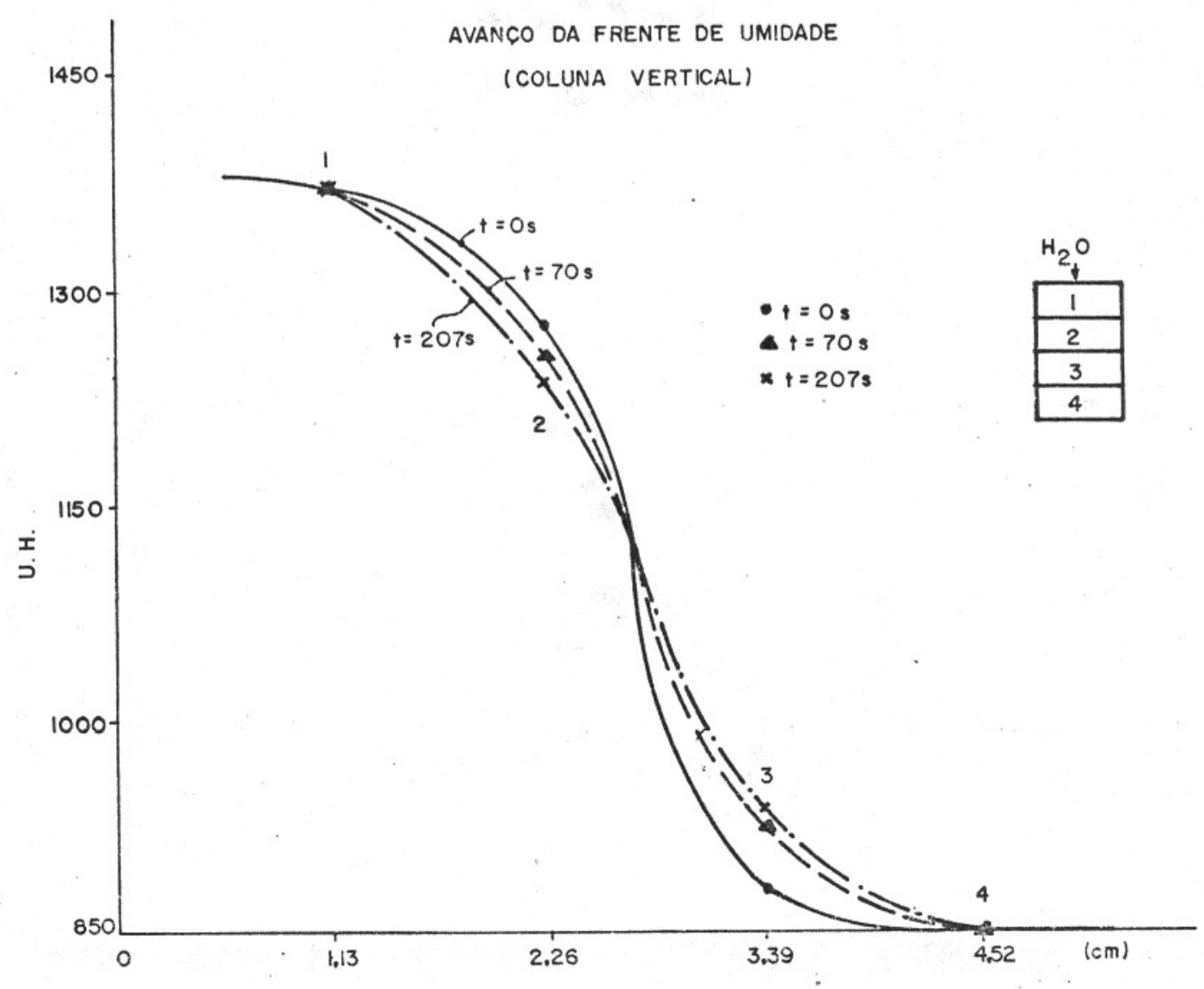

Figura 27- Avanço da frente de umidade (em U.H.) da coluna vertical (1ado esquerdo) da tomografia 5 em função da posição em três instan tes diferentes. Os números $1,2,3$ e 4 acima indicados também cor respondem aos da tomografia 5. Compare esta figura com a equivalente Figura 2 (Capítulo II) da infiltração horizontal.

A Tomografia 6 , mostrada a seguir, foi realizada para - mesmo sistema e configuração da Tomografia 5. Nela mostramos um gráfico que consideramos muito instrutivo, obtido dos dados do ěㅡ perimento da Tomografia 5, onde colocamos no eixo vertical as di ferenças de conteúdo da água aas diferentes regiões 1, 2, 3 e 4 como função do tempo. 


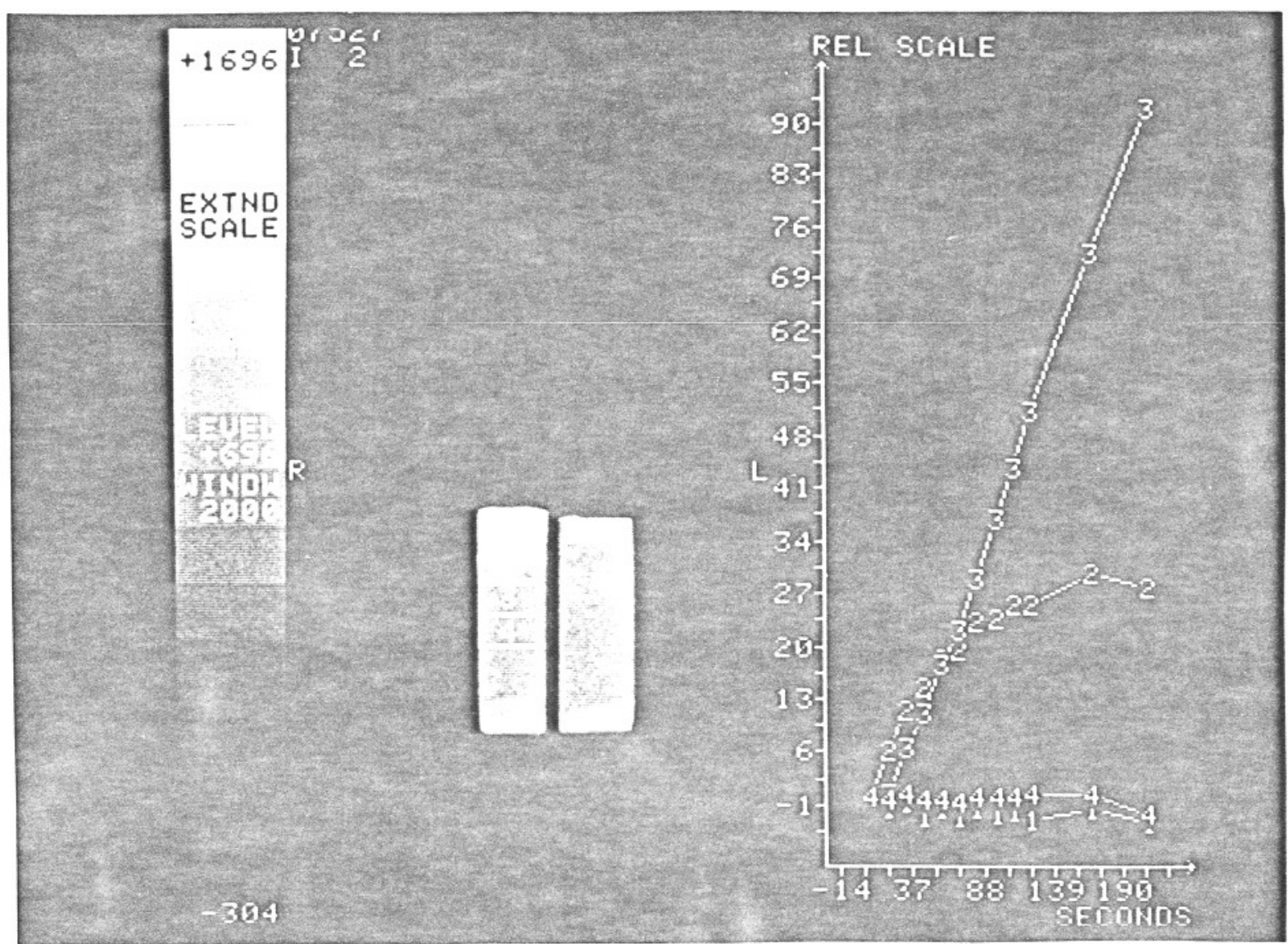

Tomografia 6 - Com a mesma configuração descrita na tomografia 5, construímos acima o gráfico das diferenças de conteúdo de água(em U.H. - escala relativa - ) das diferentes regiões $1,2,3$ e 4 co mo função do tempo. Por exemplo, na região 3, podemos observar um acréscimo contínuo do conteúdo de água apresentando uma variação relativa mais drástica. Isto mostra a presença da frente de molha mento nesta região.

Na região de interesse denotada pelo número 1, o con teúdo de água torna-se constante (há saturação) rapidamente (num tempo da ordem de 15 segundos). Na região 2, podemos ver heteroge neidades mas o valor médio do conteúdo de água aumenta com o tem po e atinge um valor médio intermediário. Na região 3 há um cres cimento contínuo do conteúdo da água com uma variação relativa mais drástica, indicando claramente que a frente de molhamento es tá atravessando esta região (isto também pode ser visto nas tomo grafias 5 ou 6, lado esquerdo). Finalmente, como na região 1, que atingiu um valor praticamente constante (e portanto com variação nula), a região 4 ainda não recebeu água e portanto a variação do seu conteúdo de água ou coeficiente de atenuação é também praticâ mente nula. 
94.

\section{CAPÍTULO VI}

\section{OUTROS RESULTADOS DA TOMOGRAFIA COMPUTADORIZADA POSSÍVEIS DE SEREM APLICADOS EM ESTUDOS DO SISTEMA ÁGUA - SOLO - PLANTA}

Pretendemos, através deste capítulo, acrescentar ao an terior alguns resultados que obtivemos da aplicação da T.C. ao sistema água - solo - planta.

E nossa intenção apresentar os resultados de forma qua litativa, acrescido de alguns comentários conforme as conveniências, sem no entanto entrar na análise quantitativa dos mesmos.

Queremos mostrar o potencial do novo método introduzido no Capítulo V, evidenciando as grandes possibilidades de sua u tilização na obtenção de novos resultados (que até então não e ram possíveis) em áreas como a da Ciência do Solo, da Física da Agua no Solo, da Fisiologia Vegetal e outras afins.

Essas novas possibilidades são consequências das pecu liaridades deste novo método. É o caso da reconstrução bi e tridị mensional da imagem do objeto (como a do solo, a da água, a da se mente, a da raiz, etc.), das medidas absolutas e relativas da den sidade global e da umidade do solo com o tempo, da deteç̧ão de inohomogeneidades, e assim por diante. Além disto, recursos como a técnica dinâmica e a ampliação da resolução da imagem (escala estendida) poderão ser, em seguida observadas.

\section{1 - INFILTRAÇÃO VERTICAL: EFEITO DA COMPACTAÇÃO \\ E DA UMIDADE DO SOLO}

Tem sido comum ${ }^{(112)}$ constatar a compactação dos solos a grícolas submetidos a intensa mecanização agrícola. Este problema cresce em relevância na mesma proporção em que a agricultura se moderniza e passa a depender cada vez mais do trabalho das máqui 
nas. É sabido que a compactação do solo, mesmo que seja somente dos primeiros centímetros de sua camada superior, acarreta altera ções muito importantes do ponto de vista das suas propriedades hi dráulico-mecânicas (erosão, aeração, capacidade de retenção da á gua, velocidade de infiltração, drenagem, etc.). Do ponto de vis ta da planta as consequências decorrentes podem ser muito graves no que se refere aos aspectos do seu crescimento, da sua fixação, do desenvolvimento de suas raízes, e das deficiências nutricio nais afetando diretamente a produção final ${ }^{(*)}$.

Ainda mais, com a ampliação das práticas culturais que se utilizam da irrigação ou mesmo da drenagem, não somente o efẹ to da compactação torna-se relevante, mas também, com cada vez mais frequência, o efeito do molhamento inicial do solo. A Figura 4 (capítulo II) ilustra este último efeito na taxa de infiltração da água no solo, numa situação genérica.

Estes dois efeitos alteram a velocidade de infiltração da água no solo assim como a velocidade da frente de umidade (tan to a da água natural da chuva como a da água administrada artifi cialmente através da irrigação). Essas alterações poderão ser ve rificadas observando os resultados das tabelas III e IV juntamen te com as Tomografias 7,8 e 9, realizadas em condições de labora tório e que passamos a apresentar.

(*) A título de informação queremos observar que conforme a refe rência 114 , foi iniciada, em 1982, na Universidade de Purdue (EUA) uma pesqui sa para identificar os efeitos da compactação de superfície no desenvolvimento e na produção do milho cultivado após a soja. A compactação do solo nas parce las do tratamento foi causada por dezesseis passagens de um grande trator de tração dupla. Após esta operação, as parcelas foram aradas, gradeadas e semea das. A parcela compactada, comparada com outras não-compactadas, mostrou uma redução na altura da planta (de 20 a 30\%) levando a uma diferença de $1883 \mathrm{Kg} / \mathrm{ha}$ na produção final. Os solos compactados produziram $8161 \mathrm{Kg} / \mathrm{ha}$ e os solos não compactados produziram $10.044 \mathrm{Kg} / \mathrm{ha}$. Foi constatada também que a compactação a presentou variação no grau de dano, ao longo da mesma cultura de milho causan do a chamada "síndrome do milho alto - milho baixo". Já foi também constatado que durante as operações de colheita, realizadas com o solo úmido, muitos agri cultores criam problemas de compactação similares a estes da experimentação. 


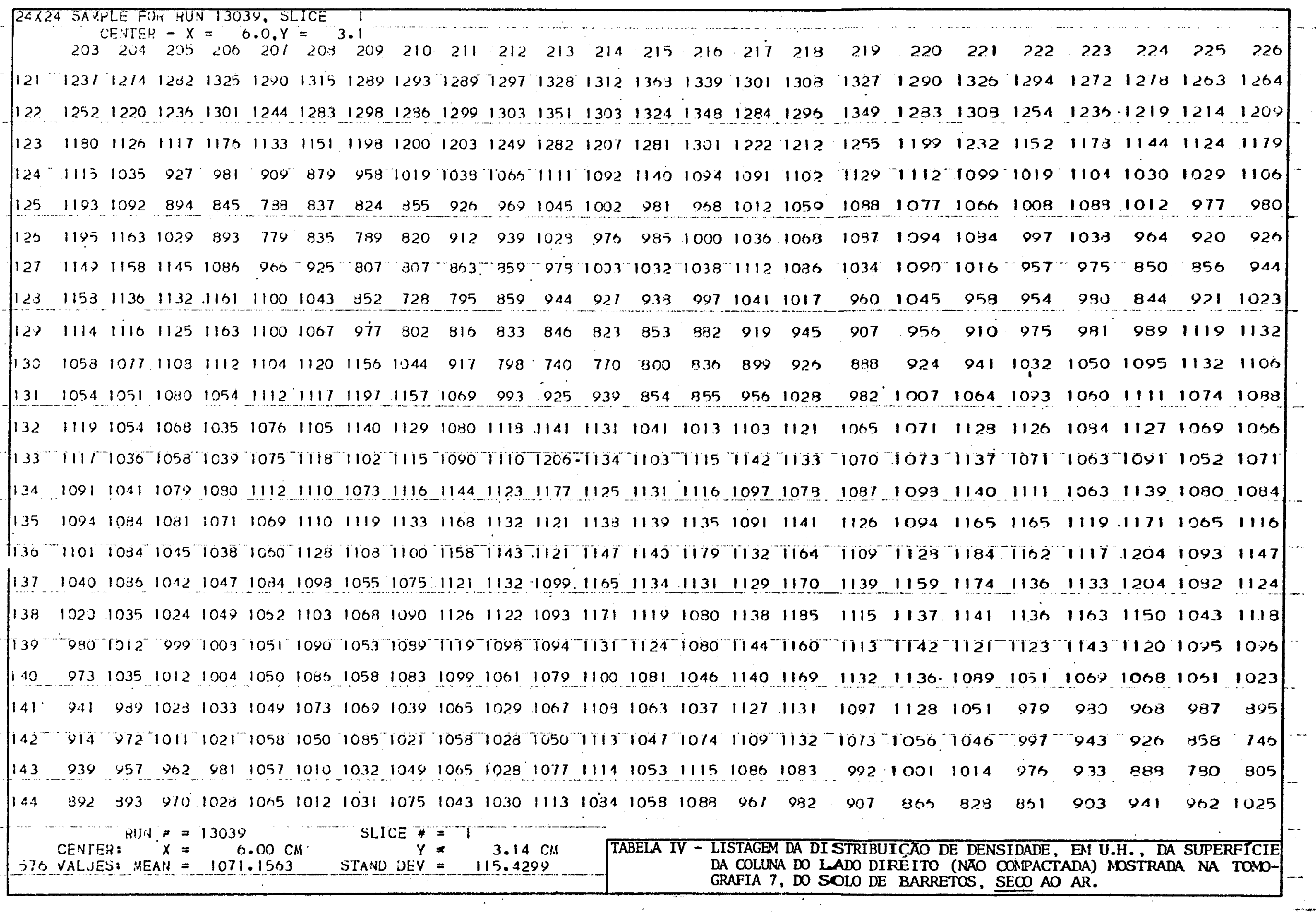




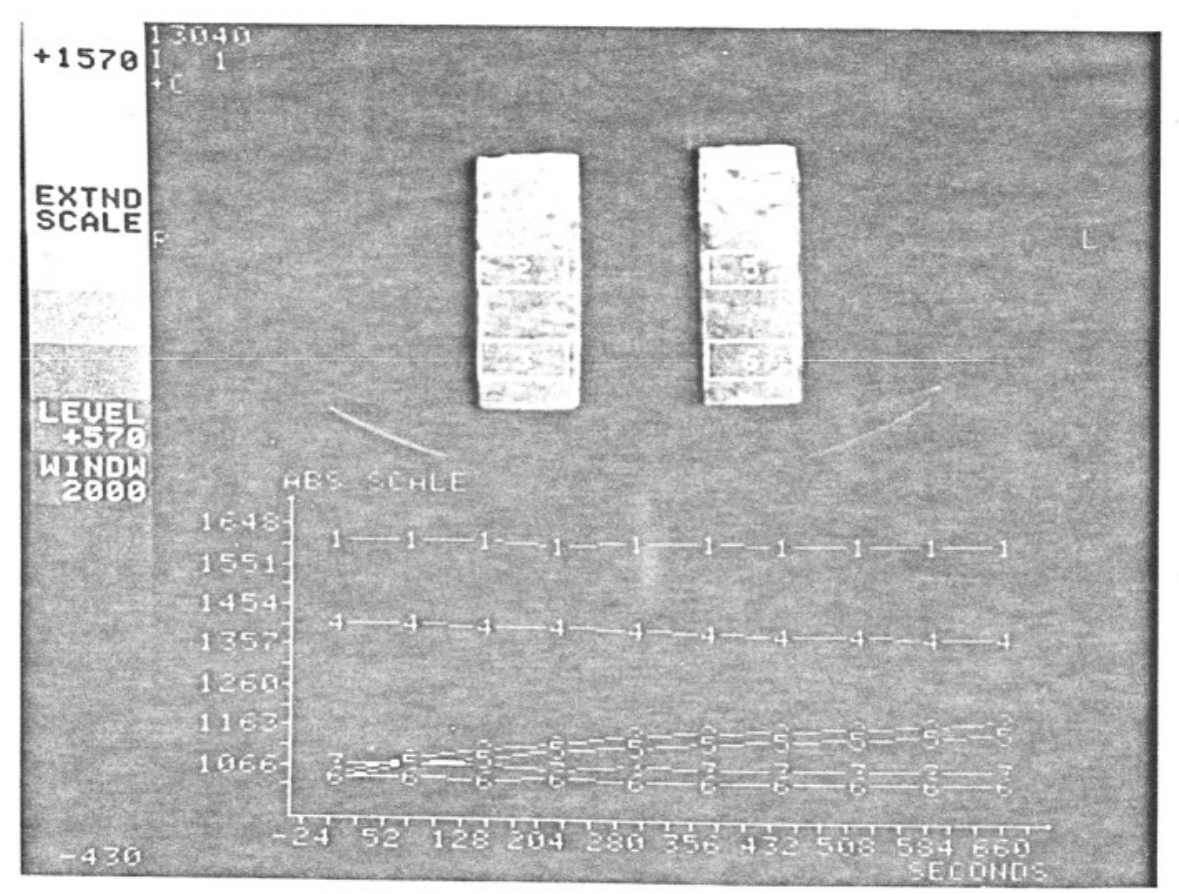

Tomografia 7 - As duas colunas são retangulares com dimensões de $25 \mathrm{~cm}^{2}$ de base e $14 \mathrm{~cm}$ de altura de solo de Barretos. A coluna do lado esquerdo (leitor) foi compactada na superfície (ver tabelas III e IV). Foram simultâneamente distribuídos $40 \mathrm{ml}$ de água em cada coluna. O gráfico permite observar a distribuição vertical da água, nos primeiros 660 segundos, através das regip̃es de inte resse 1,2 e 3 da coluna compactada e 4, 5 e 6 da coluna não com pactada.

As tabelas III e IV listam a distribuição da densidade do solo seco ao ar (em U.H.) dos primeiros milímetros da camada superior das duas colunas mostradas na Tomografia 7. Pode-se ver a diferença sensível entre as colunas com suas densidades médias na região de interesse iguais a 1298,2 U.H. e 1071,16 U.H., simu lando com isto uma coluna compactada na superfície.

Do experimento, foi possível distinguir diferenças nas velocidades de infiltração do solo compactado em comparação com o solo não compactado. Neste último, a velocidade de infiltração é maior, o que era de se esperar, pois o número de poros disponí veis na camada superior é maior. Da Tomografia 7, praticamente não se nota uma diferença sensível na velocidade média da frente de molhamento (compare as curvas 2 e 5 do gráfico). É preciso con siderar aqui vários fatores que estão intervindo, para podermos compreender o resultado. Se por um lado a velocidade de infiltra 
ção da coluna não compactada é maior, por outro lado a duração da carga hidráulica (peso da coluna de água sobre o solo) é menor. Deste modo um efeito está compensando o outro. Deve-se levar em conta também que as duas colunas encontravam-se inicialmente se cas antes da distribuição de $40 \mathrm{ml}$ de água sobre cada uma delas. Logo, o gradiente de umidade (força de difusão) pode estar preva lecendo sobre os outros efeitos (carga hidráulica e compactação).

Deve-se considerar também o efeito da não-uniformidade das colunas, principalmente a não compactada (é visível na tomo grafia 7), o que pode estar também alterando as áreas de capilari dade disponíveis.

As diferenças entre as curvas 1 e 4 advêm de pelo menos dois fatores importantes: diferença de densidade e de conteúdo de água no solo, nas regiões 1 e 4 .

No caso da coluna compactada a sua densidade na super fície é maior, o que por sua vez leva a uma menor porosidade. Lo go o solo satura com umidade menor do que com o solo de porosida de maior (não compactado).

As tabelas III e IV assim como a Tomografia 7 possuem o objetivo de exemplificar, em um caso simples, as complexidades envolvidas na interpretação de resultados do movimento da água no solo. Principalmente quando o método ou a técnica disponível é su ficientemente sensível aos vários fatores que governam tal movi mento.

Desta forma, a Tomografia Computadorizada poderá trạ zer resultados e interpretações interessantes e mais realísticas, utilizando-se dos recursos disponíveis desta técnica e do contro le das variáveis que porventura possam mascarar os efeitos que queremos observar.

A Tomografia 8 mostra as duas colunas da Tomografia 7 acompanhadas de mais uma construída nas mesmas condições mas de densidade média um pouco menor (em torno de 590 U.H. na cama da superior). 
100.

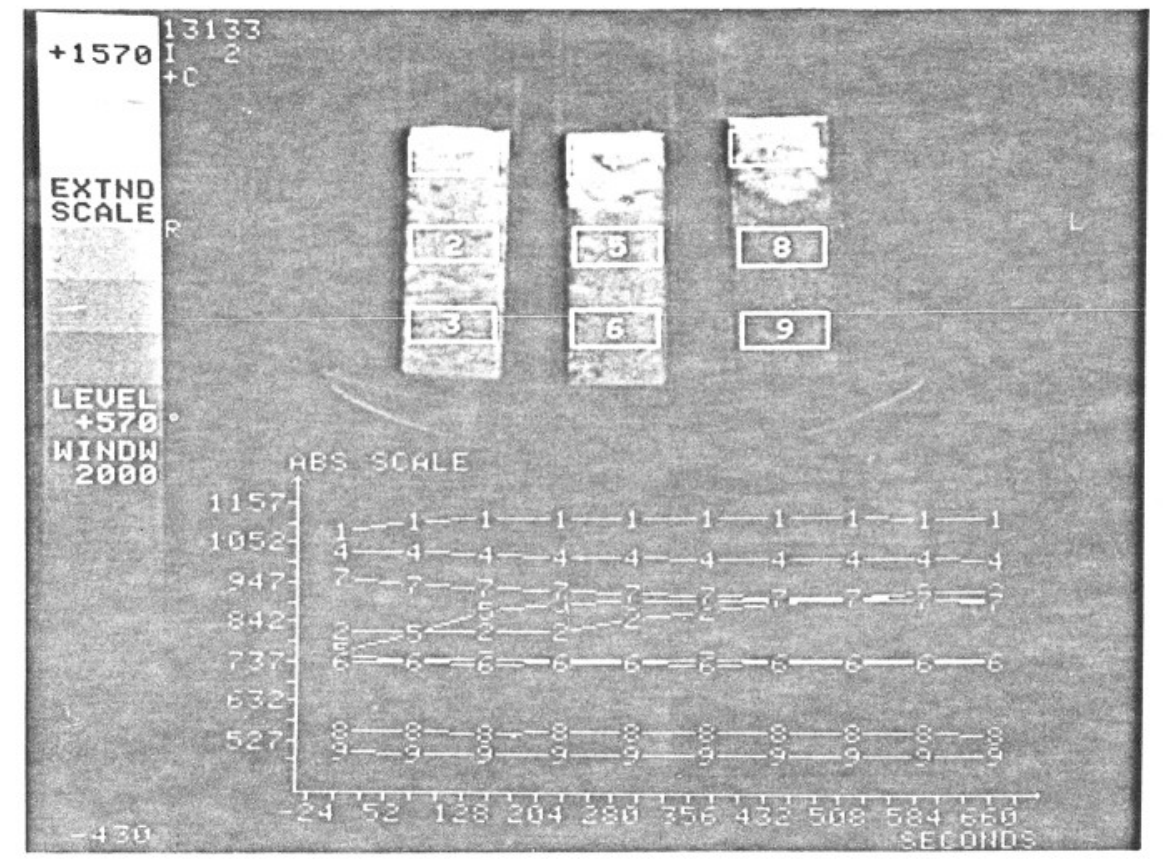

Tomografia 8 - Distribuição vertical da água no solo em três colu u nas onde as duas primeiras da esquerda para a direita já estavam molhadas (conforme revela a Tomografia 7). A primeira coluna da esquerda está compactada na superfície e a terceira recebeu água pela primeira vez. Foram distribuídos simultaneamente 40m1 de á gua nas três colunas, que contém a mesma massa de solo. São visí veis as diferenças devido a compactação e ao molhamento inicial.

As curvas 2, 5 e 8 evidenciam os efeitos mostrados na Tomografia 7 (efeitos de compactação) assim como a influência do molhamento inicial. É bastante clara a diferença entre as curvas 2 e 5 quanto ao avanço da frente de molhamento. Esta se move mais rapidamente em 5 do que em 2. Por sua vez a água ainda não che gou em 8 (isto pode ser visto tanto pelo gráfico como pela tomo grafia observando o contraste claro e escuro na primeira coluna da direita). Isto era de se esperar pois como o solo encontrava -se inicialmente seco, o número de poros disponíveis era maior do que nos outros dois casos (anteriormente molhados) em que os po ros já se encontravam parcialmente preenchidos. O resultado é bas tante parecido com o do avanço da frente de molhamento da água num solo arenoso (número menor de microporos) quando comparado a um argiloso (número maior de microporos). 
No entanto, a velocidade de infiltração é maior no so 10 inicialmente seco, desaparecendo rapidamente com isto a compo nente de carga hidráulica.'

As curvas 3 e 6 mostram que nesta região as duas prị meiras colunas da esquerda para a direita possuem a mesma densidạ de e por sua vez são maiores que a da região.9. As curvas 8 e 9, por outro lado, demonstram não haver grandes diferenças de densi dade entre o meio e a base da terceira coluna, demonstrando ainda que a água não chegou na região 8 nos primeiros 660 segundos de observação.

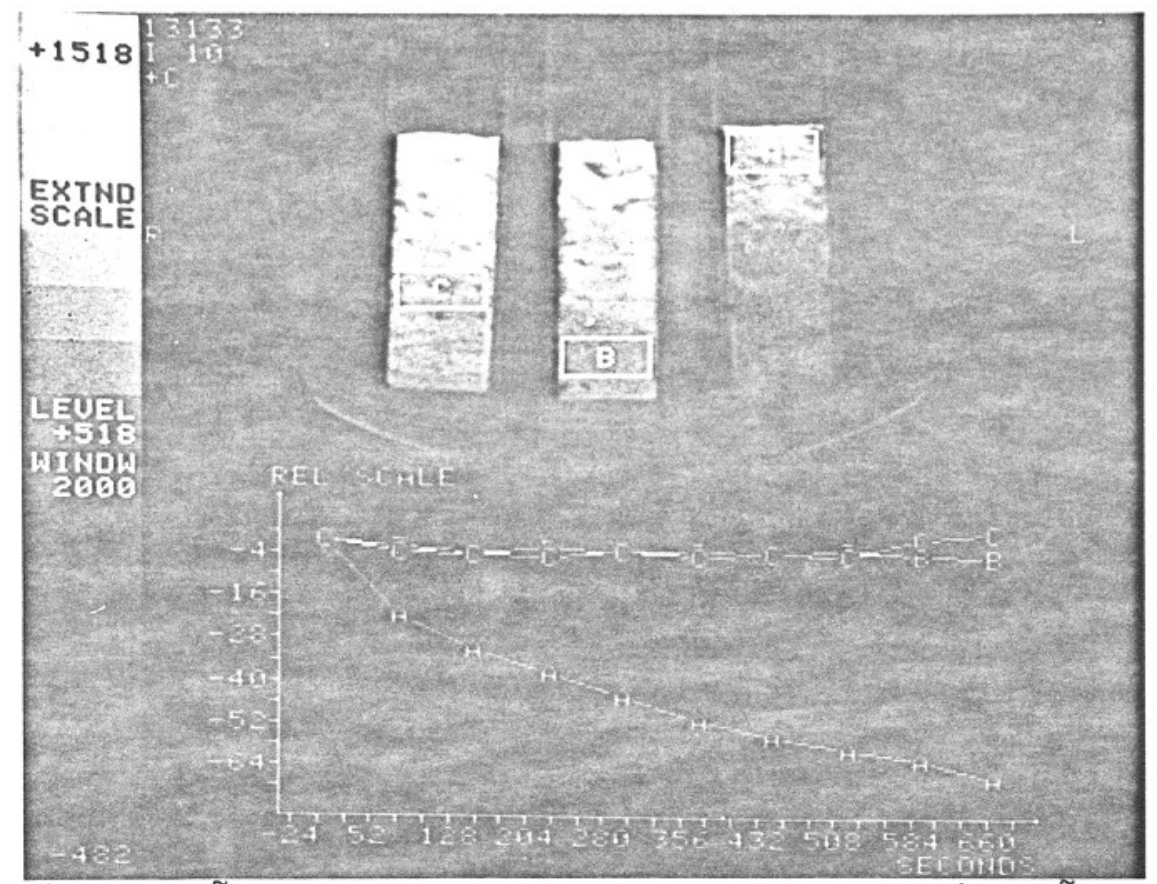

Tomografia 9 - São mostradas as mesmas colunas na situação da tomo grafia $8, \operatorname{com} \mathrm{A}, \mathrm{B}$ e C indicando as posições das regiões de inte resse. No gráfico mostra-se também a variação relativa da densida de em U.H. com o tempo. B e C praticamente não mudaram durante o tempo de observação (a água ainda não atingiu estas regiões), en quanto que a região A está perdendo água.

A tomografia 9 traz uma escala relativa onde os efei tos da compactação e do molhamento inicial são explicitados. A ve locidade da frente de molhamento da coluna que possui a letra C (compactada) é menor que a da coluna que possui a letra B (não compactada) assim como a região da letra A está perdendo água ra pidamente. Neste caso, o termo de gradiente de umidade prevalece. É também bastante sensível a diferença entre as curvas B-C e A, onde em 660 segundos houve uma variação de densidade da ordem de 70 U.H. . 


\section{2 - SIMULAÇÃO DINÂMICA E TRIDIMENSIONAL DE IRRIGAÇÃO POR GOTEJAMENTO EM UMA COLUNA DE SOLO}

A exemplo da secção 6.1, a irrigação por gotejamento possui um enorme interesse prático. No entanto, pouco se conhece do ponto de vista teórico sobre a solução analítica da Equação de Darcy em três dimensões, principalmente considerando as condições de contorno específicas desta situação (um elemento complicador importante é a fonte de água discreta) ${ }^{(*)}$. Do ponto de vista expe rimental, as técnicas usuais empregadas em Física de Solos, como por exemplo a da radiação $\gamma$ (estudada no Capítulo III), não permi tem acompanhar tridimensionalmente a frente de umidade, nem mesmo em duas dimensões (plano horizontal). Devido a estas limitações é que apresentaremos em seguida algumas tomografias, gráficos e plā nos de corte, que poderão fornecer uma nova contribuição neste im portante estudo ${ }^{(* *)}$.

(*) No capítulo II discutimos alguns aspectos da infiltração da á gua no solo em uma dimensão e pudemos constatar o grau de dificuldade ineren te, mesmo sob condições de contorno apropriadas. A solução da Equação de Dar cy, em duas ou três dimensões, no caso geral torna-se praticamente impossível.

(**) Reproduzimos, em seguida, alguns trechos da referência 115 , que relata alguns resultados preliminares da pesquisa sobre irrigação por gote " jamento iniciada no Instituto Agronômico de Campinas, em 1982 e que contribui para fundamentar o que afirmamos nesta secção: "Um dos métodos de irrigação mais auspiciosos surgidos nestes últimos anos foi o do gotejo, que propicia e conomia de material, de mão-de-obra e de água, o que constitui a razão de sua grande aceitação por parte de técnicos e agricultores. A elaboração de proje tos de irrigação por gotejo não é muito simples. Depende do conhecimento de da dos locais, principalmente os relacionados com a qualidade da água, tipo de so 10, evaporação de superfície livre de água, distribuição desta no solo, bem co mo do sistema radicular da planta. Esses dados são indispensáveis para calcu lar o número e a vazão dos gotejadores. Tratando-se de sistema que trabalha com pequena vazão e baixa pressão e que umedece apenas parte (25 a 40\%) do sis tema radicular da planta, necessita um dimensionamento cuidadoso para ser bem sucedido." Ainda mais: "Mesmo Israel e Austrália, que empregam o método há al guns anos, desenvolvem numerosas pesquisas a respeito, para confirmação dos re sultados que vem sendo obtidos. Não obstante o enorme interesse que esse méto do tem despertado em diversos países, como Israel, Austrália, Estados Unidos, México, África, Brasil, etc., verifica-se escassez de resultados experimentais para orientar os trabalhos." 
que estamos afirmando.

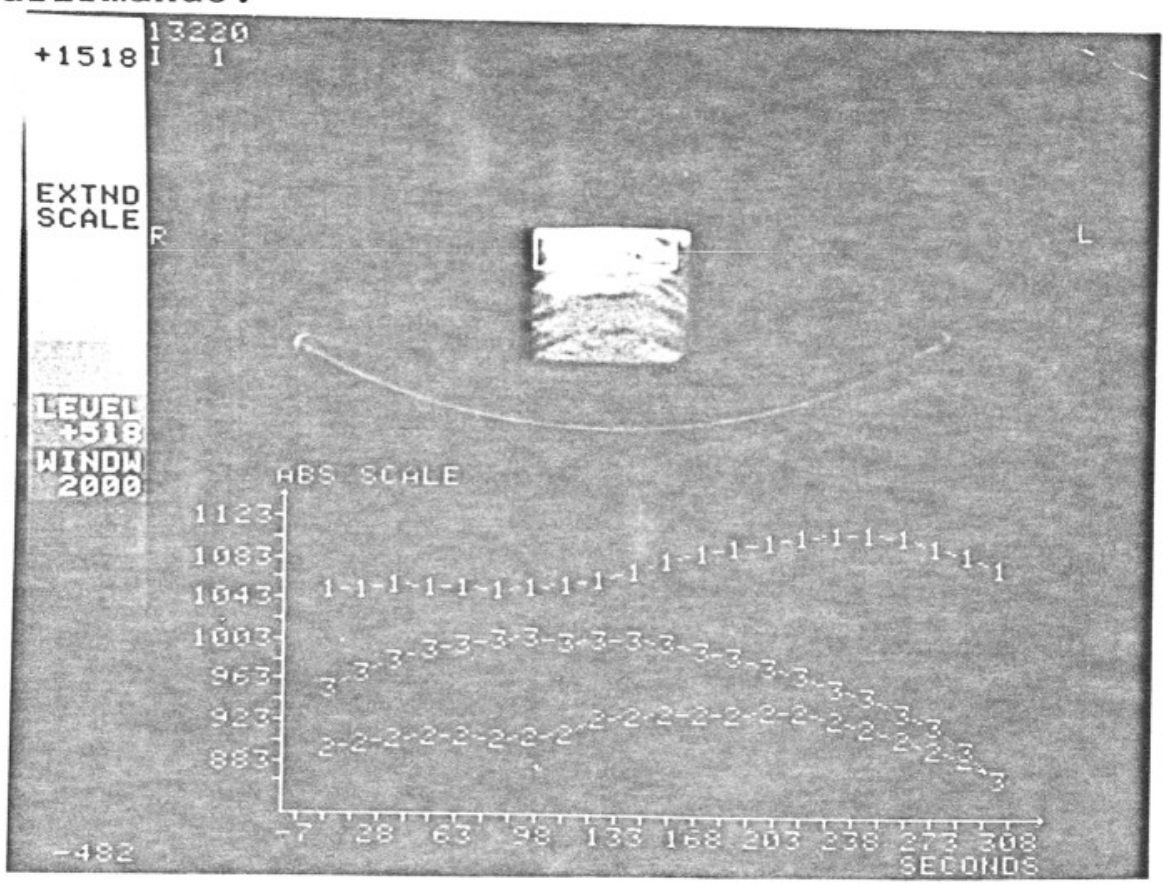

Tomografia 10 - Coluna cilíndrica de $7,5 \mathrm{~cm}$ de altura de solo de Barre tos e que possui $8,3 \mathrm{~cm}$ de diâmetro interno sendo submetida a goteja mento de fluxo de água constante e igual a $4,8 \mathrm{~cm}^{3} / \mathrm{min}$. É possível ob servar, a partir dos pontos 1,2 e 3 indicados, a distribuição da á gua no plano horizontal em função do tempo, medidas em U.H. e segun do. Note que a água caminha preferencialmente mais para a região 3 do que para a região 2 .

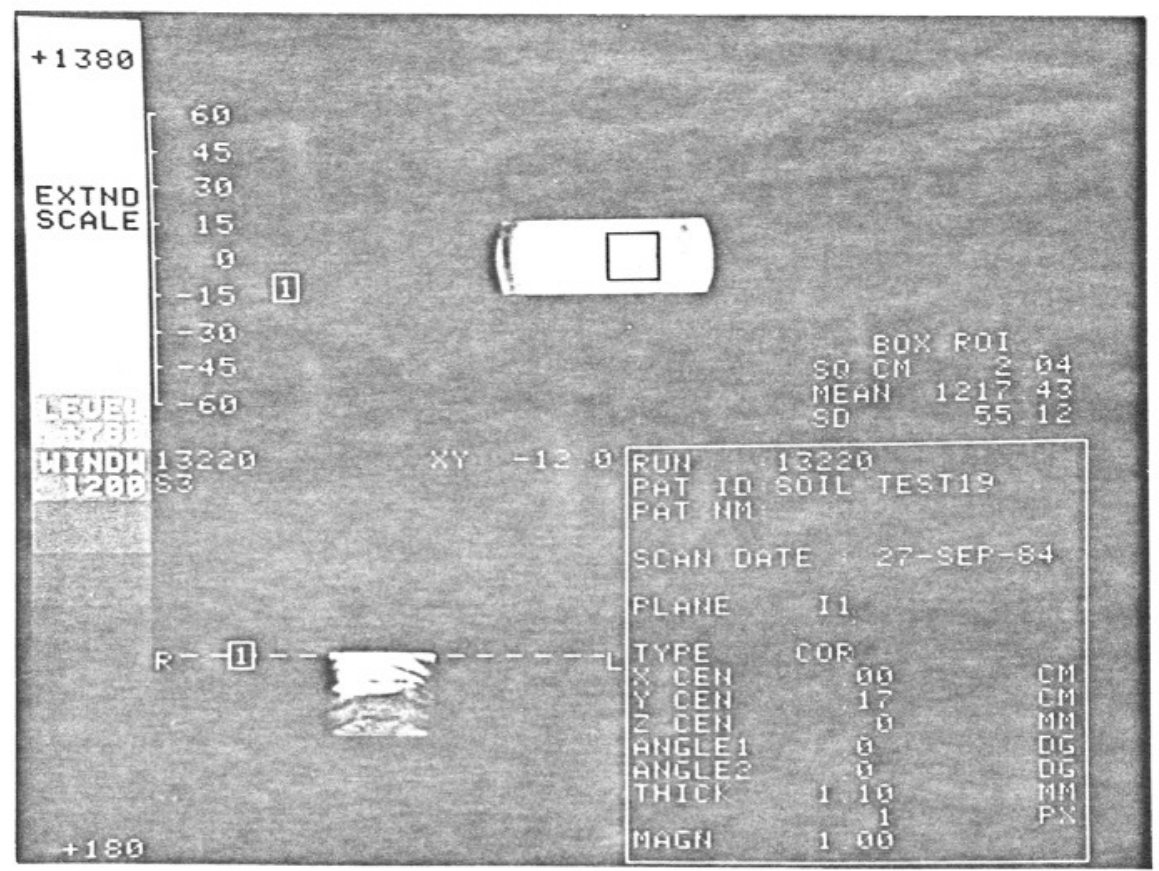

Tomografia 11 - Corte coronal da coluna de solo mostrada na tomografia 10, na posição indicada acima. Pode-se observar e medir a distribuição de água em uma secção do plano horizontal. Está indicada uma medida da densidade (em U.H.) do retângulo assinalado (1217,43 U.H.).Confirma-se a preferência da água movimentar-se mais para a esquerda (leitor) do que para a direita (respectivamente posições 3 e 2 da tomografia ante rior). 


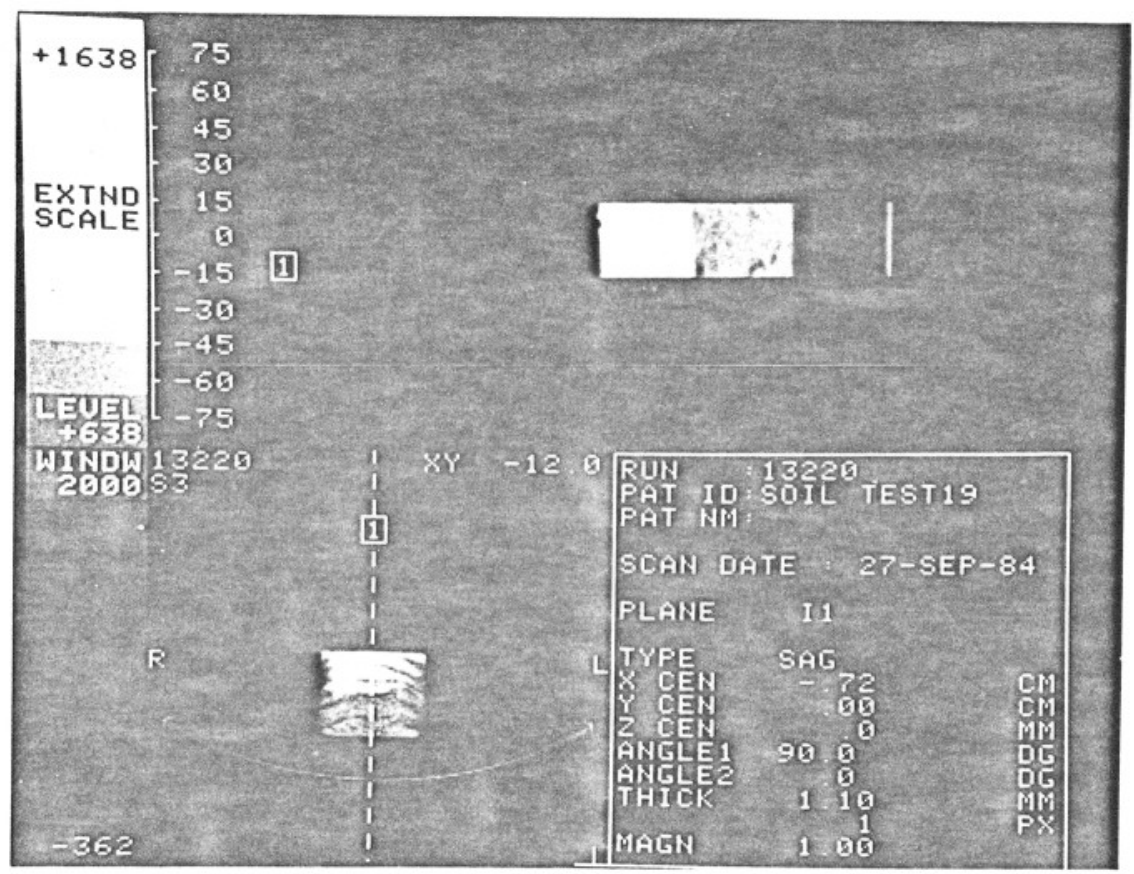

Tomografia 12 - Corte sagital da coluna de solo mostrada na tomografia 10, na posição indicada. Observe a distribuição da água em uma secção do plano vertical 1 . É possível ver acima detalhes como um corte do pequeno buraco produzido pelo choque das gotas de água sobre o solo.

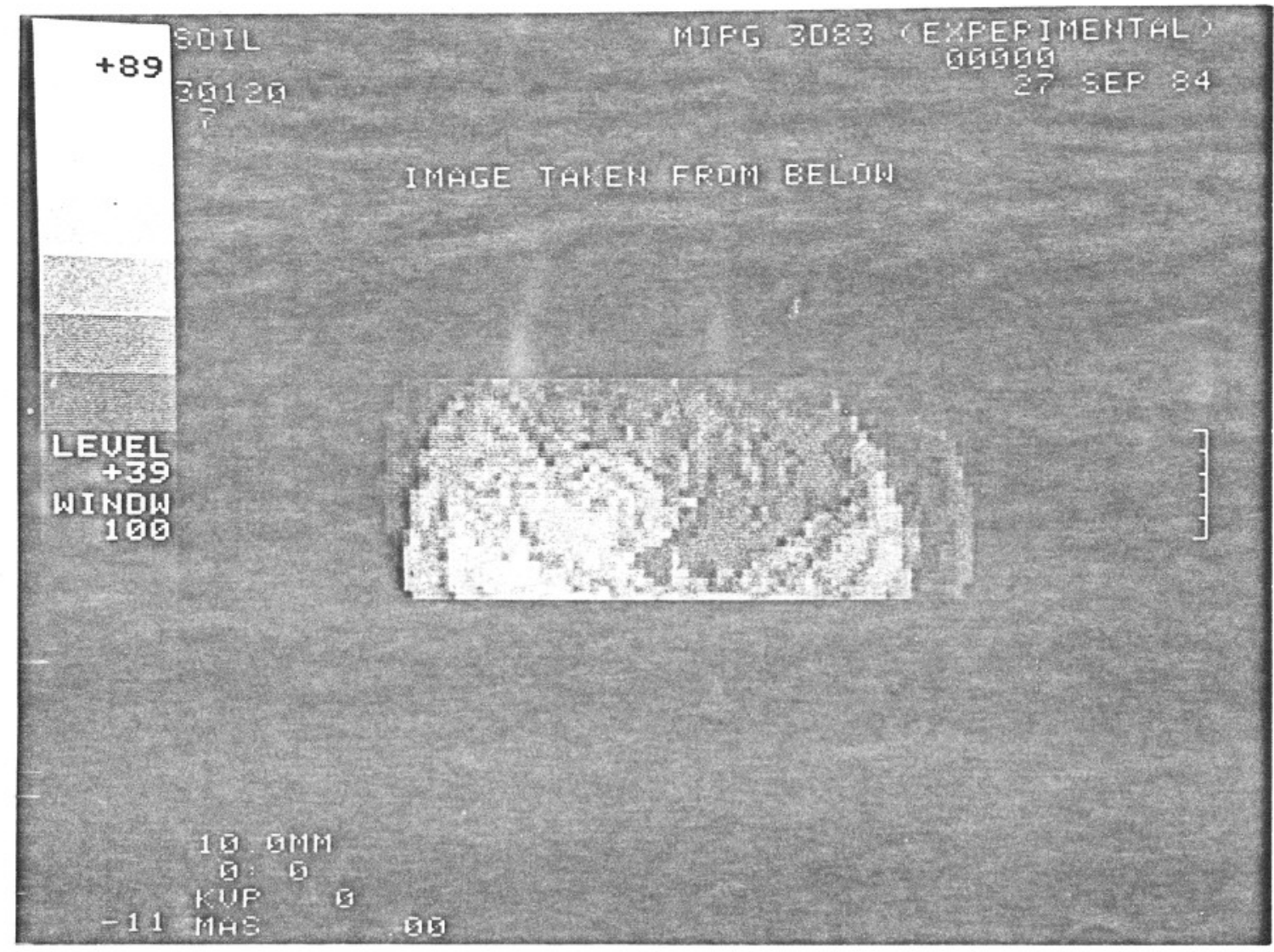

Tomografia 13 - Reconstrução tridimensional da imagem do escoamento da água no solo, simulando irrigação por gotejamento, vista de baixo para cima (infiltração horizontal e vertical da frente de molhamento). Pode-se verificar detalhadamente os contornos (fronteiras) da água no solo. 


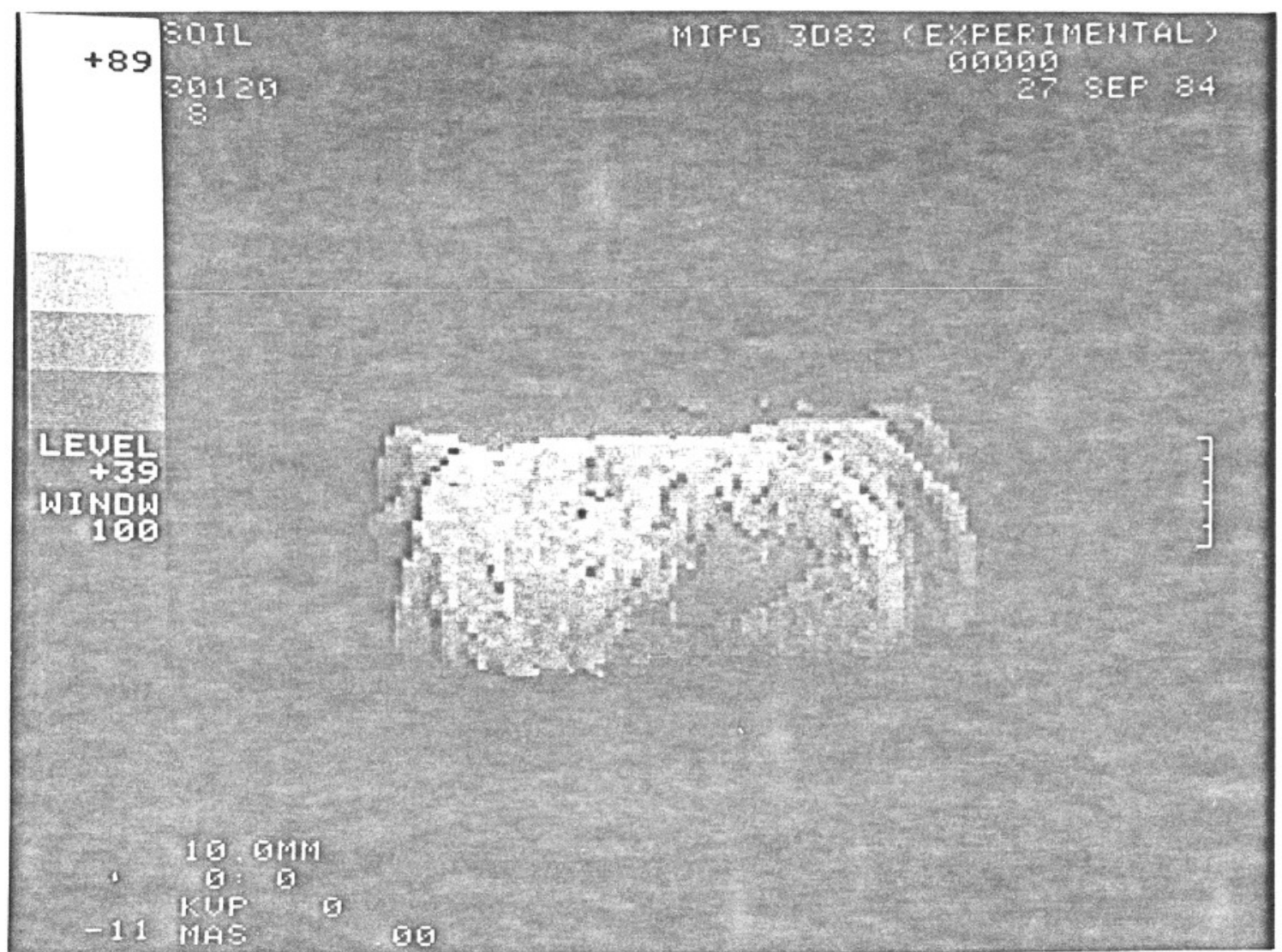

Tomografia 14 - Outra vista tridimensional, sob outro ângulo, do experi mento de simulação de irrigação por gotejamento. Consegue-se assim ob servar detalhadamente o avanço da frente de molhamento para qualquer ân gulo, plano ou posição num dado instante de tempo, em função do interes se do observador.

As imagens tomográficas que apresentamos permitem oㅁ servar, com riqueza de detalhes, a presença de direções preferen ciais do movimento da água no solo. Isto certamente ocorre devido a não existência de uniformidades do solo como diferentes densida des, compactações, condutibilidades hidráulicas além de possíveis buracos ou mesmo maior ou menor dificuldade em remover o ar dos poros de modo a poder penetrá-los.

A Figura 3 ou mesmo 4 do Capítulo II, comparadas com os resultados desta seção, evidenciam a distância que existe en tre o escoamento real da água no solo (escoamento tridimensional e irregular) do escoamento previsto por modelos unidimensionais ou mesmo bidimensionais $(116,117)$. 
As técnicas experimentais de transmissão direta atual mente existentes também não permitem obter os resultados que aca bamos de mostrar $(118,119)$.

\section{3 - MÉTODO NÃO-DESTRUTIVO DE OBSERVAÇÃO DINÂMICA E BIDI MENSIONAL DA GERMINAÇÃO E. CRESCIMENTO DE UMA SEMENTE ASSIM COMO DA ABSORÇÃO DE ÁGUA PELAS RAÍZES}

A exemplo das seções anteriores aqui também a aplica ção da tomografia computadorizada a estudos dos processos físi cos e químicos envolvidos na germinação de uma semente, no cres cimento radicular de uma planta, na evapotranspiração (equivalen te a um potencial matricial) também poderão fornecer subsídios que permitam observar novos resultados nos diferentes campos da Física de Solos, da Nutrição de Plantas, da Morfogenia e da Fí siologia Vegetal.

o fato do método ser não-destrutivo traz vantagens, possibilitando estudos que envolvem, por exemplo, a seleção gené tica de melhores sementes e plantas, estudos de estatística de germinação, crescimento de nódulos na leguminosas e evapotranspi ração (*).

A seguir apresentamos alguns resultados obtidos.

(*) Conforme entendimentos preliminares (seminário realizado) que mantivemos com o CENARGEN (Centro Nacional de Recursos Genéticos) da EM BRAPA - Brasília, será possível aplicar o método da Tomografia Computadoriza da a estes estudos. Neste sentido, estamos organizando um trabalho de coopera ção conjunta, que deverá iniciar-se brevemente. 


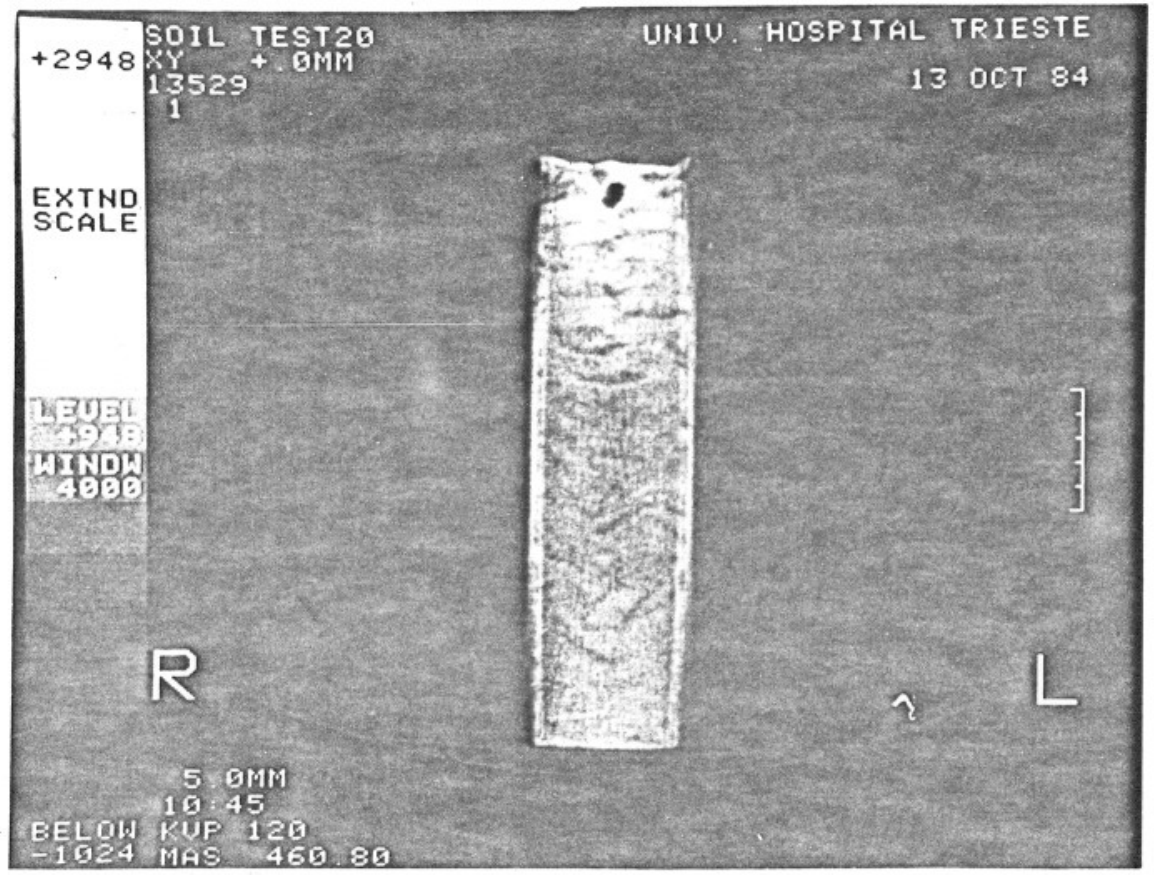

Tomografia 15 - Vista tomográfica de uma coluna cilíndrica de solo de Barretos de $25 \mathrm{~cm}$ de altura e diâmetro interno de $5,7 \mathrm{~cm}$ contendo um grão de milho no seu interior antes da germinação. Observe a presença de inohomogeneidades na distribuição de densidade da colu na, assim como a presença de água no topo e na base da mesma.

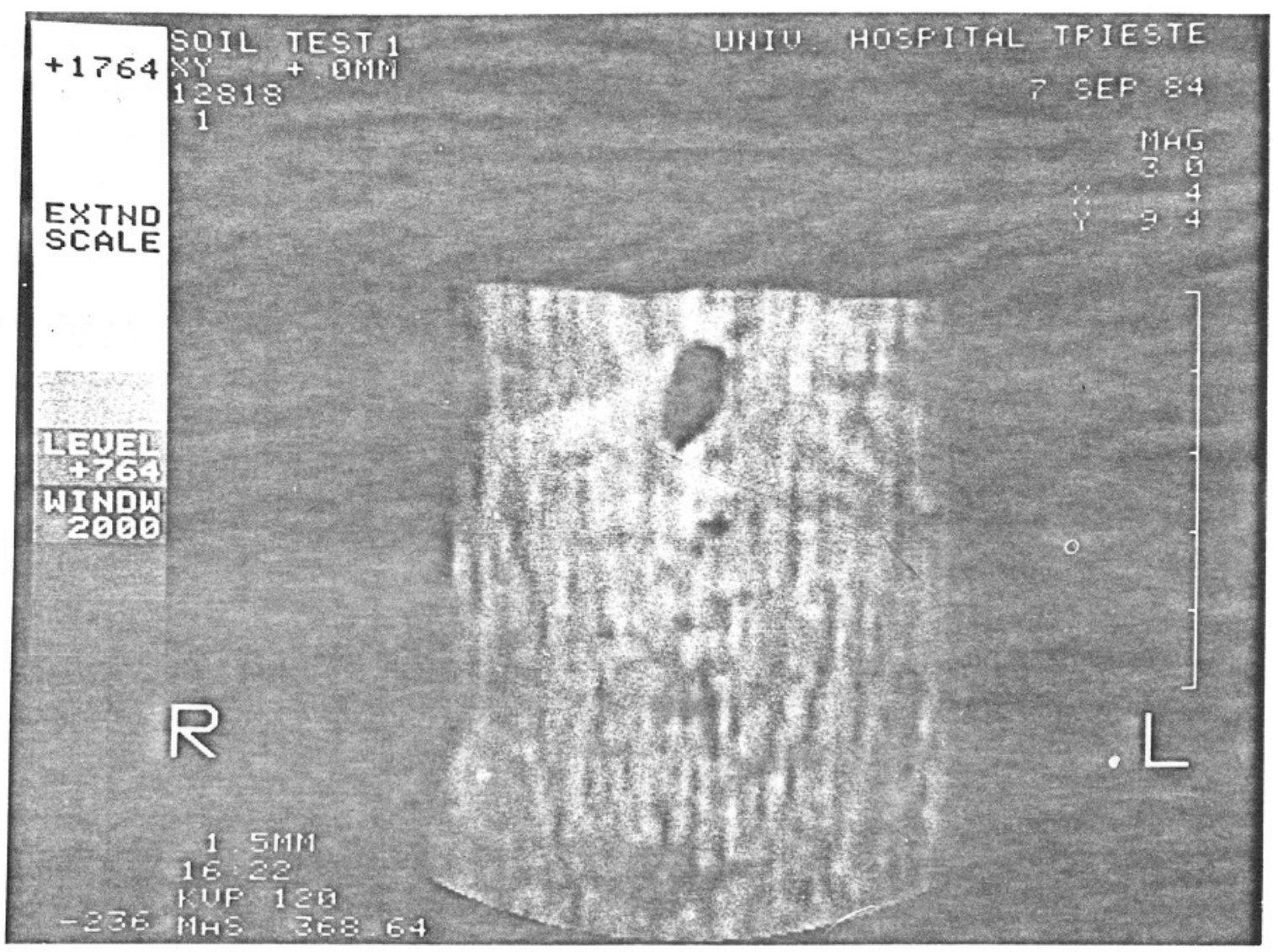

Tomografia 16 - Vista tomográfica de outro grão de milho visto de outro ângulo onde o recurso da ampliação da imagem foi usado, per mitindo observar maiores detalhes na região da semente. 


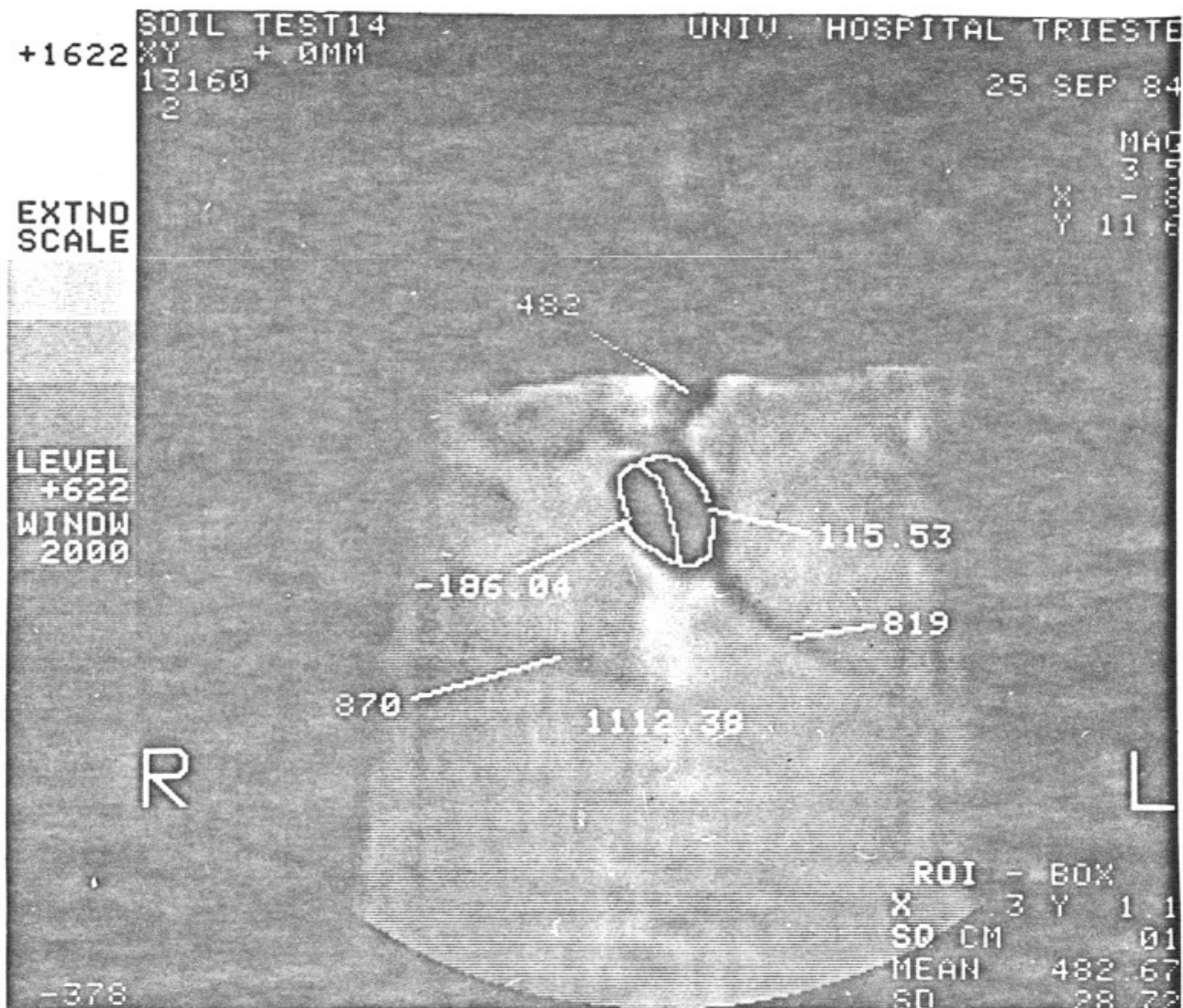

Tomografia 17 - Vista tomográfica bidimensional da semente anterior (to mografia 16) já germinada, onde podem claramente ser observadas e medidas a umidade do solo (1112,38 U.H.), a densidade das raízes (819 U.H. e 870 U.H.), a densidade da semente (115,53 U.H. e -186 U.H.), assim como a da planta (482 U.H.). Como nas tomografias anteriores, po de ser notada a presença de inohomogeneidades. Medidas periódicas das densidades (do solo, da semente, das raízes) na mesma posição ou em di ferentes ângulos permitem acompanhar detalhadamente a germinação da sê mente, o desenvolvimento das raízes, assim como o seu processo de absor ção de água e nutrientes, a distribuição e redistribuição de água na cô luna :...

As tomografias mostradas estão em duas dimensões. No entanto, uma visão tridimensional e temporal também é possível. Isto pode ser feito através do programa apropriado do computador de reconstrução de imagem tridimensional usando a técnica dinâmi ca de medida (a exemplo das tomografias 13 e 14) ou mesmo através de várias tomografias bidimensionais em diferentes ângulos e tem pos. 
Finalmente, é interessante observar que medidas perió dicas da região da semente nos mostraram que do início até o fi nal do processo de germinação a densidade média da semente passou de um valor de 267,90 U.H. para $-15,97$ U.H., com uma variação do desvio padrão de 102,86 para 212,92 respectivamente. Após a germi nação a semente passou a apresentar pelo menos duas regiões dis tintas: uma clara, de densidade média igual a 115,53 U.H. e outra escura, de densidade média igual $-186,04$ U.H.. Sabemos que valo res negativos das U.H. significam a presença do ar. Deste modo tu彑 do evidencia que o processo de germinação da semente se realiza a partir do maior consumo de nutrientes de uma dada região da semen te, restando no final um buraco com ar. o alto valor do desvio padrão (maior que o valor da própria medida) é uma demonstração da alta não uniformidade da região medida, o que seria o caso da presença de um buraco com ar. Maiores estudos neste sentido são requeridos antes de quaisquer conclusões. No entanto, fica eviden ciada a possibilidade de maiores investigações locais, bi ou trí dimensionais, dinâmicas e não destrutivas de uma dada região de interesse através dessa nova técnica introduzida. 
110.

\section{CAPÍTULO VII}

\section{ALGUNS COMENTÁRIOS E CONCLUSÕES FINAIS}

Apresentaremos, a seguir, como parte final deste traba lho, alguns comentários e conclusões que consideramos pertinen tes.

o Capítulo II nos permitiu formalizar o problema do mo vimento da água no solo através da Equação de Darcy (II-3), aco plada à equação da continuidade (II-4).

Aplicamos o resultado a duas situações de interesse, quais sejam, o estudo da infiltração horizontal (II-13) e da in filtração vertical (II-24). Mostramos, dentre outras coisas, a im possibilidade de resolvê-las analiticamente no caso mais geral, mesmo considerando condições iniciais e de contorno apropriadas como expressam respectivamente as equações (II-14) e (II-22). A razão da impossibilidade de solução analítica geral encontra-se na natureza altamente não-linear da Equação de Darcy, onde a con dutividade e a difusividade hidráulica, relacionadas pela equação (II-11), desempenham um papel decisivo.

o cálculo da condutividade ou da difusividade propi ciam importantes resultados a respeito do fluxo da água no solo, do avanço da frente de molhamento e outros que podem ser vistos no Capítulo II.

Fizemos referência a alguns métodos numéricos de solu ção, inclusive recentes como é o caso daqueles citados nas refe rências 36 e 37 . Os resultados obtidos advêm de modelos, que na maioria das vezes, baseiam-se em hipóteses que simplificam drastị camente o movimento real da água no solo. Tais modelos, em geral, são unidimensionais e consideram o solo como um meio poroso homo gêneo e uniforme, o que nem sempre pode ser considerado verdade ro. 
111.

Os cálculos da difusividade hidráulica (II-21), em ge ral, são feitos com o auxílio de medidas experimentais conforme a Figura 2 nos ilustra num caso genérico.

Desta forma foi imprescindível discutir no Capítulo III os métodos experimentais existentes de medidas como a da den sidade global, como a do conteúdo da água no solo, como a da velo cidade da frente de molhamento e assim por diante.

0 método da transmissão direta de raios $\gamma$ - tanto o de feixe monoenergético como o de feixe de dupla energia - destạ ca-se em relação ao gravimétrico e ao TDR (método bastante recen te), apresentados.

Mesmo assim é preciso considerar uma série de limitạ ções atinentes. Destacamos, como principais, as seguintes:

a) as medidas são unidimensionais [ainda assim, o valor cal culado é uma média sobre o percurso do feixe, não permi tindo observar variações puntuais ou segmentares (hetero geneidades) sobre este];

b) não é sensível à medida de velocidades altas como no cạ so da infiltração vertical da água em solos de alta con dutividade hidráulica (É o caso, por exemplo, da infil tração vertical da água em uma areia grossa, com penetra ção de $70 \mathrm{~cm}$ de água em 20 minutos ${ }^{(34)}$ ). Isto dificulta ou mesmo impede estudos dinâmicos.

c) supõe que. a densidade global é constante quando $\circ$ feixe de raios $\gamma$ monoenergéticos é utilizado (o que não é ver dade, como por exemplo, no caso de solos com argilas ex pansivas) ${ }^{(46,47)}$, além da dificuldade de colimação ou cọ mo no caso de dupla energia, pouca disponibilidade de fontes adequadas. No último caso a situação é mais difí cil pois os "picos" da radiação $\gamma$ precisam ser bastante 
distintos para evitar interferência na medida dos deteto res. Além do mais os erros ocorridos na medida da densí dade global são transferidos para a medida do conteúdo da água no solo e vice-versa, podendo comprometer a pre cisão das medidas.

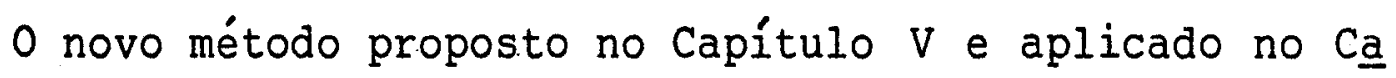
pítulo VI, faz uso da Tomografia Computadorizada cujos fundamen tos foram enunciados no Capítulo IV. Mostramos que o método da tô mografia - em concordância com outros resultados independen tes $(113,120)(\S)$, além de permitir a medida dos parâmetros anterior mente citados traz outras vantagens com contribuições novas, an tes inviáveis de serem alcançadas. É o caso de estudos não destrú tivos, dinâmicos, bi e tridimensionais, de sensibilidade a hetero geneidades do solo e da distribuição da água, conforme pode ser visto nos capítulos citados.

No entanto, antes de enunciar as principais conclusões obtidas, queremos fazer algumas considerações a respeito da ins trumentação utilizada.

Um ponto, em princípio criticável, é o de que o tomó grafo médico é um instrumento muito caro e portanto inacessível às pesquisas na área de Física da Água no solo ou outras em que o método pode ser útil.

Admitindo esta verdade, temos dois pontos a ponderar. o primeiro é que os grandes hospitais possuem pelo menos um des tes aparelhos com horário ocioso, principalmente à noite.

A ampliação do uso do tomógrafo como para os fins refe ridos nesta tese, pode contribuir para diminuir o seu custo ho ra/atividade. Esta é uma possibilidade que consideramos como con creta e real. 
Outro ponto a considerar, é que os estudos da Física da Água no Solo ou afins, não exigem um instrumento do porte de um tomógrafo médico. Um instrumento dedicado, muito mais simples e acessível pode ser desenvolvido (Veja o Apêndice, Figuras 28 e 29 ). No caso da tomografia médica, conforme já discutimos nos Cạ pítulos IV e $V$, restrições como a dose de radiação a ser ministra da ao paciente impõem limitações nas condições de operação do tú bo de $\mathrm{R}-\mathrm{X}$ como $\mathrm{KV}$ e mAs. O movimento e o posicionamento do pacien te também limitam o tempo de aquisição de dados, assim como o seu "design" e funcionamento. O fato da reconstrução da imagem ser feita imediatamente à coleta dos dados, exige programas específi cos e algorítmos mais elaborados, obrigando a presença de um com putador de alta potência. A qualidade da radiação (espectro) tam bém é limitada. Se a KV do tubo é alterada, o espectro também é alterado. Por outro lado, como os programas de reconstrução da $\underline{i}$ magem são elaborados para atuarem em um pequeno intervalo de ra diação, aparecem os artefatos quando são solicitadas atuações des tes programas em intervalos maiores.

Por exemplo, aparentemente seria interessante usar di ferentes $\mathrm{KV}$. No nosso caso, utilizamos $120 \mathrm{KV}$ e fomos obrigados a trabalhar, muitas vezes, no limite de potência do sistema. No entanto, os nossos estudos adicionais (Ver Apêndi ce) mostram a eficiência do minitomógrafo de raios $x$ ou $\gamma$ usado para medidas de Física da Água no Solo. Dos mesmos estudos (Apên dice: Figuras 31 e 32 ), utilizando diferentes energias, pudemos concluir que existe um intervalo ótimo de energia para investiga ções tomográficas do solo (ou mesmo investigações por transmissão direta). A faixa ideal para distinguir a água do solo de Barretos situa-se na região de 30 a $40 \mathrm{Kev}$ e não de $60 \mathrm{Kev}$ (como é o caso da energia da fonte de $\mathrm{Am}^{241}$, comumente empregada em estudos de Física ae Solos) ou de $70 \mathrm{Kev}$ (que corresponde ao valor médio da 
energia do espectro da radiação-X empregada na maioria dos tomó grafos médicos).

0 mini-tomógrafo dedicado apresenta outras vantagens $\underline{a}$ lém do menor custo. Possui maior versatilidade (permite alterar a energia monocromática mudando o "alvo" fluorescente secundário), adequando-o ao fim específico que se tem em vista (por exemplo, estudar o movimento da água no solo, a presença de inohomogeneida des, a presença de poluentes como metais pesados, o movimento da água carregada de solutos e outros).

Com a mudança do sistema de detecção, também é possí vel estudar a presença de componentes do solo como está expresso na Figura 33 do Apêndice. Além disso, com um programa apropriado é possível simular previamente a imagem a ser vista experimental mente (Figura 30).

Considerando estes comentários, e os resultados dos Cạ pítulos V, VI e Apêndice, podemos obter várias conclusões básicas que a seguir resumimos:

a) A Tomografia Computadorizada pode ser usada para obser var e medir quantitativamente a densidade global e o conteúdo da água no solo através das suas relações $1 \underline{\underline{i}}$ neares com os coeficientes de atenuação lineares expres sos em Unidades Hounsfield, conforme mostrado nas Figu ras 25 e 26, respectivamente. Portanto, a Tomografia Computadorizada é um novo método experimental para estụ dos da Física da Água no Solo;

b) A Tomografia Computadorizada pode ser usada em estudos dinâmicos (em tempo real) do movimento da água no solo, incluindo velocidades tão rápidas quanto $1,6 \mathrm{~mm} / \mathrm{seg}$, con forme pode ser visto, por exemplo, através da tomogra fia 4 ; 
c) A Tomografia Computadorizada pode ser usada para a ob tenção de informações sobre heterogeneidades presentes na distribuição da densidade global e do conteúdo de á gua no solo, além de informações tridimensionais usando a técnica dinâmica ou o programa de reconstrução apro priado conforme pode ser constatado, por exemplo, atra vés das tomografias 6,14 e 15;

d) A Tomografia Computadorizada pode ser usada para forne cer as distribuições espaciais e temporais simultâneas do conteúdo da água no solo, conforme mostrado nas Tomo grafias 5 e 6 ;

e) A declividade da dependência linear das Unidades Hounsfield com o conteúdo da água $\theta$ (Figura 26) varia com o solo, mas é independente da densidade global $\rho g$ para o mesmo solo. Esta conclusão mostra que a grandeza expressa em Unidades Hounsfield, é uma função de pelo menos duas variáveis: $\theta$ e $\rho_{\mathrm{g}}$, isto é, a imagem tomográ fica do solo é de fato uma função pelo menos bidimensio nal. No Apêndice, mostramos a dependência do coeficien te de atenuação (proporcional às U.H.) com o conteúdo de água $\theta$ (Figura 32) e com a energia dos fótons inci dentes (Figura 31). No entanto, nos nossos experimentos do Capítulo V e VI, mantivemos a energia constante, man tendo a voltagem do tubo constante (120 KV). Portanto, é preciso levar em conta a dependência bidimensional das U.H., na interpretação quantitativa de uma tomogrạ fia de solo;

f) A Tomografia Computadorizada pode trazer resultados com pletamente novos devido as suas peculiaridades como as listadas em $\underline{a}, \underline{b}, \underline{c}, \underline{d}$ e $\underline{e}$, além de ser um método não-destrutivo. É o caso de estudos do efeito da compacta 
ção e do umedecimento prévio do solo na infiltração vẹ tical da água (seção 6.1) ou da simulação da irrigação por gotejamento (seção 6.2) ou dos processos de germina ção de uma semente e absorção de água pelas raízes (se ção 6.3). As suas aplicações são multidisciplinares e extrapolam a Física da Água no Solo podendo ser usadas em outros campos como o da Ciência do Solo, o da Morfo genia e Fisiologia Vegetal e outros afins;

g) É possível utilizar um instrumento dedicado, como $\circ \mathrm{mi}$ nitomógrafo de Raios $x$ ou $\gamma$, apresentado no Apêndice,pa ra estudos da Física da Água no Solo(Figuras 34, 35 e 36)

A seguir, queremos deixar algumas sugestões para pos síveis trabalhos futuros que abaixo enumeramos. A maioria des tes trabalhos possui uma forte natureza multidisciplinar:

1) Aplicar a Tomografia Computadorizada para estudar $\circ$ pro blema dos solos expansivos (por exemplo: solo de Petroli na-PE, rico em argilas expansivas), analisando dentre ou tras coisas os processos de ocorrência de fissuras, após o molhamento e o secamento dos referidos solos.

2) Aplicar a Tomografia Computadorizada para estudar o pro blema do movimento da água no solo carregada de solutos (por exemplo: nutrientes e poluentes), analisando também - problema do fluxo de líquidos de duas fases imiscí veis $^{(12)}$.

3) Aplicar a Tomografia Computadorizada para estudar o cres cimento de nódulos nas raízes das leguminosas, que constí tui um importante processo de fixação do nitrogênio por 
estas culturas ${ }^{(*)}$.

4) Aplicar a Tomografia Computadorizada para estudar o pro blema do fluxo instável (12), fenômeno que aparece como re sultado da interface ar-água no solo ${ }^{(* *)}$, quando a água penetra de um solo de textura fina para outro de textura grossa. Além de ser um problema básico em Física de Solos ainda não bem entendido, possui importância prática em projetos de filtros de poluição.

5) Aplicar a Tomografia Computadorizada de RNM (Ressonância Nuclear Magnética) para estudos da Física da Água no So $10^{(* * *)}$.

6) A partir dos resultados da seção 6.3 , coletar um maior nú mero de dados referentes à germinação de uma semente, ao crescimento e à absorção de água pelas raízes, à evapo transpiração e outros de interesse, para construir um fil me que mostre detalhadamente estes processos.

7) Ampliar os estudos do minitomógrafo de Raios $x$ ou $\gamma$, apre sentado no Apêndice, em função das possíveis aplicações citadas nas sugestões anteriores e no Capítulo VI.

(*) Esta sugestão foi. fornecida pelo pesquisador e agrônomo Dr. URQUIAGA, do Centro Nacional de Biologia do Solo, da EMBRAPA-RJ.

(**) Isto ocorre na infiltração da água contra um corpo comprimi do com o ar, como por exemplo, um lençol freático perto da superfície.

(***) Já realizamos algumas discussões preliminares com o Profes sor Dr. HORÁCIO PANEPUCCI, do DFCM - IFQSC - USP.

(\$) Hainsworth e Aylmore ${ }^{(120)}$ usaram um tomógrafo EMI CT 1007 (faz parte dos primeiros modelos) e um sistema convencional de transmissão direta de $\mathrm{R}-\gamma$ para estudar um solo limo-arenoso (Bakers Hill, W.A.). Conpararam os resultados ob tidos pelos dois instrumentos com o método gravimétrico, encontrando resulta = dos positivos. Estudaram, também, a possibilidade de se usar a tomografia para avaliar a absorção da ägua por uma raiz simulada. 


\section{APÊNDICE}

\section{USO DE UM MINI-TOMÓGRAFO PARA MEDIDAS EM FÍSICA DA ÁGUA NO SOLO}

Em colaboração com o Professor Roberto Cesareo (Centro de Engenharia Biomédica da Universidade de Roma) estudamos a pos sibilidade de se utilizar em Física da Água no Solo, o mini-to mógrafo por ele construído para fins biomëdicos. Em seguida des tacaremos alguns dos resultados obtidos e que julgamos ser do interesse da presente tese. Lembramos que estamos construindo um modelo similar na UAPDIA-EMBRAPA de são Carlos. $(109,121)$

A Figura $28^{\prime}$ nos mostra um diagrama esquematizado do sistema Mini-TAC utilizado.

As principais caracteristicas de alguns de seus componentes são:

RAIO X:

Corrente: $10-20 \mathrm{~mA}$

Tensão : $\leqslant 48 \mathrm{kV}$

Ânodo : Tungstềnio

"Alvo" Secundārio: livre para escolha em função da medida.

SISTEMA MECÂNICO: :

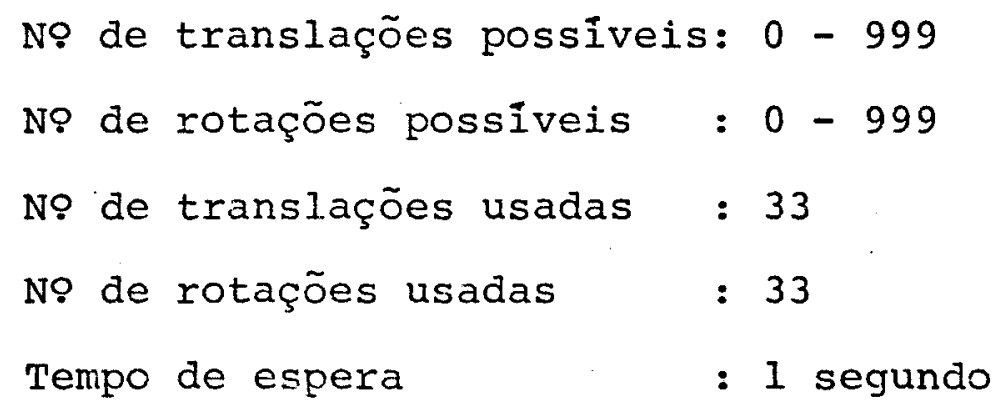




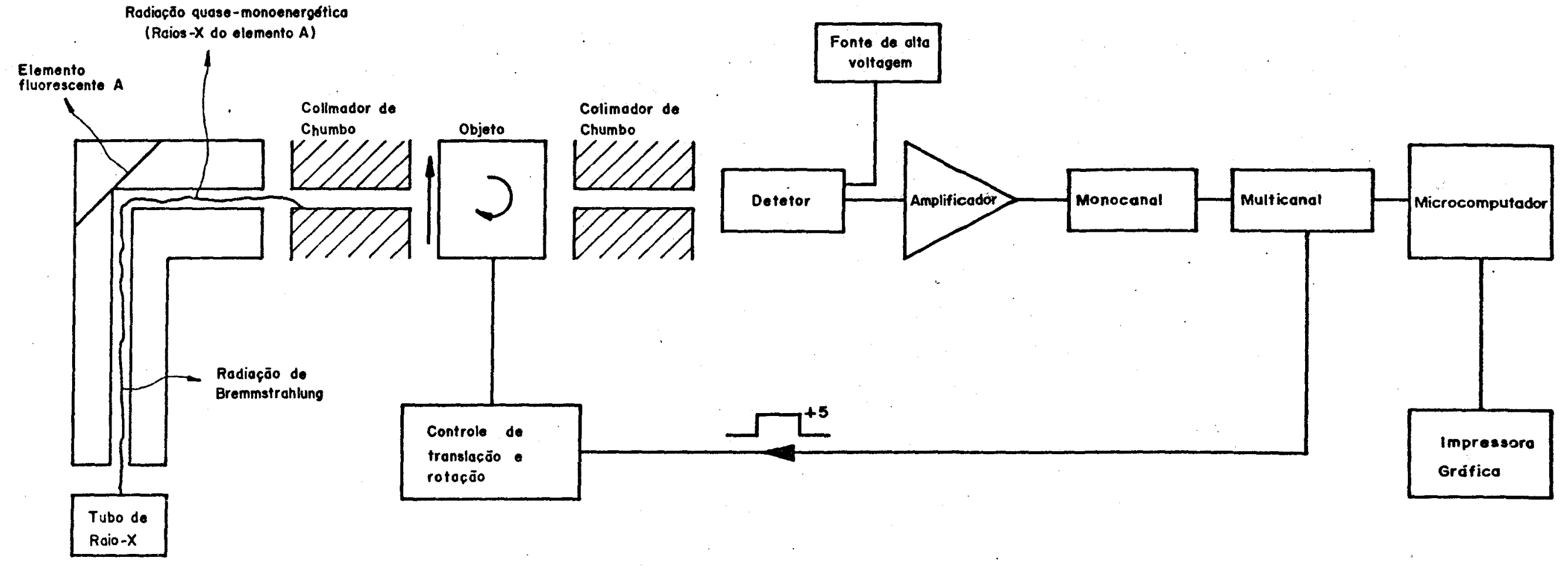

Figura 28 - Diagrama Esquemático de um Minitomógrafo de Raio-X 
FONTE DE VOLTAGEM :

\author{
Máxima: $5 \mathrm{KV}$ \\ Usada : $1350 \mathrm{~V}$
}

DETETOR :

Associa um cintilador de NaI(TI) com uma fotomultiplicadora.

A Figura 29 nos mostra uma vista geral do sistema Mini-TAC esquematizado na Figura 28.

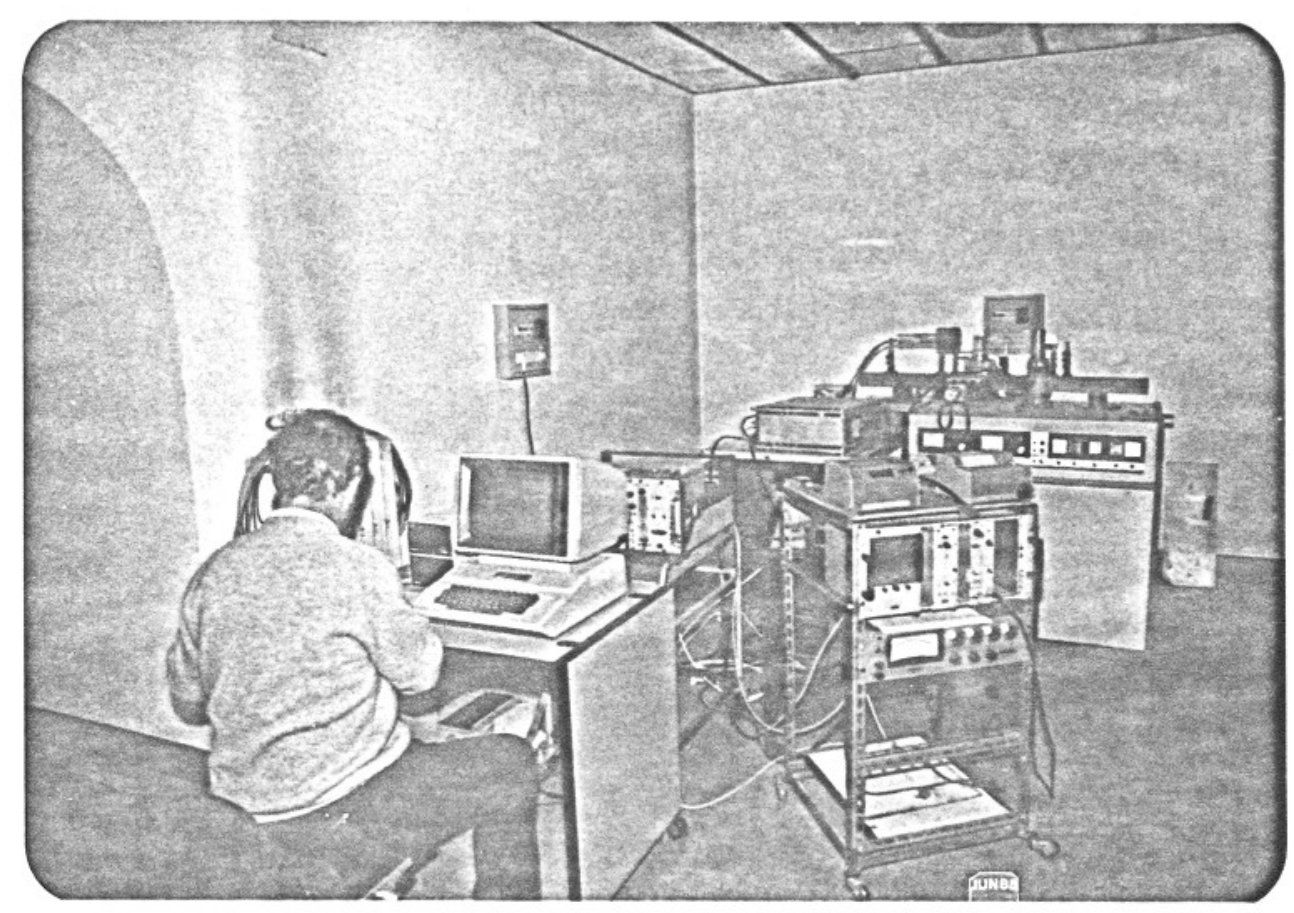

Figura 29 - Vista geral do sistema Mini-TAC existente na Universidade de Roma, mostrando a fonte e o tubo de Raio $\mathrm{X}, \mathrm{o}$ sistema mecânico, o sistema de detecção e de coleta de dados, assim como o micro-computador para o processa mento dos dados coletados.

Junto do computador existe um sistema (em lingua gem PASCAL e FORTRAN) que permite simular a imagem correspondente a um objeto (tomograma) conhecidos, a priori, os seus coefici entes de atenuação. No caso do programa PASCAL, utiliza-se um microcomputador Apple II e no caso do programa FORTRAN, utiliza -se o computador Digital PDP - 11 . 
A Figura 30 ilustra um exemplo de simulação de imagem confeccionada no micro Apple.

Dando prosseguimento aos nossos estudos, aplicamos o método da transmissão direta ao solo brasileiro. Medimos o seu coeficiente de atenuação linear $\left(\mathrm{em} \mathrm{cm}^{-1}\right)$ em função da energia da radiação incidente $(X$ ou $\gamma$ ) mostrado na Figura $31 .(122,123)$

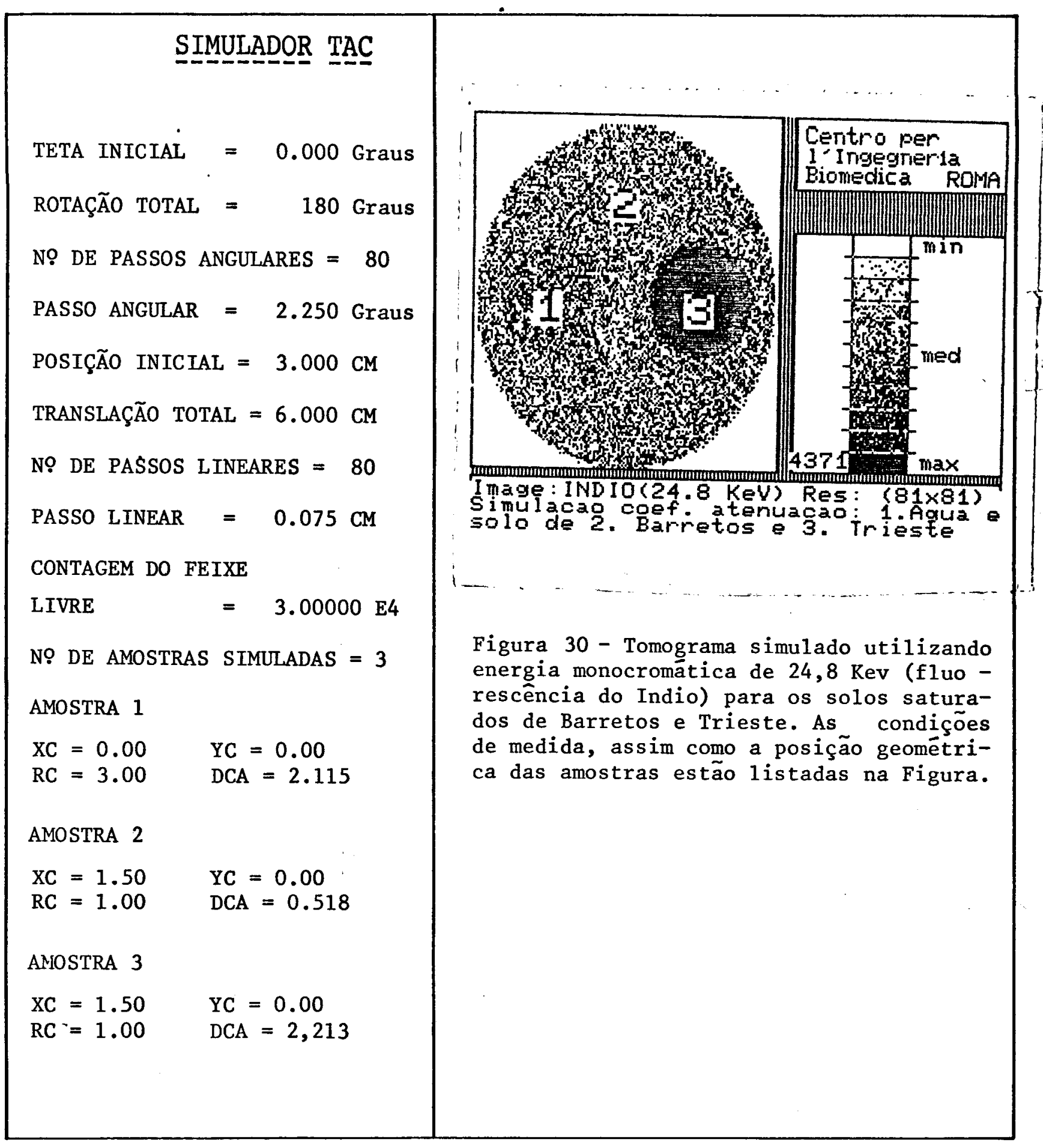




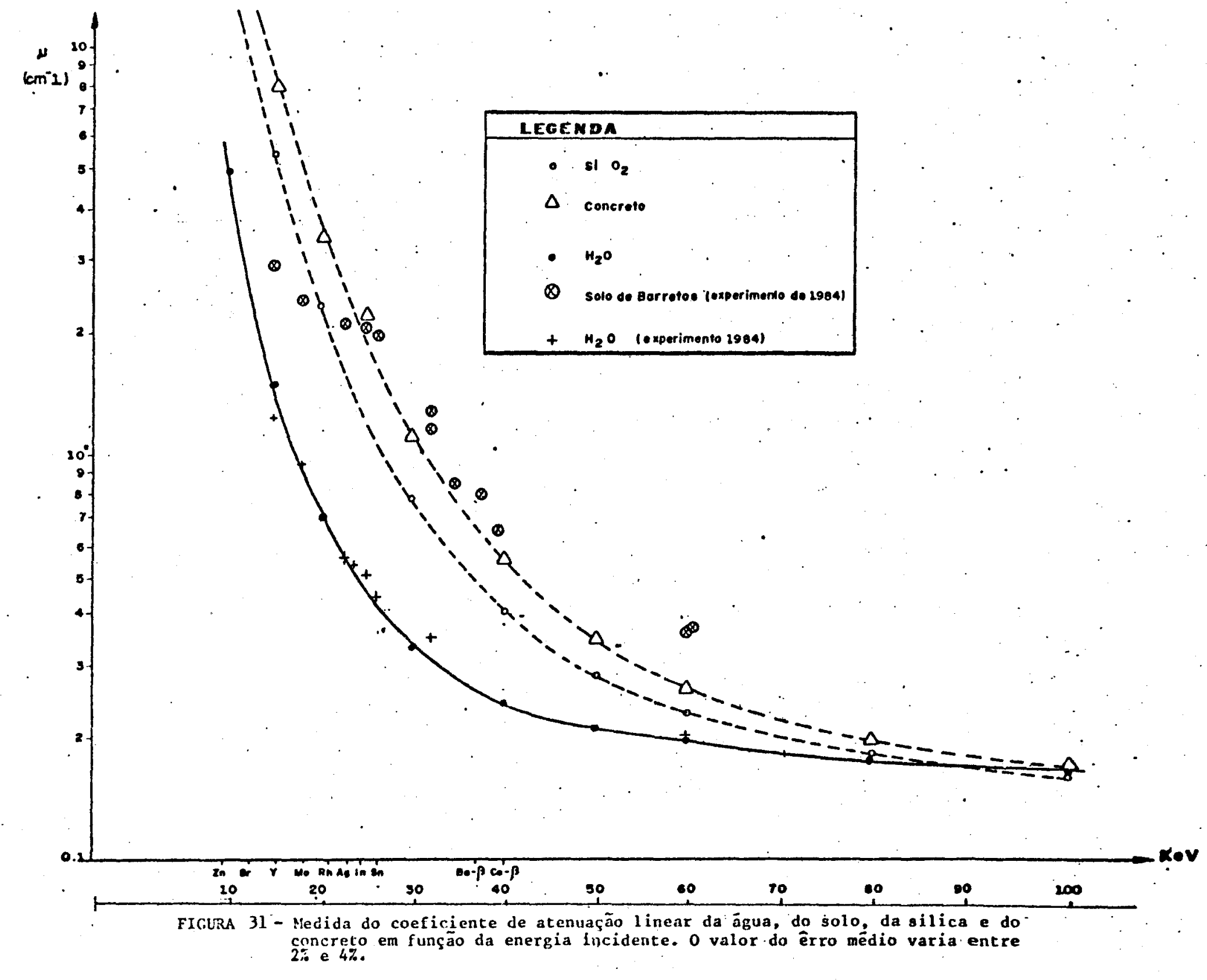


Alèm disso, utilizando ${ }^{24 I_{A m}}(60 \mathrm{Kev})$, a linha $\mathrm{K}_{\alpha}$ do Bārio (32 Kev) e a linha $k_{\alpha}$ do Cério $(34,5 \mathrm{Kev})$ estudamos a de pendência do coeficiente de atenuação linear em função do conteû́ do da água no solo, em porcentagem, conforme mostrado na Figura 32.

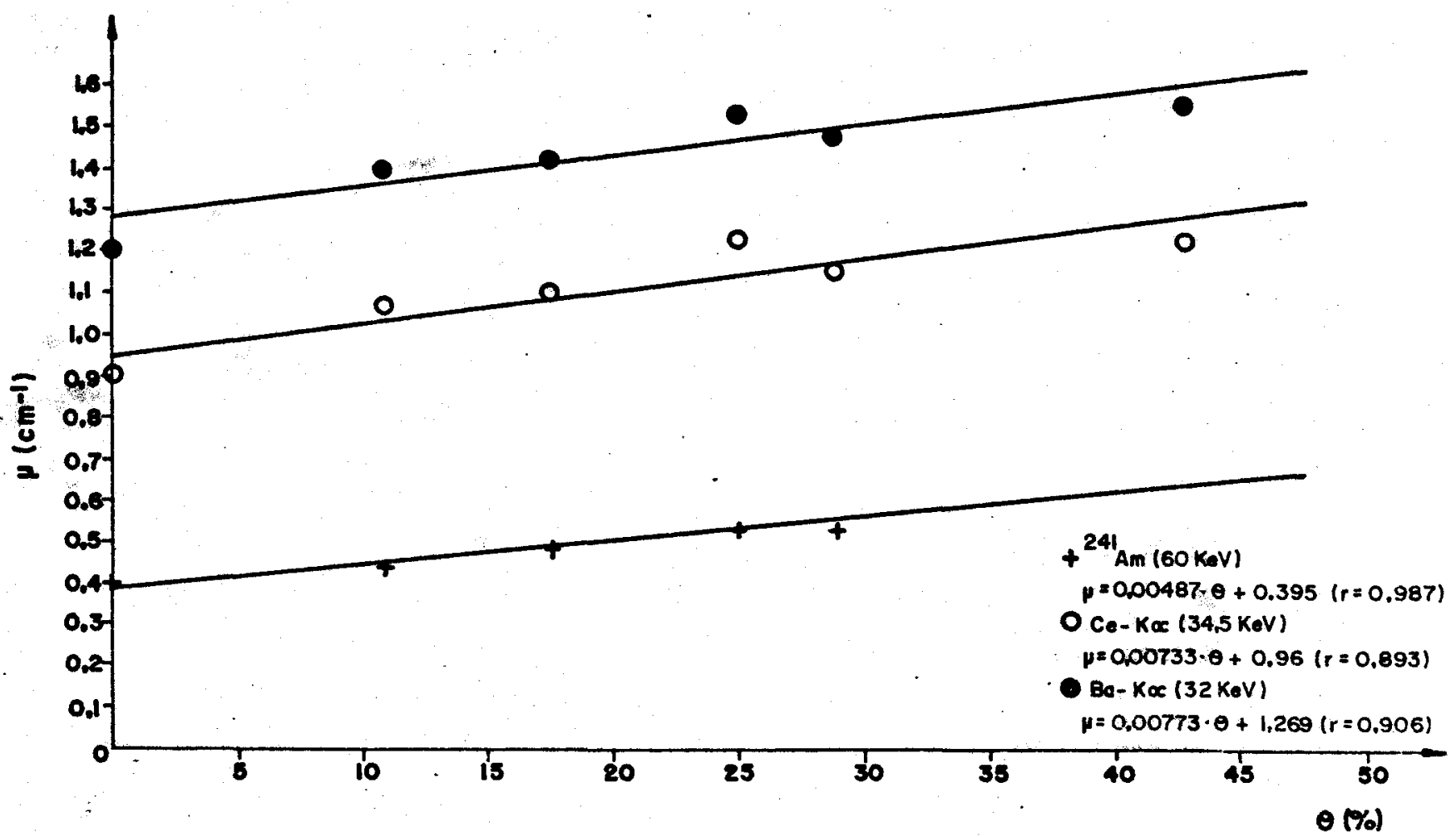

Figura 32 - Medida do coeficiente de atenuação linear do solo da região de Barretos, SP, em função do conteúdo de água no solo, em porcentagem, utilizando as energias mostradas no grä́ico.

Do gráfico da Figura 31 fica evidente que as energias . . mais apropriadas para se estudar solos (na presença de āgua) es tão na faixa de 30 a $40 \mathrm{Kev}$ e não de 60 a $70 \mathrm{Kev}$, conforme é fre quentemente usado, em Física de Solos ou no tomógrafo médico. A razão destas limitações tem origem na inexistência de fontes mais

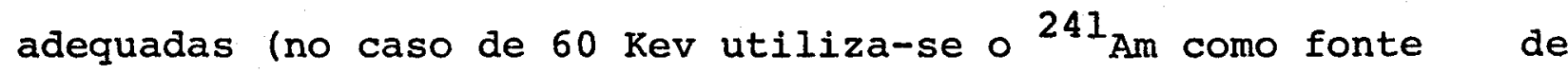
$R$ - $\gamma$ ) ou na dose permitida ao paciente. No entanto, a nossa proposta é construir "alvos" secundários de forma a produzir ra diação monocromātica de energia próxima a que desejamos. E por exemplo, o caso do Bārio - linha $\mathrm{K}_{\alpha}(32 \mathrm{Kev})$ ou de terras raras ( $\cong 40 \mathrm{Kev}$ ) utilizados como alvo secundārio. Assim, será possível adequar o instrumento ao fim especifico que se tem em vista 
(por exemplo: distinguir a água do solo), obtendo grande versati lidade experimental e melhoria da qualidade da imagem, o que sig nifica uma grande vantagem sobre as tëcnicas convencionais. A Figura 32 tambëm ajuda a ilustrar melhor o que estamos afirmando. Substituindo o detetor de Raios X $[\operatorname{NaI(TI)}]$ da Figura 28 por um contador proporcional a găs de Xenônio ${ }^{(*)}$ e um detetor HP, ${ }^{(* *)}$ de Germânio, associado a um multicanal (1024 canais) e uma perfuradora de fita, obtivemos o gráfico da Figura 33 - 0 espectro de fluorescência de Raio X foi realizado com um tubo de Raio $x$ utilizando como "alvo" secundārio a fluorescên cia do Molibdênio(17,4 Kev)! (124)

O gräfico da Figura 33 serve para caracterizar as componentes do solo da região de Barretos, SP, (para energias menores que a do Molibdênio). Pode-se observar a presença de grandes quantidades de Ferro e em menores quantidades o Titânio e o Níquel.

Finalmente, apresentamos, através das Figuras 34,35 e 36 , três tomogramas do solo da região de Barretos, SP, (seco e úmido) que obtivemos em Roma, Itália, atravēs do sistema Mini-TAC da Figura 28 . E possivel verificar a conveniência e a possibilida de da utilização do mini-tomógrafo para estudos da Física da đgua no Solo. Sem dúvida, um sistema mais em conta do que o tomó gráfo médico, além da sua alta versatilidade, podendo ser montado de acordo com o fim apropriado. Não só para estudos da Física da Agua no Solo, más também para outros fins como: en Arqueologia, Geologia, Engenharia Industrial, ensino de Medicina e aná Iises biológicas.

(*) $97 \%$ de Xe, $3 \% \mathrm{CO}_{2}$ : janela de entrada de $51 \mu \mathrm{m}$ de Be e resolução de $19 \%$ na energia de $6,4 \mathrm{Kev}^{2}$ e $11,5 \%$ na energia de $14,4 \mathrm{Kev}$.

(**) Ārea ativa de $500 \mathrm{~mm}^{2}$, largura de $7 \mathrm{~mm}$ e resolução de ener gia de $250 \mathrm{ev}$ na energia de $6,4 \mathrm{Kev}$. 


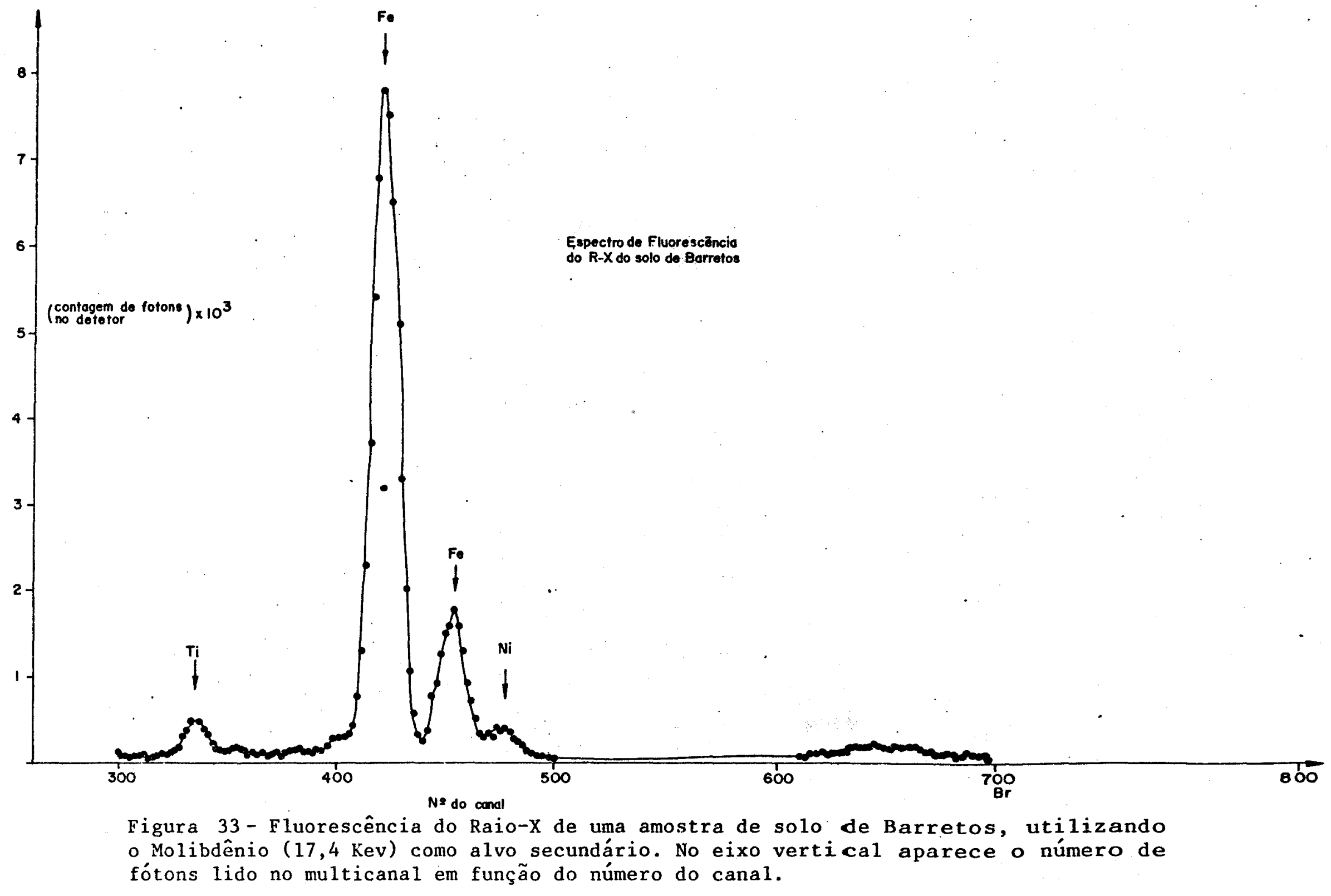


127.

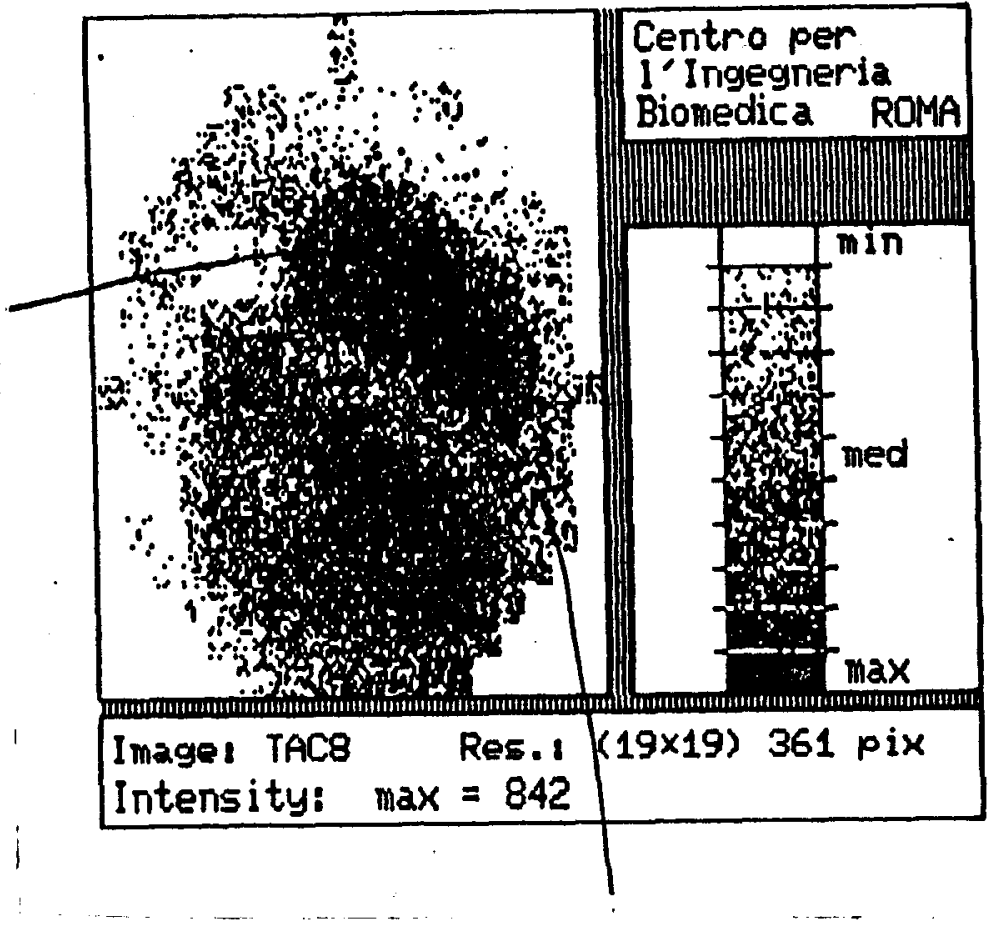

Figura 34 - Primeira tomografia experimental, utilizando o sistema Mini-TAC, da Universidade de Roma, de uma amostra de solo da região de Barretos, SP, contendo solo seco (par te inferior) e molhado (parte superior), dividido por uma parede de "plexiglass". Foi utilizada energia de $34 \mathrm{Kev}$.

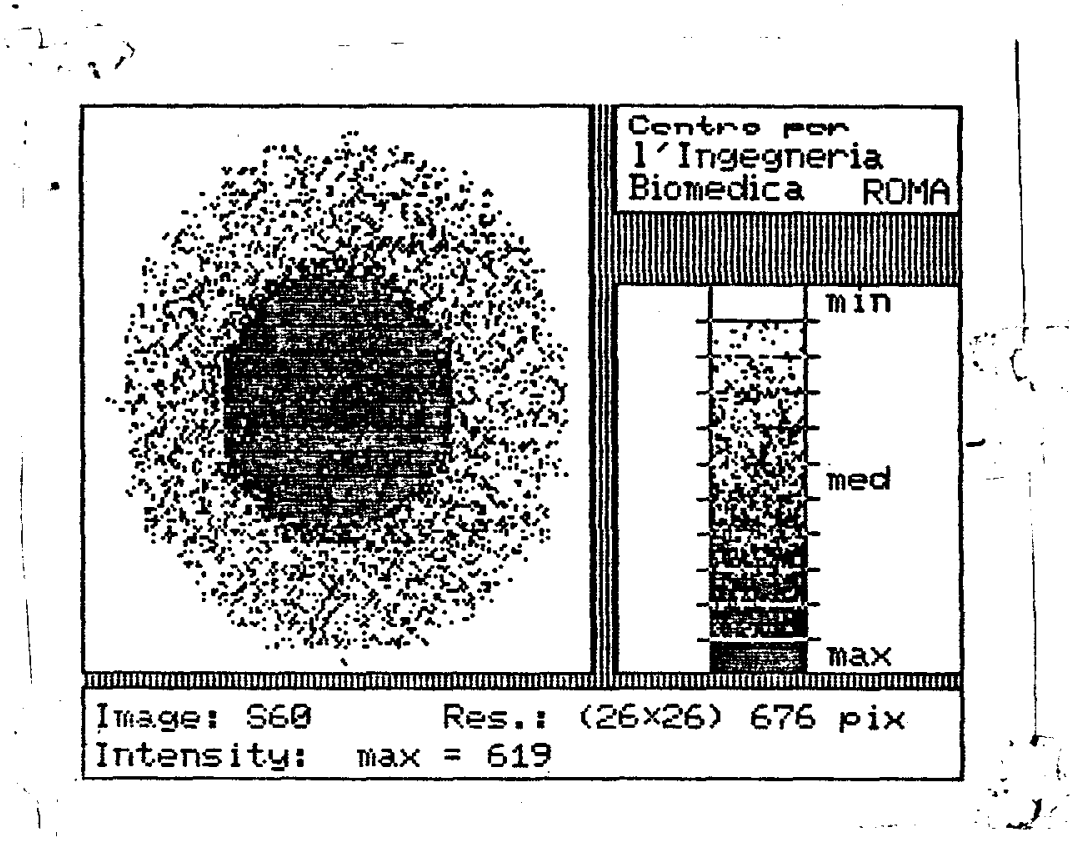

Figura 35 - Tomografia experimental de uma amostra de solo da região de Barretos, SP. O círculo escuro mostra a presença da água no solo enquanto que a região mais clara mostra o mesmo solo seco (sem água). Os coeficientes de atenuação lineares são respectivamente $0,410 \mathrm{~cm}^{-1}$ e $0,370 \mathrm{~cm}^{-1}$, na energia de 60 Kev utilizada. A diferença entre eles é de $0,04 \mathrm{~cm}^{-1}$ e o valor da intensidade máxima medida é igual a 619 . 


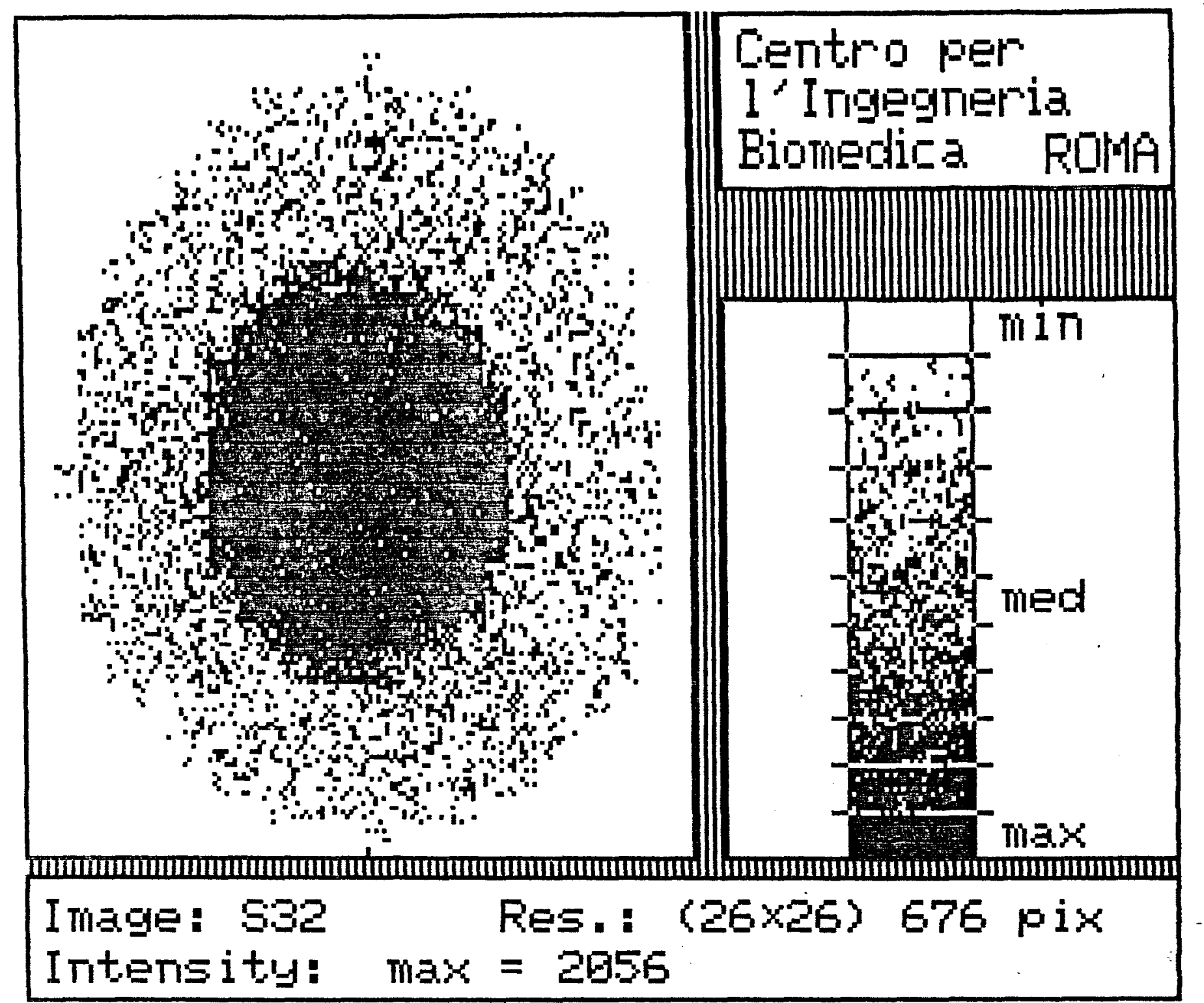

Figura 36 - Mesma configuração geométrica da Figura 35, onde foi uti lizada a energia de $32 \mathrm{Kev}$. Os valores dos coeficientes de atenuação lineares do solo com água e do solo seco são respectivamente iguais a $1,38 \mathrm{~cm}^{-1}$ e $1,19 \mathrm{~cm}^{-1}$. A diferença entre.eles é de $0,19 \mathrm{~cm}^{-1}$ e o va lor da intensidade máxima medida é igual a 2056. Compare estes resul tados com aqueles da Figura 35 ou Figura 31. Confirma-se a nossa a firmação referente a vantagem de se trabalhar com energias no inter valo de 30 a $40 \mathrm{Kev}$, se quisermos distinguir melhor a presença da ă gua em um solo como o de Barretos. A relação entre as intensidades (menor para a maior) é da ordem de $30 \%$ e a variação entre os coefí cientes de atenuação é da ordem de $21 \%$. 


\section{REFERÊNCIAS BIBLIOGRÁFICAS}

1. CRESTANA, S. 1983. Estudos sobre um modelo unidimensional pa ra a emissão espontânea na aproximação semiclássica. São Carlos, IFQSC-USP. (Tese Mestrado).

2. CELASCHI, S. 1977. Água ligada e propriedades elétricas da lisozima. São Carlos, IFQSC-USP. (Tese Mestrado).

3. ONUCHIC, J.N. 1982. Investigações em biofísica da água, caso ácido violúrico. São Carlos, IFQSC-USP. (Tese Mestrado).

4. MASCARENHAS, S. \& ONUCHIC, J.N. 1983. Bound-water in biomolucules: a Monte Carlo simulation of the bifurcated hydrogen bond in violuric acid monohydrate. Anais da Acade mia Brasileira de Ciências, $\underline{52}(2): 165-72$.

5. PROJETO DE CENTROS EMERGENTES. 1982. Estudo do Sistema água -solo-planta-atmosfera na região de Barretos. Convênio CNPq no 70.0874/81 e Convênio FINEP no 54.83/0260.00.

6. CENA (Centro de Energia Nuclear na Agricultura).. 1975. Pes quisas realizadas: 1968-1975. Piracicaba. 2v. (CENA. Bo letim de Divulgação, BI-007).

7. FRERE, A.F. 1982. Investigações de qualidade de imagens rä diológicas com um sistema densitométrico computarizado. São Carlos, IFQSC-USP. (Tese Doutorado).

8. COLLEGE ON SOIL PHYSICS, 1st, Trieste, Ago.-Set. 1983. Proceedings. Trieste, ICTP-IAEA.

9. CRESTANA, S. ; MASCAREnhas, S. ; POZZI-MUCELli, R. 1984. Static and dynamic 3 dimensional studies of water in soil using computed tomographic scanning. Trieste, Internatio nal Center for Theoretical Physics. (Internal Report, IC/84/35)

10. CREstana, S. ; MASCAREnhas, S. ; POZZI-MUCELli, R. 1986. Static and dynamic 3 dimensional studies of water in soil using computed tomographic scanning. Soil science society of America Journal ( $1 \cong$ semestre). (Aceito para publicação)

11. HILLEL, D. 1982. Introduction to soil physics. New York, Academic Press. 
12. HILLEL, D. 1980. Applications to soil physics. New York, Academic Press.

13. REICHARDT, K. 1975. Processos de transferência no sistema solo-planta-atmosfera. Campinas, Fundação Cargill.

14. REICHARDT, K. 1983. Soil moisture studies. In: COLLEGE ON SOIL PHYSICS, $1^{\text {st }}$, Trieste. Proceedings. Trieste, ICTP-IAEA.

15. MILLER, E.E. \& KLUTE, A. 1977. "Dynamics of soil water. Part I: mechanical forces". In: Irrigation of aqricultural lands. Madison, American Society of Agronomy. p.209-44. (Monograph, 2).

16. VERPLANCKE, H. 1983. Flow of water in soil. In: COLLEGE ON SOIL PHYSICS, $1^{\text {st }}$, Trieste. Proceedings. Trieste, ICTP-IAEA

17. HENIN, S. 1977. Cours de physique du sol. Paris, Orstom. v.2.

18. DARCY, H. 1856. Les fontaines publiques de la ville de $\mathrm{D} \underline{i}$ jon. Paris, Victor Dalmont. 570p.

19. HUBBERT, M.K. 1956. Darcy's law and the field equations of the flow of underground fluids. American Institute of Mining, Metrology, Petrology and Engineering. Transactions, 207:222-39.

20. SLICHTER, C.S. 1899. United States Geological Survey. Annual Report, 19-II:295-384.

21. COREY, A.T. \& KLUTE, A. 1985. Application of the potencial concept to soil water equilibrium and transport. Soil Science Society of America Journal, 49:3-11.

22. RICHARDS, L.A. 1931. Capillary conduction of liquids through porous mediums. Physics, $1: 318-33$.

23. MILleR, E.E. \& MILlER, R.D. 1956. Physical theory for cappilary flow phenomena. Journal of Applied Physics, $\underline{27}: 324-32$.

24. CHILDS, E.C. \& COLLIS-GEORGE, W. 1950. Permeability of po rous materials. Proceedings of the Royal Society of Lon don. A, 201:392-405. 
25. SWARTZENDRUBER, D. 1969. The flow of water in unsatureted soils in "Flow through porous media". New York, Academic Press.

26. PHILIP, J.R. 1955. Numerical solution of equation of the diffusivity concentration dependent. Transactions of Faraday Society, 51:885-92.

27. PHILIP, J.R. 1955. The concept of diffusion applied to soil water. Proceedings of the National Academy of Sciences, In dia, 24A: 93-104.

28. PARLANGE, J.Y. 1971. Theory of water-movement in soils: I. One-dimensional absorption. Soil Science, 111(2):134-7.

29. DEWIT, C.T. \& VAN KEULEN, H. 1972. Simulation of transport processes in soils. Wageningen, PUDOC.

30. ELRICK, D.E. \& LARYEA, K.B. 1979. Sorption of water in soils: a comparison of techniques for solving the diffusion equation. Soil Science, 128(6):369-74.

31. LIBARDI, P.L: ; REICHARDT, K. ; NIELSEN, D.R.; BIGGAR, J.W. 1980. Simple field methods for estimating soil hydraulic conductivity. Soil Science Society of America Journal, $\underline{44}: 3-7$.

32. BRUCE, R.R. \& KLUTE, A. 1956. The measurement of soil-water diffusivity. Soil Science Society of America Proceedings, 20: $458-62$.

33. LIBARDI P.L: \& REICHARDT, K. 1974. Generalização do movimen to da água no solo: infiltração horizontal. Piracicaba, CENA. 29p. (Boletim Científico, 16).

34. POPI, O. 1982. Determinação e análise de escoamentos unidị mensionais e bidimensionais transientes em meios porosos não-saturados. São Carlos, EESC/USP. (Tese Mestrado).

35. PHILIP, J.R. 1957. Numerical solution of equation of the diffusion type with diffusivity concentration dependent. II. Australian Journal of Physics, 10:29-42.

36. CHENG, A.H.D. 1984. Darcy's flow with variable permeability: a boundary integral solution. Water Resources Research, $\underline{20}(7): 980-4$. 
132.

37. STEPHENS, D.B. \& REHFELDT, K.R. 1985. Evaluation of closed-form analytical models to calculate conductivity in a fine sand. Soil Science Society of America Journal, $49(1): 12-9$.

38. GARDNER, W.H. 1965. "Water content". In: BLACK, C.A., ed. Methods of soil analysis. Madison, American Society of Agronomy. v.1, p.82-127.

39. DAS, D.K. ; SEN, A. ; DEB, D.L. 1975. Radiation methods in soil physics problems with special reference to soil water, salts and nutrient movements studies. Journal of Nuclear Agriculture \& Biology, $4: 40-6$.

40. VACHAUd, G. ; CISLER, J. ; THONY, J.L. ; DE BACKER, L. 1970. "Utilisation de l'émission gamma de l'americium-24l pour la teneur en eau d'echantillons de soils nos satures". In: IAEA. Isotope hydrology 1970. Viena. p.643-61. (IAEA-SM-129/39)

41. SAKSENA, R.S. ; CHANDRA, S. ; SINGH, B.P. 1974. A gamma transmission method for the determination of moisture content in soils. Journal of Hydrology, 23:341-52.

42. REICHARDT, K. 1965. Uso da radiação gama na determinação da densidade e umidade do solo. Piracicaba, ESALQ. 34p. (Dou toramento).

43. BELCHER, D.J. ; CUYKENDALl, T.R.; SACK, H.S. 1950. The measurement of soil moisture and density by neutron and gamma-ray scattering. Washington, Civil Aeronautics Administration. (Technical Development Report, 127).

44. FERRAZ, E.S.B. 1983. "Gamma-ray attenuation to measure water content and/or bulk densities of porous materials". In: IAEA. Isotope and radiation techniques in soil physics and irrigation studies 1983. Viena. p.449-60. (IAEA-SM-267/41).

45. STROOSNIJDER, L. \& DE SWART, J.G. 1974. Column scanning with simultaneous use of ${ }^{241} \mathrm{Am}$ and ${ }^{137} \mathrm{Cs}$ gamma radiation. Soil science, $118(2): 61-9$.

46. REGINATO, R.J. 1974. Water content and bulk density changes in a soil pedon measured with dual energy gamma-ray trans mission. Canadian Journal of soil science, 54:325-8. 
47. NOFZIGER, D.L. 1978. Errors in gamma-ray measurements of water content and bulk density in non-uniform soils. Soil Science Society of America Journal, 42:845-50.

48. SINGH, B.P. \& CHANDRA, S. 1977. Evaluation of the optimal thickness of soil between source and detector in the gamma -ray transmission method. Journal of Hidrology, 32:189-91.

49. NOREL, G. 1965. Étude des milieux poreux par absorption $d^{\prime}$ un rayonnement $X$ ou $\gamma$ émis par une source radioactive. Pa ris, Faculté des Sciences. (Tese Doutorado).

50. COWN, D.J. 1982. X-ray densitometry using an 55 Fe source. Wood Micro-densitometry Bulletin, $2(2): 25$.

51. ZUCCHI, O.L.A.D. \& NASCIMENTO Fo, V.F. 1982. Determinação dos coeficientes de atenuação de massa, de solos e água, usando um duplo feixe de radiação gama em linha (Cs-137 e Am-241) para três diferentes sistemas de deteç̧ão. Energia Nuclear e Agricultura, $\underline{4}(2): 71-81$.

52. ZUCCHI, O.L.A.D. \& NASCIMENTO Fo, V.F. 1984. Equipamentos nucleares na determinação dos coeficientes de atenuação de massa de solos e da água. Energia Nuclear e Agricultura, $\underline{6}(1): 19-45$.

53. NUTTING, P.G. 1943. Some standard thermal dehydration cur ves of minerals. United States Geological Surwey. Profes. sional Paper, 197-E.

54. TOPP, G.C.; DAVIS, J.L.; ANNAN, A.P. 1982. Electromagnetic determination of soil water content using TDR: I. Applica tions to wetting fronts and steep gradientes. Soil Scien ce Society of America Journal, $\underline{46: 672-8 .}$

55. TOPP, G.C.; DAVIS, J.L.; ANNAN, A.P. 1980. Electromagnetic determination in soil water content: measurements of coa xial transmission lines. Water Resources Research, 16(3): :574-82.

56. FELLNER-FELDEGG, H. 1969. The measurement of dielectrics in the time domain. Journal of Physical Chemistry, $\underline{73}(3): 616$ -23 . 
57. DALTON, F.N. ; HERKEBRATH, W.N. ; RAWLINS, D.S. ; RHOADES, J.D. 1984. Time-domain reflectrometry: simultaneous measurement of soil water content and electrical conductivity with a single probe. Science, 224:989-90.

58. KENG, J.C.W. \& TOPP, G.C. 1983. Measuring water content of soil columns in the laboratory: a comparison of gamma-ray attenuation and TDR techniques. Canadian Journal of Soil Science, $\underline{63}: 37-43$.

59. TOPP, G.C. \& DAVIS, J.L. 1985. Measurement of soil water content using time-domain reflectrometry. (TDR): a field evaluation. Soil Science Society of America Journal, 49:19-24

60. TOPP, G.C. \& DAVIS, J.L. ; ANNAN, A.P. 1982. Electromagnetic determination of soil water content using TDR: II. Evaluation of installation and configuration of paralell transmission lines. Soil Science Society of America Jour nal, $\underline{46}: 678-84$.

61. RAWITZ, E. 1974. "The use of radiation techniques and other physical methods in field water balance and water use efficiency studies". In: SYMPOSIUM HELD AT G. B. PLANT UNIVERSITY OF AGRICULTURE AND TECHNOLOGY, Pantnagar, Apr. 12-14, 1974. Proceedings. Bombay, Bhabha Atomic Research Centre. p.269-81.

62. COUCHAT, P.H. 1983. Les applications de la methode neutronique dans la recherche agronomique. Viena, IAEA. p.509-31. (IAEA-SM-267/42).

63. COLMAN, E.A. \& HENDRIX, T.M. 1949. Fiberglass electrical soil moisture instrument. Soil science, 67:425-38.

64. BERNARD, R. ; MARTINS, P. ; VIDAL-MADJAR, D. ; THONY, J.L. ; VAUCLIN, M. 1981. Application of the microwave remote sensing of soil moisture to the monitoring of soil water and latent heat. In: SYMPOSIUM ON REMOTE SENSING, 20th, Washington. Washington, General Assembly of the Union Radio Sci. Int.

65. WANG, J.R. ; SCHMUGGE, T.J.; GOULD, W.I. ; GLAZER, W.S. ; FUCHS, J.E. 1982. A multi-frequency radiometric measure ment of soil moisture content over bare and vegetated fields. Geophysical Research Letters, $9(4): 416-9$. 
66. BOCAGE, E.M. 1921. Patent no 536464, Paris, France. Citado em "History of tomography" por J. Massiot. Medicina Mundi, $\underline{19}(3): 106-15$.

67. BROOKS, R.A. \& DI CHIRO, G. 1976. Principles of computer assisted tomography (CAT) in radiographic and radioisotopic imaging. Phys. Med. Biol. 21 (5):689-732. .

68. HERMAN, G.T. 1980. Image reconstruction from projections: the fundamentals of computerized tomography. New York, Academic Press.

69. NEWTON, T.H. \& POTTS, D.G. 1981. Radiology of the skull and brain: technical aspects of computed tomography. St.Louis, c.v. Mosby. v.5, p.3853-917.

70. RADON, J. 1917. In the determination of functions from their integrals along certain manifolds. Berichte über die Verhandlungen, 69:262-77. (ger).

71. BRACEWELL, R.N. 1956. Strip integration in radioastronomy. Australian Journal of Physycs, 9:198-217.

72. DE ROSIER, D.J. \& KLUG, A. 1968. Reconstruction of three dimensional structures from electron micrographs. Nature, $\underline{217}: 130-4$.

73. GORDON, R.; BENDER, R.; HERMAN, G.T. 1970. Algebraic recons truction techniques (ART) for three-dimensional electron microscopy and X-ray photography. Journal of Theoretical Biology, 29: $471-81$.

74. ROWLEY, P.D. 1969. Quantitative interpretation of three-dimensional weakly refractive phase objects using holographic Interferometry. Journal of Optical Society of America, $\underline{59}$ (2) : 1496-8 :

75. BERRY, M.V. \& GIBBS, D.F. 1970. The interpretation of optical projections. Procedings of the Royal Society of London. $A, \underline{314}(1517): 143-52$. 
76. JUNGINGER, H.G. \& VAN HAERINGEN, W. 1972. Calculation of three-dimensional refractive-index field using phase integrals. Optics Communications, $5(1): 1-4$.

77. HOUNSFIELD, G.N. 1972. A method of and apparatus for examination of a body by radiation such as $\mathrm{X}$ - or gammaradiation. British Patent № 1283915, London. Issued to EMI LTd. Application filed Aug. 1968.

78. HOUNSFIELD, G.N. 1973. Computerized transverse axial scanning (tomography): Part 1. Description of system. British Journal of Radiology, $\underline{46}: 1016-22$.

79. LEDLEY, R.S. ; DI CHIRO, G. ; LUESSENHOP, A.J. ; TWIGG, H.L. 1974. Computerized transaxial X-ray tomography of the human body. Science, $186(4160): 207-12$.

80.TAKAHASHI, S. 1957. Rotation radiography. Tokyo, Japan Society for the Promotion of Science.

81. OLDENDORF, W.H. 1961. Isolated flying spot detection of radiodensity discontinuities - displaying the internal structural pattern of a complex object. I.R.E. Transactions on Biomedical Electronics, $\underline{8}: 68-72$.

82. KUHL, D.E. \& EDWARDS, R.Q. 1963. Image - separation radio isotope scanning. Radiology, $\underline{80}: 653-61$.

83. KUHL, D.E. ; HALE, J. ; EATON, W.L. 1966. Transmission scanning: a useful adjunct to conventional emission scanning for accurately keying isotope deposition to radiographic anatomy. Radiology, 87:278-84.

84. CORMACK, A.M. 1963. Representation of a function by its line integrals, with some radiological applications. Journal of Applied Physics, 34:2722-7.

85. CORMACK, A.M. 1964. Representation of a function by its line integrals with some radiological applications. II. Journal of Applied Physics, 35:2908-13.

86. TRETIAK, C.J. ; EDEN, M. ; SIMON, W. 1969. In: INTERNATIONAL CONFERENCE ON MED. BIOL. ENG..,8th, Chicago, Session 12-1. 
87. BATES, R.H.T. \& PETERS, T.M. 1971. Towards improvements in tomography. New Zealand Journal of Science, 14:883-96.

88. MUEHLLEHNER, G. \& WITZEL, R.A. 1971. Section imaging by computer calculation. Journal of Nuclear Medicine, $\underline{12}$ (2) : 76-84.

89. CROWE, K.M.; BUDINGER, T.F.; CAHOON, J.L.; ELISCHER, V.P.; HUESMAN, R.H.; KANSTEIN, L.L. 1975. IEEE Transactions on Nuclear Sciences, NS-22(3):1752-4.

90. CORMACK, A.M. \& KOEHLER, A.M. 1976. Quantitative proton to mography: preliminary experiments. Phys. Med. Biol., 21 (4) : 560-9.

91. GREENLEAF, J.F.; JOHNSON, S.A.; SAMAYOA, W.F.; DUCK, F.A. 1975. In: Image processing for $2-D$ and $3-D$ reconstruction from projections, Stanford, Aug. 4-7 (Opt. Soc. Am.) p. MA2-1 to 4 .

92. LAUTERBUR, P.C.; HOUSE, W.V.; KRAMER, D.M.; CHEN, C.N.; PORRE TO, F.V.; DULCEY, C.S. 1975. In: Image processing for 2D and 3-D reconstruction from projections; stanford, Aug. 4-7 (Opt. Soc. Am.) p.MA10-1 to 4 .

93. ANDERSON, D.L. \& DZIEWONSKI, A.M. 1984. Seismic tomography . Scientific American, 251 (4):60-8.

94. SANTOS, C.A.C. 1982. Um algoritmo itérativo em tomografia computadorizada aplicada em testes não destrutivos. Rio de Janeiro, UFRJ: 104p. (Tese Mestrado).

95. CARSLAW, H.S. 1930. Introduction to the theory of Fourier's series and integrals. London, Macmillan.

96. CROWTHER, R.A.; DE ROSIER, D.J.; KLUG, A. 1970. The reconstruction of a three-dimensional structure from projections and its applications to electron microscopy. Proceedings of the Royal Society of London.A, 317:319-40.

97. MERSEREAU, R.M. \& OPPENHEIM, A.V. 1974. Digital reconstruction of multidimensional signals from their projections. Proceedings of the IEEE, $\underline{62}(10): 1319-38$. 
98. THOMPSON, A.R. \& BRACEWELL, R.N. 1974. Interpolation and Fourier transformation of fringe visibilities. Astro nomical Journal, 79:11-24.

99. ZERNIKE, F. 1934. Beugungstheorie des schneidenverfahrens und seiner verbesserten form, der phasenkontrastmethode. Physica, $\underline{1}: 689-704$.

100. BORN, M. \& WOLF, E. 1959. Principles of optics. London, Pergamon Press.

101. CENSOR, Y. 1983. Finites series: expansion reconstruction methods. Proceedings of the IEEE, 71(3):409-19.

102. SCUDDER, H.J. 1978. Introdution to computer aided tomo graphy. Proceedings of the IEEE, $\underline{66}(6): 628-37$.

103. LEWITT, R.M. 1983. Reconstruction algorithms: transform methods. Proceedings of the IEEE, $71(3): 390-408$.

104. KAK, A.C. 1979. Computerized tomography with X-ray emis sion and ultrasound sources. Proceedings of the IEEE, $\underline{67}$ (9) $: 1245-72$.

105. RAMACHANDRAN, G.N. \& LAKSHMINARAYANAN, A.V. 1971. Three dimensional reconstruction from radiographic and electron micrographic application of convolutions instead of Fourier transforms. Proceedings of the National Academy

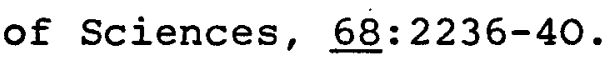

106. SHEPP, L.A. \& LOGAN, B.F. 1974. The Fourier reconstruc tion of a head section. IEEE Transactions on Nuclear Sci ences, NS-21: $21-42$.

107. HERMAN, G.J.; LAKSHMINARAYANAN, A.V.; NAPARSTEK, A. 1976. Reconstruction using divergent day shadowgraphs. Comput. Biol.Med., $\underline{6}: 259$.

108. REBELO, A.M.O. 1984. Reconstrução de imagem em tomografia computadorizada usando o método de convolução. Rio de Jâ neiro, UFRJ. 89p. (Tese Mestrado).

109. CeSAREo, R. ; GIANNINI, M. ; STORELli, L. 1983. A minią ture $\mathrm{X}$-ray tomography scanner employing radioisotopic sources. In: INTERNATIONAL CONFERENCE ON APPLICATIONS OF PHYSICS TO MEDICINE AND BIOLOGY, Trieste. proceedings. p. 631. 
110. MCCULLOUGH, E.C. 1980. Specifying and evaluating the performance of computed tomography (CT) scanners. Medical Physics, $\underline{7}(4): 291-7$.

111. BORASI, G. ; CASTELLANI, G. ; DOMENICHINI, R. ; FRANCHINI, M. ; GRANATA, M. ; TORRESIN, A. ; TOSI, G. 1984. Image quality and dose in computerized tomography: evaluation of four CT scanners. Medical Physics, 11(3):321-5.

112. URQUiAgA CABALLERO, S. 1984. Comunicação pessoal e relató rio do Projeto ASPAB - Convênio FINEP-FEB № 54.83/0260.00 e Convênio CNPq-INTEC no 70.0874/81.

113. PETROVIC, A.M. ; SIEBERT, J.E. ; RIEKE, P.E. 1982. Soil bulk density analysis in three dimensions by computed tomographic scanning. Soil Science Society of America Journal, $\underline{46}: 445-50$.

114. STEINHARDT, G.C. 1983. Soil compaction: a hidden problem. Tradução de T. Yamada. Informações Agronômicas (21):1-3.

115. BARRETO, G.B. 1982. Projeto experimental de um sistema de irrigação por gotejo. Boletim Técnico do Instituto Agro nômico de Campinas, 5:1-23.

116. WALKER, W.R. \& HYMPHERYS, A.S. 1983. Kinematic-wave furrow irrigation model. Journal of Irrigation and Drainage. Engineering, $\underline{109}(4): 377-92$.

117. FOK, Y.S. ; CHUNG, S.O. ;. LIU, C.C.D. 1982. Two-dimensional exponential infiltration equations. Journal of the Irri gation and Drainage Division, 108(IR4):231-41.

118. DIRKSEN, C. \& HUBER, M.J. 1978. Soil water flow model with two-dimensional automatic gamma-ray attenuation scanner. Water Resources Research, 14 (4):611-4.

119. KUMAR, B. \& SINGH, B.P. 1982. Displacement of soil water by simulated rainfall by gamma-ray transmission method and by Ra-Be neutron probe. In: WORKSHOP ON NUCLEAR TECH NIQUES IN HYDROLOGY, New Delhi. Proceedings. p.189-97.

120. HAINSWORTH, J.M. \& AYLMORE, L.A.G. 1983. The use of computer-assisted tomography to determine spatial distribution of soil water content. Australian Journal of Soil Research, 21 : $435-43$. 
121. GIAMMARTINI, S. 1981. Misure nucleari e tomografia assiale computerizzata per la caratterizzazione della frazione di vuoto. (Tesi di Laurea in misure nucleari). Rela tore Prof. M. Grannini.

122. CESAREO, R. 1984. Tecniche nucleari de analisi in medicina. Roma, La Goliardica. (Collana di Bioingegneria), 5 .

123. CESAREO, R. \& GIANNINI, M. 1980. Elemental analysis by means of X-ray attenuation measurements. Nuclear Instru ments and Methods, 169:551-5.

124. CESAREO, R. \& VIEZzOLI, G. 1983. Trace element analysis in biological samples by using XRF spectrometry with secondary radiation. Phy. Med. Biol., 28 (11):1209-18. 